AMRL-TR-78-65

AT2, 01656

C. A. tio

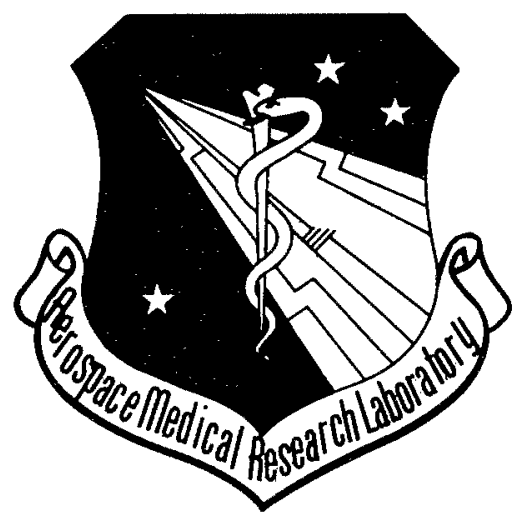

\title{
ENVIRONMENTAL QUALITY RESEARCH \\ FISH AND AUFWUCHS BIOASSAY
}

\section{Third Annual Report}

STEPHEN A. KLEIN

DA VID JENKINS

THE REGENTS OF THE UNIVERSITY OF CALIFORNIA

UNIVERSITY OF CALIFORNIA, IRVINE

IR VINE, ORANGE COUNTY, CALIFORNIA 92664

NOVEMBER 1978

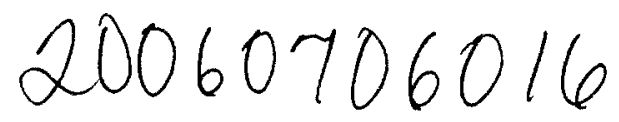

Approved for public release; distribution unlimited.

AEROSPACE MEDICAL RESEARCH LABORATORY

AEROSPACE MEDICAL DIVISION

AIR FORCE SYSTEMS COMMAND

WRIGHT-PATTERSON AIR FORCE BASE, OHIO 45433

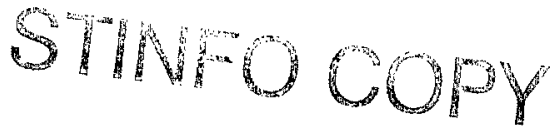




\title{
NOTICES
}

When US Government drawings, specifications, or other data are used for any purpose other than a definitely related Government procurement operation, the Government thereby incurs no responsibility nor any obligation whatsoever, and the fact that the Government may have formulated, furnished, or in any way supplied the said drawings, specifications, or other data, is not to be regarded by implication or otherwise, as in any manner licensing the holder or any other person or corporation, or conveying any rights or permission to manufacture, use, or sell any patented invention that may in any way be related thereto.

Please do not request copies of this report from Aerospace Medical Research Laboratory. Additional copies may be purchased from:

\author{
National Technical Information Service \\ 5285 Port Royal Road \\ Springfield, Virginia 22161
}

Federal Government agencies and their contractors registered with Defense Documentation Center should direct requests for copies of this report to:

Defense Documentation Center

Cameron Station

Alexandria, Virginia 22314

\section{TECHNICAL REVIEW AND APPROVAL AMRL-TR-78-65}

The experiments reported herein were conducted according to the "Guide for the Care and Use of Laboratory Animals," Institute of Laboratory Animal Resources. National Research Council.

This report has been reviewed by the Information Office $(O !)$ and is releasable to the National Technical Information Service (NTIS). At NTIS, it will be available to the general public, including foreign nations.

This technical report has been reviewed and is approved for publication.

\section{FOR THE COMMANDER}

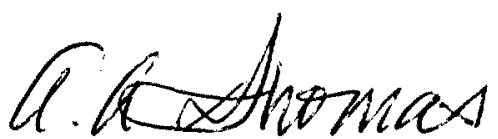

ANTHONY A. THOMAS, MD

Director

Toxic Hazards Division

Aerospace Medical Research Laboratory

AIR FORCE $/ 56780 / 5$ February $1979-100$ 
SECURITY CLASSIFICATION OF THIS PAGE (When Data Entered)

\begin{tabular}{|c|c|}
\hline REPORT DOCUMENTATION PAGE & $\begin{array}{l}\text { READ INSTRUCTIONS } \\
\text { BEFORE COMPLETING FORM }\end{array}$ \\
\hline \begin{tabular}{l|l|} 
1. REPORT NUMBER & 2. GOVT ACCESSION NO. \\
AMRL-TR-78-65 &
\end{tabular} & 3. RECIPIENT'S CATALOG NUMBER \\
\hline \multirow{2}{*}{$\begin{array}{l}\text { 4. TITLE (and Subtitio) } \\
\text { ENVIRONMENTAL QUALITY RESEARCH FISH AND } \\
\text { AUFWUCHS BIOASSAY - THIRD ANNUAL REPORT }\end{array}$} & $\begin{array}{l}\text { 5. TYPE OF REPORT A PERIOD COVEREO } \\
\text { Annual Report } \\
1 \text { June } 1977-31 \text { May } 1978\end{array}$ \\
\hline & 6. PERFORMING ORG. REPORT NUMBER \\
\hline $\begin{array}{l}\text { 7. AUTHOR(s) } \\
\text { Stephen Klein } \\
\text { David Jenkins }\end{array}$ & $\begin{array}{l}\text { 8. CONTRACT OR GRANT NUMBER(s) } \\
\text { F33615-76-C-5005 }\end{array}$ \\
\hline $\begin{array}{l}\text { 9. PERF́RMING ORGANIZATION NAME AND ADORESS } \\
\text { The Regents of the University of California } \\
\text { University of California, Irvine } \\
\text { Irvine, Orange County, California } 92664\end{array}$ & $\begin{array}{l}\text { 10. PROGRAMELEMENT, PROJECT, TASK } \\
\text { AREA A WORK UNIT NUMBERS } \\
62202 \mathrm{~F} ; 6302 / 04 / 17\end{array}$ \\
\hline \multirow{2}{*}{$\begin{array}{l}\text { 11. CONTROLLING OFFICE NAME AND ADDRESS } \\
\text { Aerospace Medica1 Research Laboratory, Aerospace } \\
\text { Medical Division, Air Force Systems Command, } \\
\text { Wright-Patterson Air Force Base, OH } 45433\end{array}$} & $\begin{array}{l}\text { 12. REPORT DATE } \\
\text { November } 1978\end{array}$ \\
\hline & $\begin{array}{l}\text { 13. NUMBER OF PAGES } \\
89\end{array}$ \\
\hline \multirow[t]{2}{*}{ 14. MONITORING AGENCY NAME \& ADDRESS(if different from Controlling Office) } & $\begin{array}{l}\text { 15. SECURITY CLASS. (of this report) } \\
\text { Unclassified }\end{array}$ \\
\hline & $\begin{array}{l}\text { 15a. DECLASSIFICATION/DOWNGRADING } \\
\text { SCHEDULE }\end{array}$ \\
\hline
\end{tabular}

Approved for public release; distribution unlimited

7. DISTRIBUTION STATEMENT (of the sbstract entered in Block 20, If different from Report)

18. SUPPLEMENTARY NOTES

19. KEY WORDS (Continue on reverse side if necessary and identlfy by block number)

Fish

Toxicity

Bioassay

Hydrazine

Aufwuchs

20. ABSTRACT (Continuo on roverso sido if necossary and identify by block number)

This report contains the results of research efforts of a project concerned with defining the effects of potential environmental contamination resulting from the use of certain Air Force materials on freshwater and saline water f1sh. Materlals being evaluated include JP-4 and the hydrazines. Techniques for exposing organisms to these substances are discussed and results of such exposures are presented. 


\section{SUMMARY AND CONCLUSIONS}

1. This report deals with two topics:

a. The toxicity of the jet fuel, JP-4, to the flagfish (Jordanella floridae).

b. The toxicity of the rocket fuel components, hydrazine, 1, 1-dimethylhydrazine (UDMH), and 1-methylhydrazine (MMH), to the three-spine stickleback (Gasterosteus acuteatus) and to aufwuchs.

2. A qualitative method was developed for the analysis of aqueous JP-4 solutions; quantitative gas chromatographic methods were refined.

3. Results of a continuous-flow, partial chronic bioassay (195 days duration) of the water-soluble fraction (WSF) of JP-4 to flagfish supported the following conclusions:

a. There was no significant effect on egg hatchability in the range of $\mathrm{JP}-4$ concentrations examined $(0-6.6 \mathrm{mg} / 1 \pm 1.9 \mathrm{mg} / 1)$.

b. At the highest JP-4 concentration, newly-hatched fry were lethargic and deformed.

c. The two highest JP-4 concentrations $(6.6 \pm 1.9$ and $4.7 \pm 1.0 \mathrm{mg} / \mathrm{l})$ significantly reduced flagfish survival. The no-effect level, judged from survival was between $3.0 \neq 1.0$ and $4.7 \pm 1.0 \mathrm{mg} \mathrm{JP}-4 / 1$.

d. Flagfish growth and development was retarded at a11 JP-4 concentrations tested $(1.5 \neq 0.8$ to $6.6 \pm 1.9 \mathrm{mg} / 1)$.

e. On the basis of fish weight and length regression analyses, the predicted mean maximum no-effect level was $0.60 \pm 0.20 \mathrm{mg} \mathrm{JP}-4 / 1$.

f. JP-4 accumulation in flagfish whole-body tissue was a function of aqueous $\mathrm{JP}-4$ concentration. The mean accumulation ratio $\frac{\mathrm{mg} \mathrm{JP}-4 / \mathrm{kg} \text { wet weight }}{\mathrm{mg} \mathrm{JP}-4 / 1 \text { solution }}$ was $272 \pm 90$. This value is slightly higher than that of 159 determined for JP-8 in a previous flagfish chronic bioassay (1977 annual report).

g. Analysis of the specific tissues of golden shiners exposed to WSF of JP-4 demonstrated that the WSF of JP -4 accumulated primarily in the gastro-intestinal tract. Accumulation in tissues was proportional to aqueous JP-4 concentration. Flagfish were too small to dissect for specific tissue analysis.

h. The product of the fuel solubilizer (WSF of JP-4) changed both qualitatively and quantitatively during the weekly intervals between fuel replenishment. Qualitatively there was a significant depletion of two major components by differential solubilization rather than biodegradation. Quantitatively, WSF of JP-4 concentrations fell from 
$19.2 \pm 3.7 \mathrm{mg} / 1$ at $18 \mathrm{hr}$ to $16.1 \mathrm{mg} / 1$ at $168 \mathrm{hr}$.

4. Results of UDMH toxicity studies on stickleback and aufwuchs in San Francisco Bay water supported the following conclusions:

a. In jar tests with 24-hr UDMH renewal the 96-hr LC50 for stickleback was $1.6 \mathrm{mg} / 1$.

b. In analog tank "spill" studies (i.e. no renewal), the 96-hr no-effect level as judged by stickleback survival was between initial UDMH concentrations of 3.2 and $10 \mathrm{mg} / 1$. UDMH decayed rapidly; after $24 \mathrm{hr}$ on 1 y some $20 \%$ remained.

c. The no-effect level for fully-developed aufwuchs exposed to a UDMH "spill" for $24 \mathrm{hr}$ was between initial UDMH concentrations of 3.2 and $10 \mathrm{mg} / 1$.

5. Results of MMH toxicity studies to stickleback and aufwuchs in San Francisco Bay water supported the following conclusions:

a. In jar tests with 24-hr MMH renewal, the mean 96-hr LC50 for stickleback was $0.36 \mathrm{mg} / 1$.

b. In analog tank "spill" studies, the $96-\mathrm{hr}$ no-effect level as judged by stickleback survival was between inicial MMH concentrations of 1.0 and $3.2 \mathrm{mg} / 1$. MMH decayed to less than $10 \%$ of its initial concentration in $3.5 \mathrm{hr}$. Fully-developed aufwuchs exposed to an MMH spill for $24 \mathrm{hr}$ showed no toxic response in the range of initial $\mathrm{MMH}$ concentrations examined $(0-3.2 \mathrm{mg} / 1)$.

c. Aufwuchs exposed to MMH in a metabolic response test showed that the no-effect level as determined by the photosynthetic index was between 0.32 and $3.2 \mathrm{mg} / 1$.

6. Results of hydrazine toxicity studies on stickleback, aufwuchs, crabs (Hemigrapsus oregonensis), and mussels (Mytilus edulis) in Bay water supported the following conclusions:

a. Previously-reported work indicated the following hydrazine toxicities:

(1) Jar test (24-hr renewal) on stickleback - 96-hr LC 50 of $3.4 \mathrm{mg} / 1$.

(2) "Spill" test toxicity to stickleback - 96-hr no-effect level between 3.2 and $5.6 \mathrm{mg} / 1$.

(3) "Spill" test toxicity to aufwuchs - 96-hr no-effect level between 0 and $3.2 \mathrm{mg} / 1$.

b. A 96-hr continuous-flow bioassay with hydrazine being added continuously to maintain a constant concentration throughout the bioassay indicated a no-effect level between 0 and $2.2 \mathrm{mg} / 1$ for aufwuchs and the following 96-hr LC 50's:

(1) Stickleback $-5.4 \mathrm{mg} / 1$ (95\% confidence limits of 4.5 to $6.6 \mathrm{mg} / 1$ ). 
(2) Crabs - $3.6 \mathrm{mg} / 1$ ( $95 \%$ confidence limits could not be computed).

(3) Mussels - not affected in range examined (0-5.7 mg/1).

c. A 14-day (336-hr) continuous-flow study with constant hydrazine concentrations indicated the following hydrazine toxicities:

(1) The 336-hr LC 50 for stickleback was $1.07 \mathrm{mg} / 1$ ( $95 \%$ confidence limits of 0.78 to $1.47 \mathrm{mg} / 1$ ).

(2) The 336-hr LC 50 for crabs was $0.56 \mathrm{mg} / 1$ (95\% confidence limits could not be computed).

(3) No mortality of mussels occurred in the range examined ( 0 to $1.72 \pm 0.30 \mathrm{mg} / 1)$.

(4) Aufwuchs growth was inhibited at all hydrazine levels examined $(0.53 \pm 0.19$ to $1.72 \pm 0.30 \mathrm{mg} / 1)$; thus the no-effect level was less than $0.53 \neq 0.19 \mathrm{mg} / 1$.

(5) Chlorophy11 a content and gross photosynthesis appeared to be sensitive indicators of hydrazine toxicity.

(6) Chlorophy11 b content was higher in aufwuchs exposed to hydrazine than in control aufwuchs.

(7) Chlorophy11 $c$ content was an unreliable indicator of hydrazine toxicity and pheophytin a was present in negligible amounts or was absent in a11 aufwuchs tested. (8) The photosynthetic indices, $P I(w t)$ and $P I$ (chl a) were useful
indicators of hydrazine toxicity.

(9) There was greater diversity of species in the control aufwuchs than in the hydrazine-exposed aufwuchs.

(10) There was some evidence of aufwuchs adaptation to hydrazine levels of $0.53 \pm 0.19$ and $0.98 \neq 0.36 \mathrm{mg} / 1$. Longer-term studies with denser aufwuchs growths are needed for conclusive evidence. 
The research reported herein was conducted at the Sanitary Engineering Research Laboratory, University of California at Berkeley, under the terms of contract F 33615-76-C-5005 with the U.S. Air Force. The contract monitor was Maj. C. B. Harrah, Aerospace Medical Research Laboratory, Wright-Patterson AFB, Ohio. Professors David Jenkins and Robert C. Cooper were the Principal Investigators. Mr. Stephen Klein was the project manager. Ms. P. C. Ulrichs, $\mathrm{Mr}$. Robert Okazaki, and Mr. Gary Silverman were responsible for the conduct of bioassays. Ms. Elyse Heilshorn, candidate for the M.S. degree in Sanitary

Engineering, and Mr. Sang-Eun Lee, doctoral candidate in Sanitary Engineering, served as research assistants. 
SUMMARY AND CONCLUSIONS . . . . . . . . . . . . . . 1

PREFACE . . . . . . . . . . . . . . . . . . . . 4

LIST OF TABLES . . . . . . . . . . . . . . . . . . 8

LIST OF FIGURES . . . . . . . . . . . . . . . . 10

1. INTRODUCTION . . . . . . . . . . . . . . . . . . 12

2. MATERIALS AND METHODS . . . . . . . . . . . . . 12

Fuel . . . . . . . . . . . . . . . . . 12

Water-Soluble Fraction (WSF) of Fuel . . . . . . . . . . 12

Solubilizer Cleaning. . . . . . . . . . . . . . . 14

Gas Chromatographic (GC) Analysis of Fuels . . . . . . . . . 14

Quantitative Analysis . . . . . . . . . . . 14

Is othermal Operation . . . . . . . . . . . 14

Temperature Program Operation. . . . . . . . 14

Internal Standard . . . . . . . . . . . 14

Extraction of Fuel from Water . . . . . . . . . 14

Extraction of JP-4 from Fish . . . . . . . . 15

JP-4 Evaporation Correction . . . . . . . . . 15

Reproducibility of JP -4 Measurement. . . . . . . 15

Precision of Quantitative GC Analysis . . . . . . 15

Qualitative Analysis of JP-4 . . . . . . . . . 15

Purging Standard Mixtures of Normal Hydrocarbons. . . . 16

Chronic Bioassays . . . . . . . . . . . . . . 18

Egg Cups . . . . . . . . . . . . . . . . . . . 18

Fry Chambers . . . . . . . . . . . . . . . 21

LC 50 Determination . . . . . . . . . . . . . . . 21 
Golden Shiners . . . . . . . . . . . . . . . . . 21

Flagfish . . . . . . . . . . . . . . . . . . 21

Mineral Quality of Water . . . . . . . . . . . . . 21

Central Bay Analog-Tank Operations . . . . . . . . . . 22

Central San Francisco Bay Water . . . . . . . . . 25

Bay Water Characteristics . . . . . . . . . . . 25

Hydrazine . . . . . . . . . . . . . . . . 25

1 -Methyl Hydrazine $(\mathrm{MMH})$. . . . . . . . . . . . . 25

1, 1-Dimethyl Hydrazine (UDMH) . . . . . . . . . . . 28

Decay Rate of the Hydrazines . . . . . . . . . . . 28

Fish . . . . . . . . . . . . . . . . . . 28

Mussel . . . . . . . . . . . . . . . . . . . 28

$\mathrm{Crab}$. . . . . . . . . . . . . . . . . . 28

Aufwuchs . . . . . . . . . . . . . . . . . 28

Cages . . . . . . . . . . . . . . . . . . . 31

3. CHRONIC BIOASSAY FLAGFISH EXPOSED TO JP-4 . . . • • . 31

Introduction . . . . . . . . . . . . . . . . . . . 31

Procedure . . . . . . . . . . . . . . . . . 31

Results of JP-4 Concentration Measurements . . . . . . . . 32

JP-4 Quantitation . . . . . . . . . . . . . . 32

Effect of Fuel Age on JP-4 Concentration . . . . . . . 36

Effect of Fuel Age on Qualitative Nature of WSF of JP-4 . . 36

Egg Hatchability Results . . . . . . . . . . . . . . 39

Fry Survival - In Chamber and Tank . . . . . . . . . . . 42

Fry Growth - In Chamber and Tank . . . . . . . . . . . 44

Fry Lengths . . . . . . . . . . . . . . . . . . 44

Fry Weights . . . . . . . . . . . . . . . 44 
No-Effect Level of WSF of JP-4 on Fish Weight and Length . 47 JP-4 Accumulation in Flagfish Whole-Body Tissue. . . . . . 47

4. JP-4 ACCUMULATION IN GOLDEN SHINERS . . . . . . . . . 51 Accumulation in $32 \%$ Dilution of WSF of JP-4 . . . . . . . 51 Accumulation in $12 \%$ Dilution of WSF of JP-4 . . . . . . . 52

5. THE HYDRAZINES . . . . . . . . . . . . . . . . . 54 UDMH Studies. . . . . . . . . . . . . . . 54

Jar Test . . . . . . . . . . . . . 54

Analog Study . . . . . . . . . . . . 55

MMH Studies . . . . . . . . . . . . . . 55

Jar Test. . . . . . . . . . . . . . 55

Analog Study . . . . . . . . . . . . . 58

Hydrazine Studies . . . . . . . . . . . . . 62

Introduction . . . . . . . . . . . . . . . 62

The 96-hr Continuous-Flow Bioassay - Analog Tanks . . . 62

Procedure . . . . . . . . . . . . . . 62

Bay Water Characteristics . . . . . . . . . 65

Hydrazine and Ammonia Nitrogen Concentrations . . . 65

Mortality Results for the Fish, Crab, and Mussels . . 65

The 14-Day Continuous-Flow Bioassay - Analog Tanks . . 73

Procedure . . . . . . . . . . . . . . 73

Bay Water Characteristics . . . . . . . . . 73

Results of the Hydrazine, $\mathrm{NH}_{3}-\mathrm{N}$ and $\mathrm{pH}$ Measurements $\quad 73$

Mortality Results for Stickleback and Crab . . . . . 73

Mussels . . . . . . . . . . . . . . 77

Aufwuchs Results . . . . . . . . . . . . . 77

Discussion . . . . . . . . . . . . . . . • 83

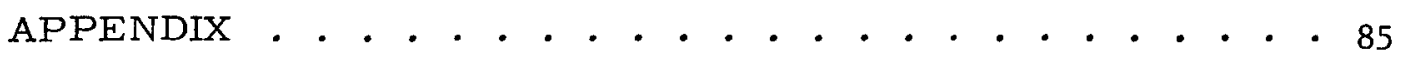

REFERENCES . . . . . . . . • • • • • • • 86 


\section{LIST OF TABLES}

Table

1. Retention Time and Recovery of Purge Standards

2. Characteristics of Dilution Water for Flagfish Chronic Bioassay . 22

3. WSF and Dilution Water Flow Rates to Achieve Desired Percent Dilutions for Continuous-Flow Bioassay . . . . . . . . 32

4. JP-4 Concentrations During Chronic Flagfish Bioassay . . . . . 34

5. Actual vs. Nominal Percent WSF of JP-4 . . . . . . . . . . . 35

6. Depletion of Selected JP-4 Components During the Seven-Day Period of Solubilizer Operation. . . . . . . . . . . . 37

7. Depletion of Selected JP-4 Components in Static Solubilization Tests . . . . . . . . . . . . . . . . . . . . 39

8. Hatchability of Flagfish Fry in the Presence of JP-4 . . . . . 40

9. Cumulative Percentage Fry Hatched in the Presence of WSF of JP-4

10. Cumulative Survival of Fry in Egg Cups . . . . . . . . . . . . 42

11. Survival of Flagfish Fry Exposed to WSF of JP-4 in the Fry

Chamber and Exposure Tank . . . . . . . . . . . 43

12. Growth Rate of Flagfish from Day 11 to Day 195 as Assessed by Mean Length . . . . . . . . . . . . . . . 45

13. Effect of WSF of JP-4 on Flagfish Wet Weights . . . . . . . . 50

14. Analysis of Variance and Linear Correlation. . . . . . . . . 50

15. Ratio of WSF of JP-4 Concentrations in Flagfish Whole-Body

Tissue to Aque ous WSF of JP-4 Concentration After 195 Days Exposure . . . . . . . . . . . . 51

16. Accumulation and Purging Rate of $32 \%$ Dilution of WSF of JP-4 in Golden Shiner. Body Tissues . . . . . . . . . . 53

17. Accumulation and Purging Rate of $12 \%$ Dilution of WSF of JP-4 in Golden Shiner Body Tissues . . . . . . . . . 53

18. Effect of UDMH on Stickleback: Static Acute Bioassay with 24-hr Renewal of UDMH . . . . . . . . . . . . . . 55

19. Effect of UDMH Spill on Stickleback Survival in Analog Tanks . . 56

20. Effect of UDMH Spill on Aufwuchs . • • • • • • • • • • • • 57 
21. Survival of Stickleback Exposed to $\mathrm{MMH}$ in a Static 24-hr

Renewal Bioassay . . . . . . . . . . . . . . . . .

22. Decline in $\mathrm{MMH}$ Concentration During a 24-hr Period Under

Static Bioassay Conditions.

23. Survival of Sticklebacks in a Simulated MMH Spill in Central

San Francisco Bay Water . . . . . . . . . . . . . 60

24. $\mathrm{MMH}$ and $\mathrm{NH}_{3}-\mathrm{N}$ Concentrations During $\mathrm{MMH}$ Spill Study . . . . 60

25. Effect of $\mathrm{MMH}$ Spills on Aufwuchs . . . . . . . . . . . . 61

26. Response of Aufwuchs to $\mathrm{MMH}$ Added During the Photosynthetic Index Measurement. . . . . . . . . . . . . . . 63

27. MMH Concentration Profile in Central San Francisco Bay

Water in the Presence of Aufwuchs . . . . . . . . . 64

28. Dissolved Oxygen Concentration Profile in a Solution of $3.2 \mathrm{mg} / \mathrm{L}$ $\mathrm{MMH}$ in Central San Francisco Bay Water . . . . . . . . 64

29. Physical and Chemical Characteristics of Central San Francisco

Bay Water During Continuous -Flow Bioassay of Hydrazine . • 66

30. Hydrazine and Ammonia-Nitrogen Concentrations in the 96-hr

Continuous-Flow Bioas say

31. Toxicity of Hydrazine to Sticklebacks in Central San Francisco

Bay Water

32. Toxicity of Hydrazine to Hemigrapsus oregonensis (Crabs) in

Central San Francisco Bay Water . . . . . . . . . . .

33. Toxicity of Hydrazine to Mytilus edulis (Mussels) in Central

San Francisco Bay Water . . . . . . . . . . . . . .

34. Standing Crop and Productivity of Aufwuch Communities Exposed to Four Concentrations of Hydrazine at 0,48 , and $96-\mathrm{hr}$ Periods.

35. Physical and Chemical Characteristics of Central San Francisco

Bay Water During 14-Day Continuous-Flow Bioassay of

Hydrazine

36. Hydrazine, $\mathrm{NH}_{3}-\mathrm{N}$, and $\mathrm{pH}$ Concentrations in the 14-Day

Continuous-Flow Bioassay Concentration, mean $\pm \mathrm{s}$

37. Toxicity of Hydrazine to Stickleback in 14-Day Continuous-

Flow Bioassay. . . . . . . . . . . . . . . . . 75

38. Toxicity of Hydrazine to Crab in 14-Day Continuous-Flow Bioassay 76

39. St: nding Crop and Productivity of Aufwuchs Communities Exposed to Four Concentrations of Hydrazine for Periods of 168 and $336 \mathrm{Hr} 78$ 
1. Fuel Contact and Delivery System . . . . . . . . . . 13

2. Purge-and-Trap Apparatus for Qualitative Analysis of JP-4 .

3. Comparis on of Purge to Pentane Extraction Analysis of

WSF of JP-4. . . . . . . . . . . . . . . . 20

4. General View of Analog Tanks . . . . . . . . . . . . 23

5. Close-up View of Analog Tank . . . . . . . . . . . . . 24

6. Flow Diagram of the Analog Tank System . . . . . . . . . 26

7. Bay Water Supply System for Analog Tanks . . . . . . . . . 27

8. Decay of the Hydrazines in Aerated Bay Water . . . . . . . . 29

9. Fish Cages and Aufwuchs Growth Rack Suspended in Analog Tank. . . . . . . . . . . . . . . . 30

10. Flow Diagram of Chronic Flagfish Bioassay of WSF of JP-4 . . 33

11. Preferential Depletion of WSF of JP-4 Components from Solubilizer Product with Fuel Age-Purge Technique . . . . . 38

12. Replication of Bank A and Bank B Flagfish Growth Rates . • . 46

13. Effect of JP-4 Concentration on Fry Weight and Length . . . . 48

14. Regression Analyses of Fry Weights and Lengths . . . • • - 49

15. Chlorophyll a, $\underline{b}$, and $c$ Concentrations in Aufwuchs Exposed to Indicated Hydrazine Concentrations at 0,48 , and 96-hr Intervals in Continuous-Flow Salt Water Bioassays . . . . . . . . .

16. Gross Photosynthesis of Aufwuchs Communities Exposed to Indicated Hydrazine Concentrations at 0,48 , and $96-\mathrm{hr}$ Intervals in Continuous-Flow Salt Water Bioassays . . . . .

17. Photosynthetic Index [PI (wt)] of Aufwuchs Communities Exposed to Indicated Hydrazine Concentrations at 0,48 , and 96-hr Intervals in Continuous-Flow Salt Water Bioassays.

18. Photosynthetic Index [PI (chl)] of Aufwuchs Communities Exposed to Indicated Hydrazine Concentrations at 0,48 , and 96-hr Intervals in Continuous-Flow Salt Water Bioassays.

19. Effect of Indicated Concentration of Hydrazine on Dry Weight of Growth on Aufwuchs 
20. Variation of Chlor ophyll Content of Aufwuchs Biomass with Hydrazine Concentrations . . . . . . . . . . . .

21. Gross Photosynthesis of Aufwuchs Exposed to Four

Concentrations of Hydrazine . . . . . . . . . . . . .

22. $\quad P I_{(w t)}$ of Aufwuchs Exposed to Four Concentrations of Hydrazine . . . . . . . . . . . . . . . . . .

23. $\mathrm{PI}_{(\mathrm{ch} 1)}$ of Aufwuchs Exposed to Four Concentrations of Hydrazine . . . . . . . . . . . . . . . . . . 


\section{INTRODUCTION}

Studies included in this report are directed toward providing information on the toxicity to aquatic life of the kerosene-based jet fuel, JP-4, and the rocket fuel components hydrazine, monomethylhydrazine (MMH), and unsymmetrical dimethylhydrazine (UDMH). These materials are currently in use by the U.S. Air Force.

To define the environmental impact of a toxicant on aquatic life, an experimental protocol has been established. This protocol for jet fuels includes conducting acute static, acute continuous-flow, and chronic continuous-flow bioassays on warm-water and cold-water fish species. A chronic continuous-flow study of 6-months duration on the effect of the water-soluble fraction (WSF) of JP-4 on the warm-water fish species, flagfish (Jordanella floridae), is reported herein. The study started with eggs produced by laboratory-reared flagfish; it included a growth and development period and concluded with an examination of fish tissue for fuel accumulation.

Studies on rocket fuel components have been conducted in saline water from San Francisco Bay at the large-scale analog facility of the Sanitary Engineering Research Laboratory. The experimental protocol includes performing acute static, acute "spil1", and 14-day continuous-flow bioassays on the 3-spine stickleback (Gasterosteus aculeatus) and aufwuchs (attached periphyton growths). In some of these studies the Bay mussel (Mytilus edulis) and the mud-flat crab (Hemigrapsus oregonensis) were also examined. "Spill" studies have been concluded on the three rocket fuels, and a 14-day continuous-flow study on hydrazines will include 14-day continuous-flow studies on MMH and UDMH toxicity and an additional study to determine the no-effect level of hydrazine on aufwuchs.

\section{MATERIALS AND METHODS}

FUEL

JP-4 is a kerosene-based jet fuel consisting of a complex mixture of aliphatic and aromatic hydrocarbons with a density of $0.746 \mathrm{~g} / \mathrm{m} 1$. JP-4 was supplied by the Aerospace Medical Research Laboratory, Wright-Patterson Air Force Base, Ohio.

\section{WATER-SOLUBLE FRACTION (WSF) OF FUEL}

For continuous-flow bioassays a continuous supply of water saturated with the water soluble fraction (WSF) of JP-4 was furnished by a fuel-contacting device (see Figure 1). Two such devices were constructed, each capable of producing $650 \mathrm{ml} / \mathrm{min}$ of $\mathrm{WSF}$, to supply the $1300 \mathrm{ml} / \mathrm{min}$ required to operate 10 bioassay tanks.

Each device consisted of 5 glass 'columns (each $1.2 \mathrm{~m}$ long and $3.8 \mathrm{~cm}$ in diameter) connected in series. The columns were each charged with 1 liter of fuel; the remainder of the liquid column $(0.71)$ was water. The flow of water was downward through each column of fuel. The flow from the final column of the series entered a 9-1 glass carboy which served as a filter and separation chamber. The carboy contained a stainless steel baffle to reduce the velocity of the water stream and a layer of pure fuel to aid in absorbing minutely-dispersed fuel droplets. 


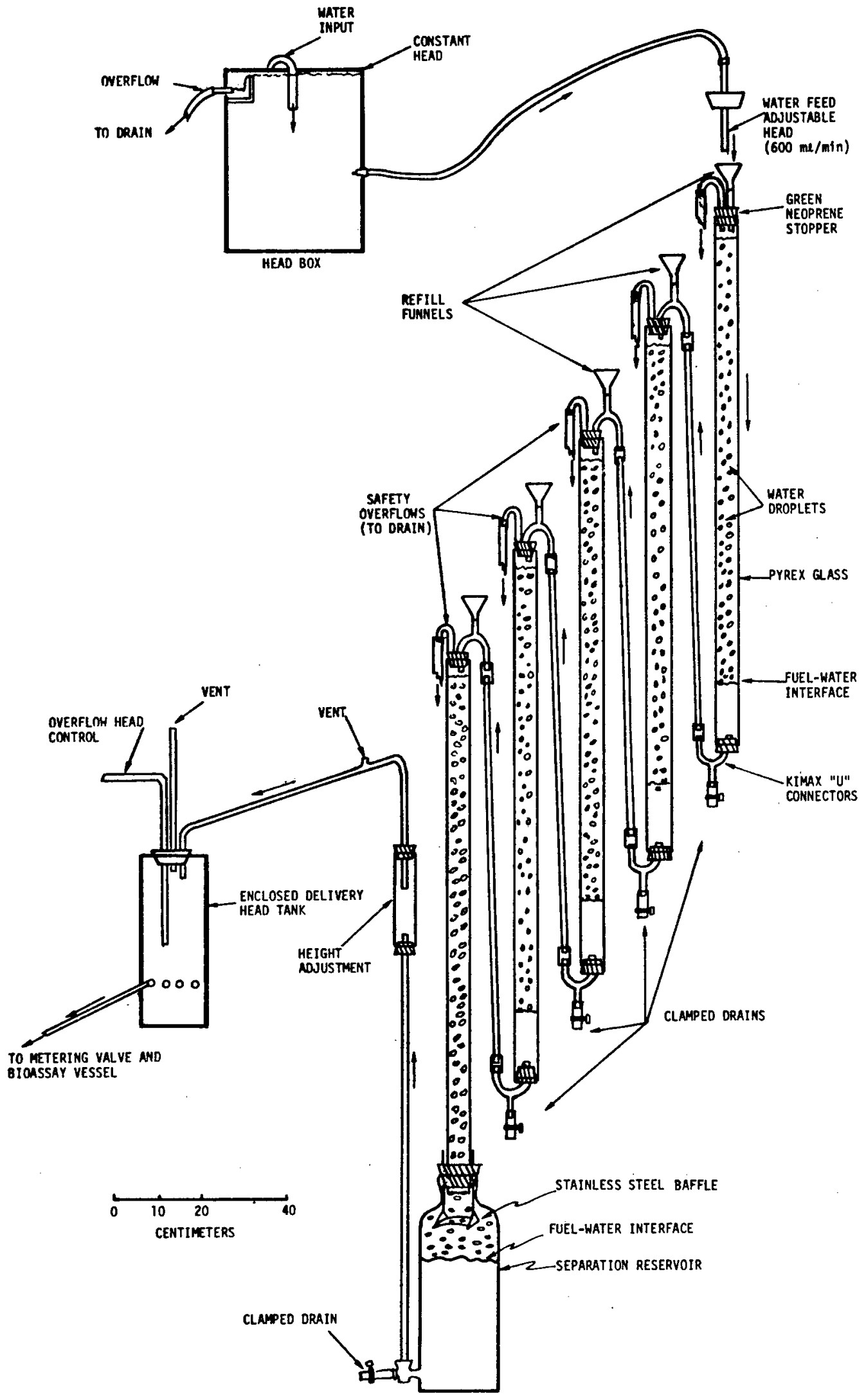

FIGURE 1. FUEL CONTACT AND DELIVERY SYSTEM 
The tap water entering the device from a constant head tank was first dechlorinated by passage through a 25-gal (94.51) bed of activated carbon $76 \mathrm{~cm}$ deep contained in a 50-gal (189 1) stainless steel drum.

\section{SOLUBILIZER CLEANING}

A biological slime gradually builds up on the walls of the glass columns. Because of this, the solubilizers were cleaned thoroughly once per week. The slime had to be removed regularly to prevent interference in the operation of metering valves and to minimize changes in the nature and concentrations of JP-4 in the solubilizer product. Satisfactory cleaning was achieved by rinsing with Labtone organic detergent solution ${ }^{2}$ followed by a 2 -hr exposure to a $1 \%$ NaOCL solution.

After cleaning, the solubilizers were replenished with fresh fuel. The maximum fuel age was 7 days, and the maximum dilution ratio (liters of water throughput per liter of fuel) was 907.

\section{GAS CHROMATOGRAPHIC (GC) ANALYSIS OF FUELS}

Two types of GC analysis of JP-4 were conducted, Quantitative analysis was performed to determine the total JP-4 concentration (mg/1) in a water or fish sample. Qualitative analysis was performed to determine the composition of JP-4 contained in various types of sample. A Fisher Model 4800 gas chromatograph with dual flame ionization detectors and $6.1 \mathrm{~m} \mathrm{x} 0.32 \mathrm{~cm} 0 . \mathrm{D}$. stainless steel columns packed with $10 \%$ SE 30 on $80 / 100$ Chrom $W$ was used for both types of analysis. Accessory GC equipment included a Fisher Series 5000 Recordall recorder and an Autolab minigrator for digital integration of peaks.

\section{Quantitative Analysis}

Complete details of the GC techniques for quantitative JP-4 analysis (including standard curves, typical chromatograms, the internal standard technique, and the method for extraction of fuel from water) were presented in the November 1977 Second Annual Report, AMRL-TR-77-54. They will be summarized briefly here.

Isothermal Operation was conducted at a temperature of $160 \mathrm{C}$. For both isothermal and temperature-programed operation, the injection and detector temperatures were $270 \mathrm{C}$ and $200 \mathrm{C}$ respectively. The $\mathrm{N}_{2}$-carrier gas flow rotameter setting was 3.0 at 80 psig. The detector flame $\mathrm{H}_{2}$ flow was set at a rotameter reading of 4.5 .

Temperature Program Operation. For suitable peak differentiation there was an initial delay of $3 \mathrm{~min}$. at $60 \mathrm{C}$ followed by a temperature increase of $4 \mathrm{C} / \mathrm{min}$ to $200 \mathrm{C}$ and a final delay of $30 \mathrm{~min}$.

Internal Standard. The internal standard selected for JP-4 analysis was the normal $\mathrm{C}_{14^{-h y d r o c a r b o n ~}}$-tetradecane. The JP-4 mass in a given sample was obtained ${ }^{14}$ by multiplying the ratio of the JP-4 area to $C_{14}$ area by the mass of $\mathrm{C}_{14}$ added.

Extraction of Fuel from Water. Prior to quantitative GC analysis of water samples for JP-4, a 300-m1 water sample was extracted with two successive

1 Ayailable from Van Waters and Rogers Scientific Co. 
25-ml aliquots of pentane. The volume of the combined pentane extracts was reduced to $3 \mathrm{ml}$ by rotary evaporation at room temperature and $\sim 25 \mathrm{~mm} \mathrm{Hg}$. A volume of $2 \mu 1$ of the concentrated extract was injected into the GC.

Extraction of JP-4 from Fish. Whole-body tissue, muscle tissue, or specific organ tissues of fish were ground in a Virtis "45" tissue grinder in the presence of pentane. The extract was passed through a column of sodium sulfate, then concentrated to $15-25 \mathrm{~m} 1$ using a rotary evaporator. The concentrate was filtered through florosil, and the volume reduced by rotary evaporation to about $3 \mathrm{~m} 1$ prior to GC analysis.

JP-Evaporation Correction. In the process of evaporation of the pentane extract of JP-4 to $3 \mathrm{ml}$ prior to GC analysis, a portion of the JP-4 was lost. The magnitude of this loss was determined by a comparison of the GC traces of a pentane extract before and after evaporation. For 8 samples of the WSF of JP-4 (taken from the solubilizer) the "before evaporation" results averaged $22.62 \pm 1.31 \mathrm{mg} / 1$ and the "after evaporation" results averaged 10.28 $\pm 0.75 \mathrm{mg} / 1$. The mean percentage loss based on the "before evaporation" value was $54.5 \pm 2.4 \%$ with a coefficient of variation, $\left(C_{y}\right)$, of $4.4 \%$. Based on these values a correction factor of 2.20 was used to multiply the JP-4 values obtained from evaporated samples.

To obtain adequate GC sensitivity in the analysis of the "before evaporation" samples, very large injections (on the order of $8 \mu 1$ ) were required. Samples could not be processed routinely in this manner because repeated injections of such large volumes caused severe GC operational problems.

Reproducibility of JP-4 Measurement. Nine injections of the same sample were made over a 3-day period. The mean uncorrected JP-4 value was $9.74 \pm 0.76 \mathrm{mg} / 1$ $\left(\mathrm{C}_{\mathrm{V}}=7.8 \%\right)$ and the mean corrected value was $21.43 \pm 1.67 \mathrm{mg} / 1$. The application of the correction factor (2.20) increased the sample standard deviation by a factor of 2.2 .

Precision of Quantitative GC Analysis. The precision of the JP-4 analytical method based on 48 pairs of duplicate analyses was $\pm 0.85 \mathrm{mg} / 1$ (Appendix), as assessed by the standard deviation of the 48 individual standard deviations (from a mean of means of $18.50 \mathrm{mg} / 1$ ). The analytical precision of $\mathrm{JP}-4$ measurements was poorer than the value of 0.24 previously determined for JP- 8 (November 1977 Second Annual Report, AMRL-TR-77-54) because of the magnitude of the evaporation loss correction factor for JP-4 (2.2 compared with 1.5 for JP-8).

\section{Qualitative Analysis of JP-4.}

The conventional method of qualitative analysis by temperature programming a reduced volume pentane extract of an aqueous sample could not be used for JP-4. The rotary evaporation step caused substantial loss of the more volatile fractions and so rendered the method unsuitable for assessing qua1itative changes which might occur in the bioassay system due to biodegradation or selective dissolution and evaporation of fuel components.

To overcome this deficiency the purge gas analytical technique of Bellar and Lichtenberg (1974) was investigated. The method is applicable to hydrocarbons that boil below $150 \mathrm{C}$ and aliphatic and aromatic compounds that are less than $2 \%$ water soluble. An inert gas, bubbled through a water sample, transfers organics from the aqueous to the gaseous phase. The organics are then trapped on a porous polymer column at a temperature of less than 30c. Trapped organics are then thermally desorbed, swept from the trap directly into the GC column, 
and analyzed using temperature programming.

A number of procedural and equipment modifications were made to accomodate Bellar and Lichtenberg's method to the analysis of the diverse mixture of compounds in $\mathrm{JP}-4$.

The design of the purge-and-trap system is depicted in Figure 2. The flow of $\mathrm{N}_{2}$ carrier gas to the gas chromatograph is split so that $\mathrm{N}_{2}$ may be used to purge a liquid sample (e.g. WSF of JP-4). A 5-ml capacity Bellar and Lichtenberg purging device was used with a $\mathrm{N}_{2}$ flow rate of $20 \mathrm{ml} / \mathrm{min}$ for a period of $15 \mathrm{~min}$.

The trap consisted of a $25.4 \mathrm{~cm}$ length of $0.64 \mathrm{~cm} 0 . \mathrm{D}$. stainless stee 1

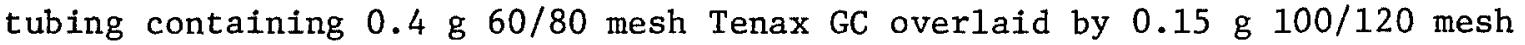
Porapak Q. This combination of polymers was used because Tenax GC adsorbed the higher boiling point compounds in JP-4 but did not trap the more volatile components. Porapak Q trapped the lower boiling point compounds, but also irreversibly trapped the higher molecular weight compounds. Therefore the Porapak Q had to follow the Tenax GC in the trapping train and the flow of carrier gas had to be reversed during desorption. The trap was located in an oven which consisted of a $20.3 \mathrm{~cm}$ length of $0.95 \mathrm{~cm}$ copper tubing with a $61 \mathrm{~cm}$ length of heating tape wound around it. The temperature was controlled by a rheostat and was raised to $180 \mathrm{C}$ during the 500-sec desorption period.

During the purging period valves No. 3 and No. 5 were closed and the other valves were opened enabling the volatile organics to accumulate in the trap and the purge gas to be vented to the open air. During thermal desorption valves No. 1 and No. 2 were closed and valves No. 3 , No. 4, and No. 5 were opened. This permitted the bulk of the carrier gas flow to sweep through the GC column at the same time that a portion of the flow desorbed volatiles from the trap and concentrated them on the head end of the GC column (maintained at room temperature during desorption). This method yielded the best differentiation of early peaks - better than a single $\mathrm{N}_{2}$ flow through the trap at any rate tested. For the final $100 \mathrm{sec}$ desorption, all of the flow was directed through the trap to insure complete displacement of adsorbed compounds.

Upon conclusion of desorption, valves No. 3 and No. 5 were closed and valve No. 4 was opened to permit the normal flow of carrier gas. The GC oven temperature was then raised to $60 \mathrm{C}$ and following a 3-min initial delay the temperature was raised at a rate of $4 \mathrm{C} / \mathrm{min}$ to $200 \mathrm{C}$. The period required to chromatograph JP-4 was approximately $45 \mathrm{~min}$. Processing one sample took about $90 \mathrm{~min}$.

The purge method was unsuitable for quantitative analysis because of the diverse nature of the compounds comprising JP-4. To fully purge the higher molecular weight compounds from solution, excessively long purge periods were necessary. For example, $n-C_{11}$ must be purged for $1 \mathrm{hr}$ at the recommended rate of $20 \mathrm{ml} / \mathrm{min}$ to achieve $99 \%$ transfer. Long purge periods can cause venting of the lower molecular weight compounds from the trap when their retention index is exceeded. Thus, it would be necessary to collect successive fractions to analyze JP-4 quantitatively by this method. This is far too tedious a method for routine quantitative analysis.

Purging Standard Mixtures of Norma1 Hydrocarbons

A mixture of standards was prepared by weighing out known amounts of the 


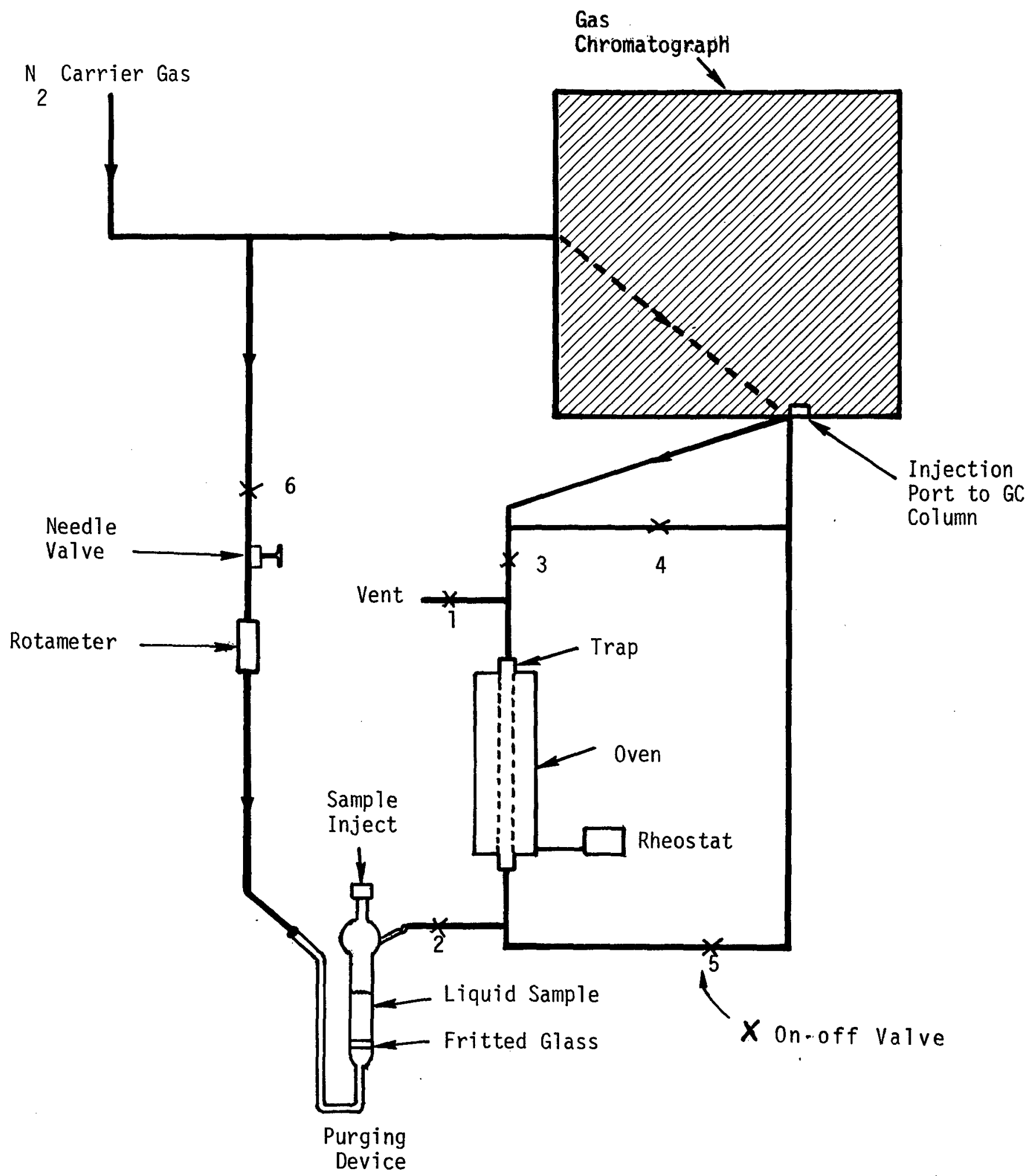

FIGURE 2. PURGE-AND-TRAP APPARATUS FOR QUALITA TIVE ANALYSIS OF JP-4 
$\mathrm{C}_{6}$ through $\mathrm{C}_{14}$ alkanes and diluting them to $100 \mathrm{~m} 1$ with $\mathrm{CS}_{2}$. Into $2 \mathrm{~m} 1$ of water in the purge flask, $9 \mu 1$ of the standard mixture was injected and the purging and desorption process was carried out. The results (Table 1) indicate that the peak areas per unit mass for the $\mathrm{C}_{6}-\mathrm{C}_{9}$ hydrocarbons were virtually identical. The mean of these four values was taken to be $100 \%$ recovery. This assumption is consistent with results of Bellar and Lichtenberg (1974) who reported $100 \%$ recovery for $\mathrm{C}_{6}-\mathrm{C}_{9}$ hydrocarbons using their purge-and-trap technique. Above $\mathrm{C}_{9}$ the recoveries became progressively poorer for each successive1y higher molecular weight compound in the homologous series.

The usefulness of the purge-and-trap method for the qualitative analysis of the WSF of JP-4 was assessed. Figure 3 compares chromatograms of the WSF of JP-4 by the purge-and-trap method and the pentane extraction method with chromatograms of a standard mixture of $\mathrm{C}_{6}-\mathrm{C}_{14}$ alkanes derived from the same two techniques. The purge-and-trap technique (the two chromatograms on the left) indicates that about $90 \%$ of the WSF of JP-4 can be accounted for by compounds with carbon numbers up to and including $\mathrm{n}-\mathrm{C}_{10}$ (based on percent of total area through the $n-C_{10}$ hydrocarbon retention time). On the other hand, the direct injection of the evaporated pentane extract indicates that approximately $70 \%$ of the WSF of JP-4 mass can be accounted for by compounds with carbon numbers up to and including $\mathrm{n}-\mathrm{C}_{10}$. The purge-and-trap method tends to overemphasize the low molecular weight fraction of the WSF of JP-4 by giving excellent recoveries of compounds below $n-C_{10}$ and poorer recoveries of higher molecular weight components. The quantitative method gives a low estimate of the low molecular weight fractions of the WSF of JP-4 largely because of the volatility losses during rotary evaporation. Also, the presence of pentane in the injected sample masks several of the low molecular weight JP-4 peaks. Thus, an exact representation of the WSF of JP-4 is not produced by either method but the purge-and-trap method accurately displays the predominant (perhaps $80 \%$ ) compounds present. More importantly, the highly soluble compounds, which are completely recovered by the purge-and-trap method, are those likely to be depleted in a system continuously producing a water soluble fraction from a single batch of fuel. Therefore, the purge-and-trap method should be useful for a study of the qualitative changes of the composition of WSF of JP-4 with time of solubilization. The poor recovery of the higher molecular weight compounds has little, if any, impact on the usefulness of the purge-and-trap method for these purposes.

\section{CHRONIC BIOASSAYS}

Continuous flow bioassay exposure tanks were of stainless steel construction, $121.9 \mathrm{~cm}$ long, $30.5 \mathrm{~cm}$ wide, and $30.5 \mathrm{~cm}$ deep. They could be compartmentalized by removable size $40-010$ mesh $\left(0.144-\mathrm{mm}^{2}\right.$ size opening and $0.25-\mathrm{mm}$ size wire) stainless steel screens. A standpipe controlled water depth at $20.3 \mathrm{~cm}$ giving a tank capacity of $80 \mathrm{~L}$. The WSF of JP-8 was produced in the fue1-contacting device described previously and delivered through a manifold system consisting of a $3.2 \mathrm{~cm} \mathrm{I.D.} \mathrm{lucite} \mathrm{tube.} \mathrm{WSF} \mathrm{flow} \mathrm{was} \mathrm{controlled} \mathrm{through} \mathrm{stain-}$ less steel micro-metering valves located in the manifold above each bioassay vessel. Dilution water was fed into a similar manifold at the rate of $1400 \mathrm{ml} /$ min and also delivered into bioassay vessels through micro-metering valves.

\section{EGG CUPS}

Egg cups for egg hatchability studies were $118.3 \mathrm{~cm}^{3}$ glass jars with their bottoms replaced by a 40-010 mesh stainless steel screen. Egg cups were suspended in the stainless steel bioassay vessels and agitated by an electric 
Table 1

Retention Time and Recovery of Purge Standards

$\begin{array}{cccccc}\text { n-Alkane } & \begin{array}{c}\text { Mass } \\ \text { Purged } \\ \text { ng }\end{array} & \begin{array}{c}\text { Retention } \\ \text { Time } \\ \text { sec }\end{array} & \begin{array}{c}\text { Peak Area } \\ \text { mv-sec }\end{array} & \begin{array}{c}\text { Area/Mass } \\ \text { mv-sec/ng }\end{array} & \begin{array}{c}\text { Estimated } \\ \text { Recovery } \\ \%\end{array} \\ C_{6} & 283.5 & 174 & 127192 & 448.7 & 100 \\ C_{7} & 300.6 & 408 & 134444 & 447.3 & 100 \\ C_{8} & 317.7 & 696 & 143892 & 452.9 & 100 \\ C_{9} & 326.7 & 1010 & 147110 & 450.3 & 100 \\ C_{10} & 336.6 & 1316 & 148778 & 442.0 & 98.2 \\ C_{11} & 346.5 & 1608 & 139086 & 401.4 & 89.2 \\ C_{12} & 336.6 & 1844 & 116718 & 346.8 & 77.0 \\ C_{13} & 357.3 & 2058 & 45622 & 127.7 & 28.4 \\ C_{14} & 351.0 & 2256 & 20074 & 57.2 & 12.7\end{array}$

* Estimated $100 \%$ recovery based on mean area/mass of $\mathrm{C}_{6}-\mathrm{C}_{9}$. 

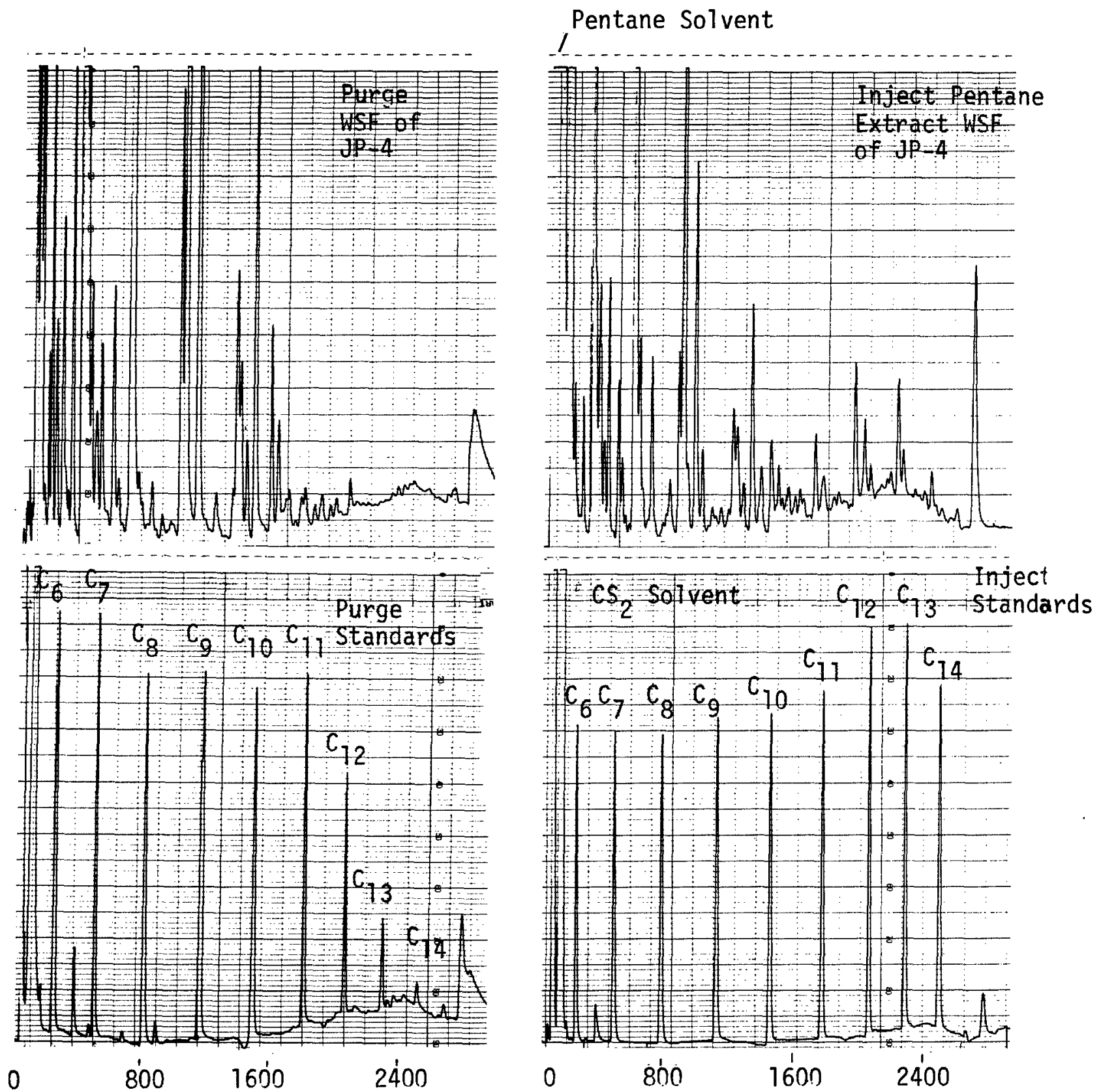

FIGURE 3. COMPARISON OF PURGE TO PENTANE EXTRACTION ANALYSIS OF WSF OF JP-4 
motor and pulley system.

FRY CHAMBERS

Fry chambers were glass, $30.5 \mathrm{~cm}$ long, $15.2 \mathrm{~cm}$ wide, and $30.5 \mathrm{~cm}$ deep, with 40-100 mesh stainless screens at each end to permit free circulation of water. The chambers were designed to fit into the stainless steel fish tanks.

\section{LC 50 DETERMINATION}

LC 50 values in "spil1" studies were determined from a plot of the log concentration vs. percent mortality according to Standard Methods (1975). In continuous-flow bioassays the LC 50 values were determined from the estimated line of best fit of concentration vs. effect plotted on logarithmic-probability paper. The $95 \%$ confidence limits were computed according to Litchfield and Wilcoxon (1949).

\section{GOLDEN SHINERS}

Golden Shiners were obtained from the Sierra Bait Company, a commercial fish hatchery located near Sacramento, CA. Large fish ( $10 \mathrm{~cm}$ long) were used to determine the target organs in which fuel accumulated.

\section{FLAGFISH}

Flagfish were obtained from a commercial aquarium and cultured in the laboratory to produce eggs for hatchability and subsequent growth and development studies. These fish are considered to be of intermediate sensitivity, and were selected for bioassay work because they are easy to sex and mate and have a short egg-to-egg cycle.

Flagfish spawning aquaria were set up in a room separate from the bioassay room maintained at $22 \mathrm{C}$, the optimal temperature for breeding. A ratio of one male to 5 females was maintained in 4 spawning aquaria which were $98.3 \mathrm{~L}$ tanks. The water was filtered by a commercial pump-filtration system and aerated by air pumps that dispensed air through air stones. Each tank contained two substrates to receive the eggs, consisting of dark green yarn wrapped around stainless steel cloth.

Four 56.7 L capacity aquaria were used as holding tanks for eggs and developing fry. Dechlorinated water flowed through these tanks at a rate that approximated one residence time per day. It was removed by pumps.

Debris was removed daily from the aquaria. In addition, they were thoroughly cleaned once per week by sponging the sidewalls and bottoms. Disease was controlled by applications of Malachite Green to eggs upon their transfer from spawning aquaria into hatching aquaria.

\section{MINERAL QUALITY OF WATER}

Two sets of water analyses were performed during the flagfish chronic bioassay, one at the start and the other at the conclusion of the study. Results of analyses, conducted in accordance with Standard Methods (1975), are presented in Table 2 . 
Table 2

Characteristics of Dilution Water for Flagfish Chronic Bioassay

\section{Parameter}

Total solids

Total dissolved solids

Total hardness (as $\mathrm{CaCO}_{3}$ )

$\mathrm{C1}$

$\mathrm{Mg}^{++}$

$\mathrm{Ca}^{++}$

$\mathrm{Na}^{+}$

$\mathrm{K}^{+}$

$\mathrm{SO}_{4}=$

$\mathrm{F}^{-}$

$\mathrm{pH}$

Conductivity

\section{Value}

$56 \mathrm{mg} / 1$

$44 \mathrm{mg} / 1$

$34 \mathrm{mg} / 1$

$6.4 \mathrm{mg} / 1$

$3.0 \mathrm{mg} / 1$

$10.5 \mathrm{mg} / 1$

$3.0 \mathrm{mg} / 1$

$1.0 \mathrm{mg} / 1$

$1.8 \mathrm{mg} / 1$

$0.48 \mathrm{mg} / 1$

8.9

$65 \mu \mathrm{mhos} / \mathrm{cm}$

\section{CENTRAL BAY ANALOG-TANK OPERATIONS}

Studies of the effect of hydrazines on plant and animal species indigenous to the Central San Francisco Bay were conducted in water pumped from the Central San Francisco Bay to large analog tanks located at SERL. A general view of the analog tanks is shown in Figure 4. The 12 analog tanks were rectangular and each of $4.2 \mathrm{~m}^{3}$ capacity ( $3 \mathrm{~m} \mathrm{long,} 1.22 \mathrm{~m}$ wide and $1.14 \mathrm{~m}$ deep). The tanks were constructed from heavily-reinforced marine plywood with all of the interior and exterior surfaces fiberglassed.

In each tank there was an air agitation system consisting of $2.5 \mathrm{~cm}$ PVC pipe perforated along its entire $1-\mathrm{m}$ length and connected with flexible tubing to a compressed air header. The air mixer was mounted horizontally $30 \mathrm{~cm}$ above the bottom and $30 \mathrm{~cm}$ out from the tank wall along the short axis of the tank. In continuous-flow studies the mixer was mounted vertically in one corner of the tank.

Bay water pumped to the tanks entered plexiglas 20-L capacity constanthead boxes. One such box served each cluster of 4 tanks (Figure 5). Water flow to each tank was regulated by $1.3 \mathrm{~cm}$ PVC valves.

For continuous-flow studies hydrazine stock solutions and Buchler polystaltic feed pumps were housed in refrigerated polystyrene containers located adjacent to the constant-head boxes (Figure 6) to minimize pumping distance. 


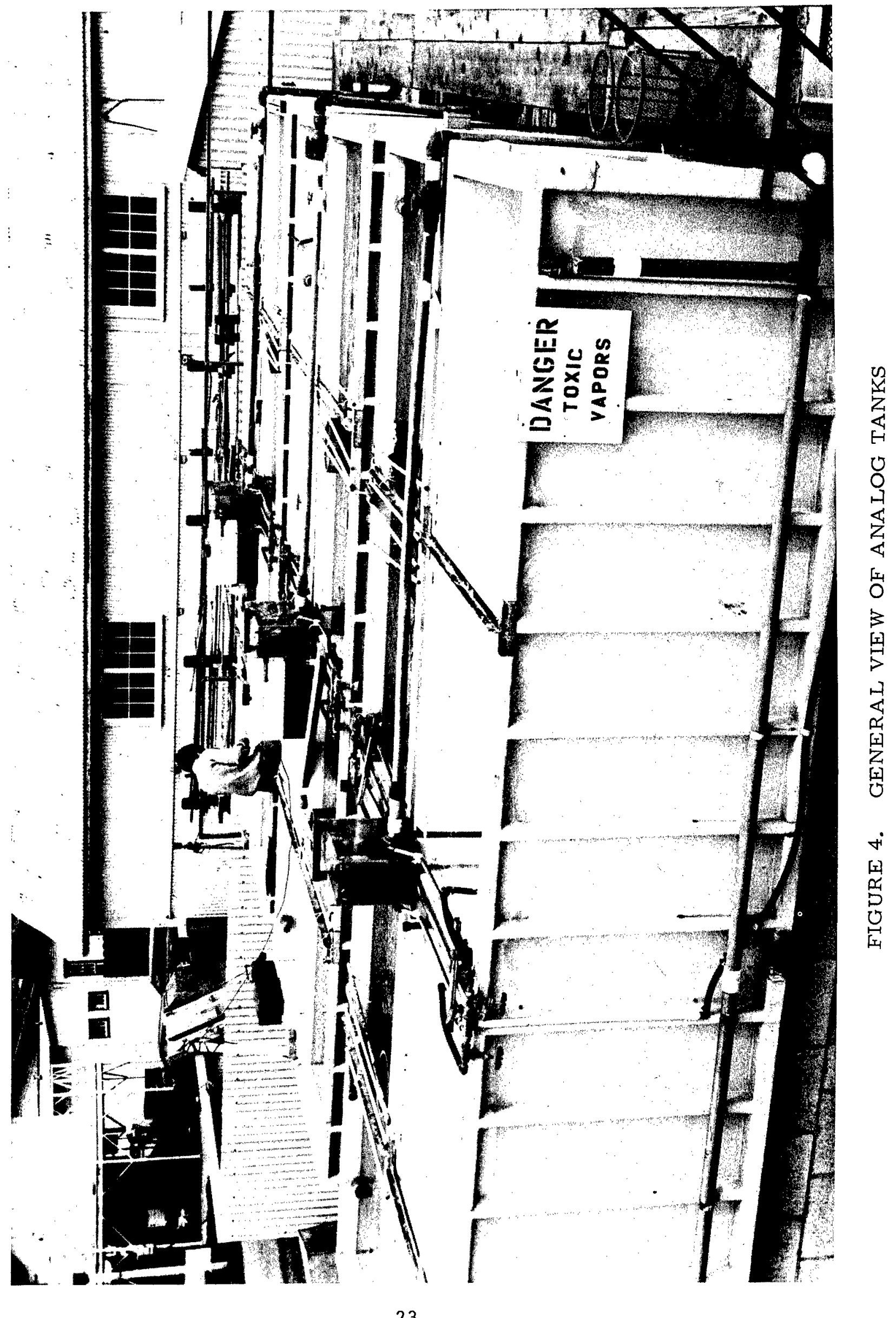




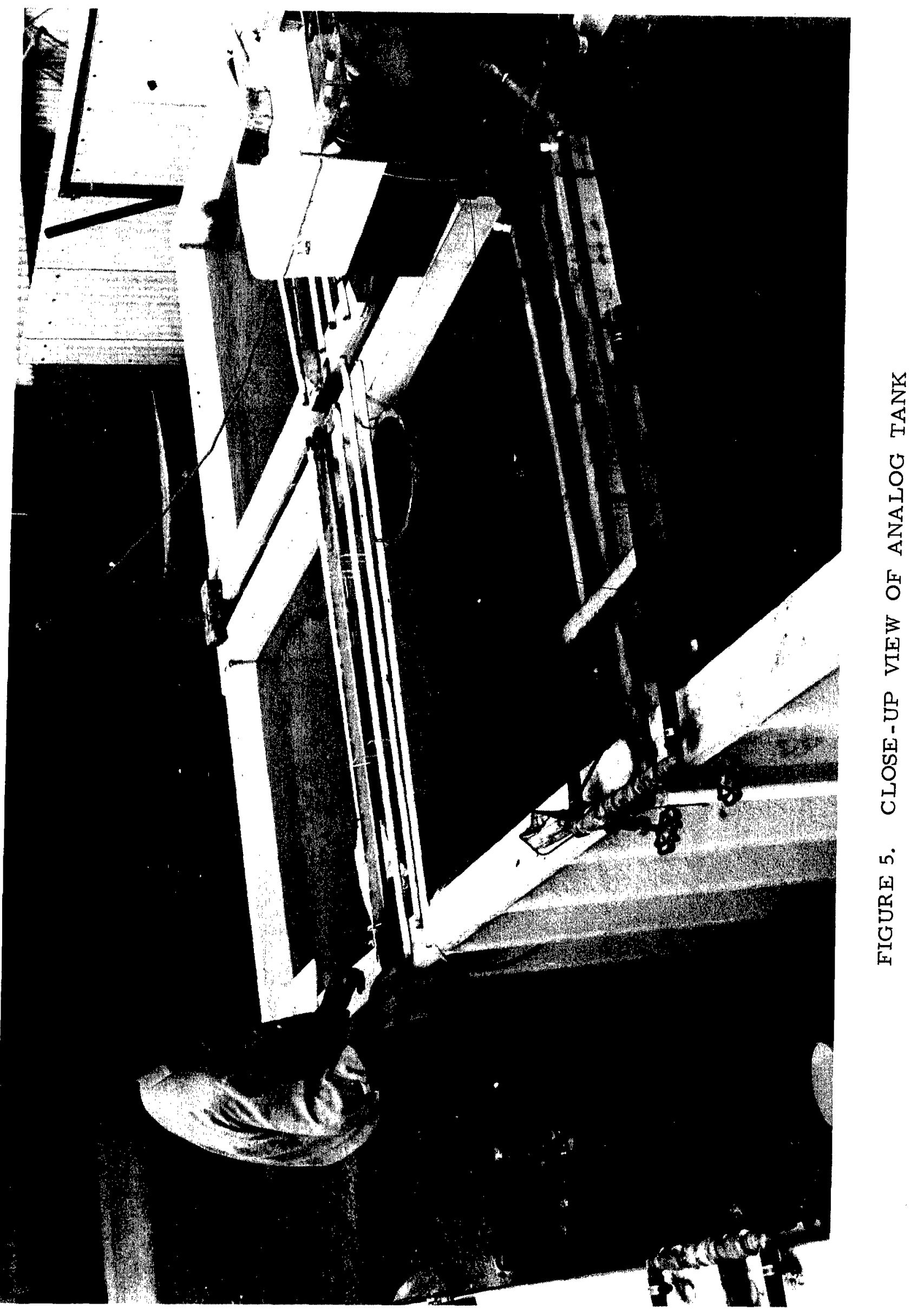


Hydrazine was pumped into the $2.5 \mathrm{~cm}$ pipes which distributed Bay water from the head tank to the analog tanks. The point of hydrazine input provided $122 \mathrm{~cm}$ of tubular mixing with Bay water prior to the entry of the mixture into the analog tank. A float switch mounted in each head tank deactivated hydrazine pumps in the event of an interruption in the flow of Bay water.

Discharge from the analog tanks was piped to a treatment tank for hydrazine destruction. The tank, $244 \mathrm{~cm} \times 122 \mathrm{~cm} \mathrm{x} 61 \mathrm{~cm}$ deep, was constructed of epoxy-coated plywood and was baffled as shown. in Figure 6 to prevent short circuiting. Hydrazine was destroyed by vigorous aeration.

\section{CENTRAL SAN FRANCISCO BAY WATER}

Central San Francisco Bay water was delivered to the analog tanks from an intake $1.04 \mathrm{~km}$ offshore. This system delivered good quality Bay water representative of that in the Central San Francisco Bay. The intake location was sufficiently deep to remain well submerged at low tide and permit continuous operation. A sketch of the Bay water supply system is shown in Figure 7. The intake station consisted of a $7.6 \mathrm{~cm}$ flexible polyehtylene pipe anchored to a platform piling at a point $0.3 \mathrm{~cm}$ above the Bay bottom. Water was withdrawn by a $5 \mathrm{hp} 1750 \mathrm{RPM}$ Gould pump located $0.91 \mathrm{~km}$ from the intake at the end of a $1219 \mathrm{~m}$ pier. The pumping unit was in a protective casing residing on the bottom of the slough to minimize head loss from the intake point. Priming was accomplished by two pumps which withdrew slough water and backflushed the pipeline for $2 \mathrm{hr}$ before suction was initiated by the main pump. The Bay water was delivered to the analog tanks which were located approximately $488 \mathrm{~m}$ inland from the pump station.

\section{BAY WATER CHARACTERISTICS}

In each of the bioassays with Bay water the water characteristics were examined by removing water from one of the analog tanks and determining chloride, total alkalinity, suspended solids, total solids, $\mathrm{NH}_{3}-\mathrm{N}$, and $\mathrm{pH}$. All determinations were performed in accordance with Standard Methods (1975) except for $\mathrm{NH}_{3} \mathrm{-N}$ which was determined by the phenolhypochlorite method (Solarzano, 1969). Salinity, temperature, pH, and Do were measured daily by a hydrometer, thermometer, Copenhagen Mode1 $22 \mathrm{pH}$ Meter, and a Yellow Springs Instrument Model 57 Oxygen Meter with a Model 542A Self-stirring Bottle Probe, respectively.

\section{HYDRAZINE}

Practical grade hydrazine monohydrate of $99 \%$ purity (J.T. Baker Company of Phillipsburg, N.J.) was used in continuous-flow studies. This material contained $64 \%$ active ingredient (hydrazine) by weight. Results are reported as $\mathrm{mg} \mathrm{N} \mathrm{N}_{2} \mathrm{H}_{4} / \mathrm{L}$.

Hydrazine was analyzed by the method of Watt and Chrisp (1952) which is based on the development of a yellow color upon the addition of p-dimethy1aminobenzaldehyde (DMBA) to solutions of hydrazine in dilute HC1. After a 10-min color development period the percent transmittance at $458 \mathrm{~nm}$ was read on a Bausch and Lomb Spectronic 70. The method had a sensitivity of $0.01 \mathrm{mg}$ $\mathrm{N}_{2} \mathrm{H}_{4} / \mathrm{L}$.

\section{1-METHYLHYDRAZ INE (MMH)}

MMH of $98 \%$ purity, obtained from the Aldrich Chemical Company of Milwaukee, 


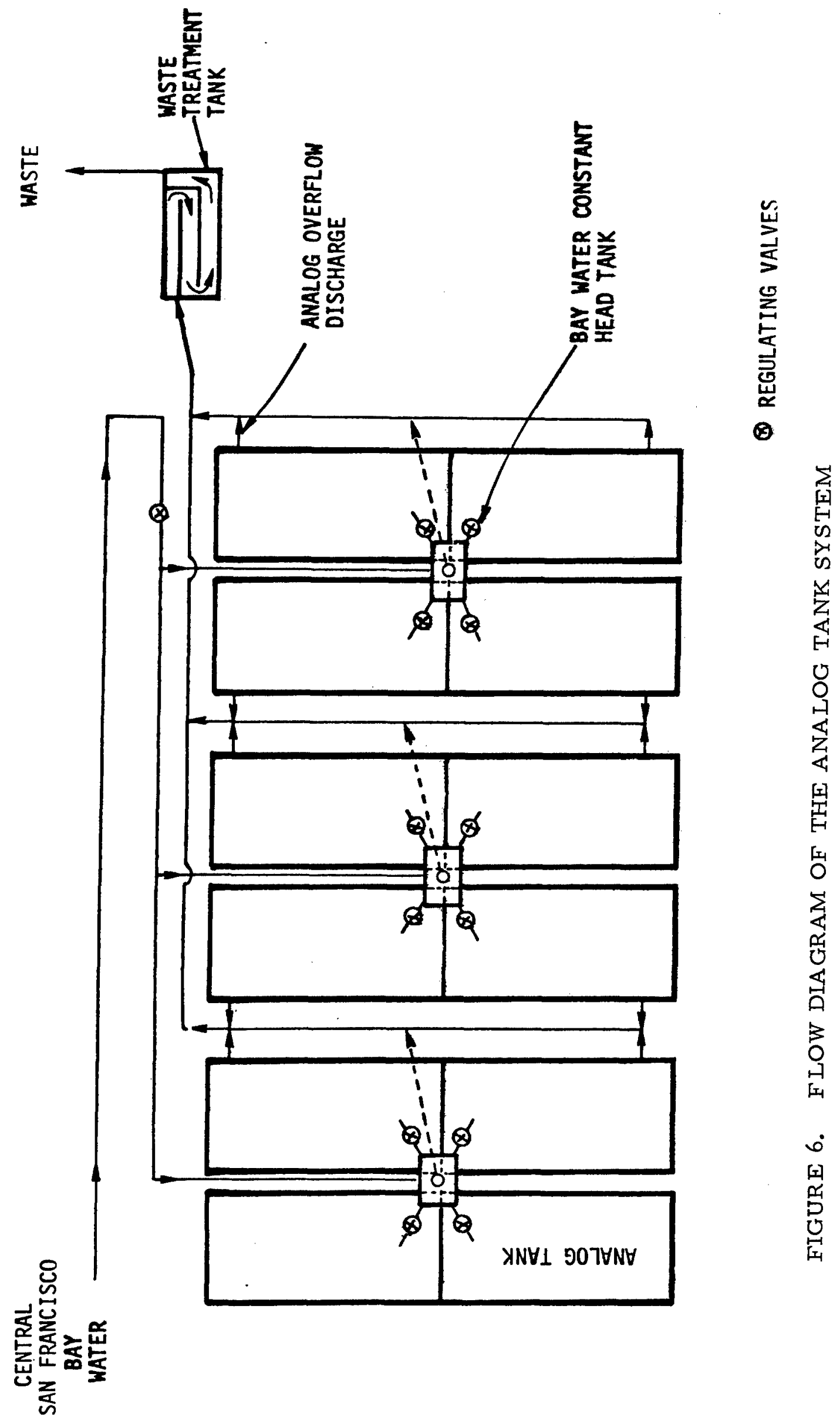




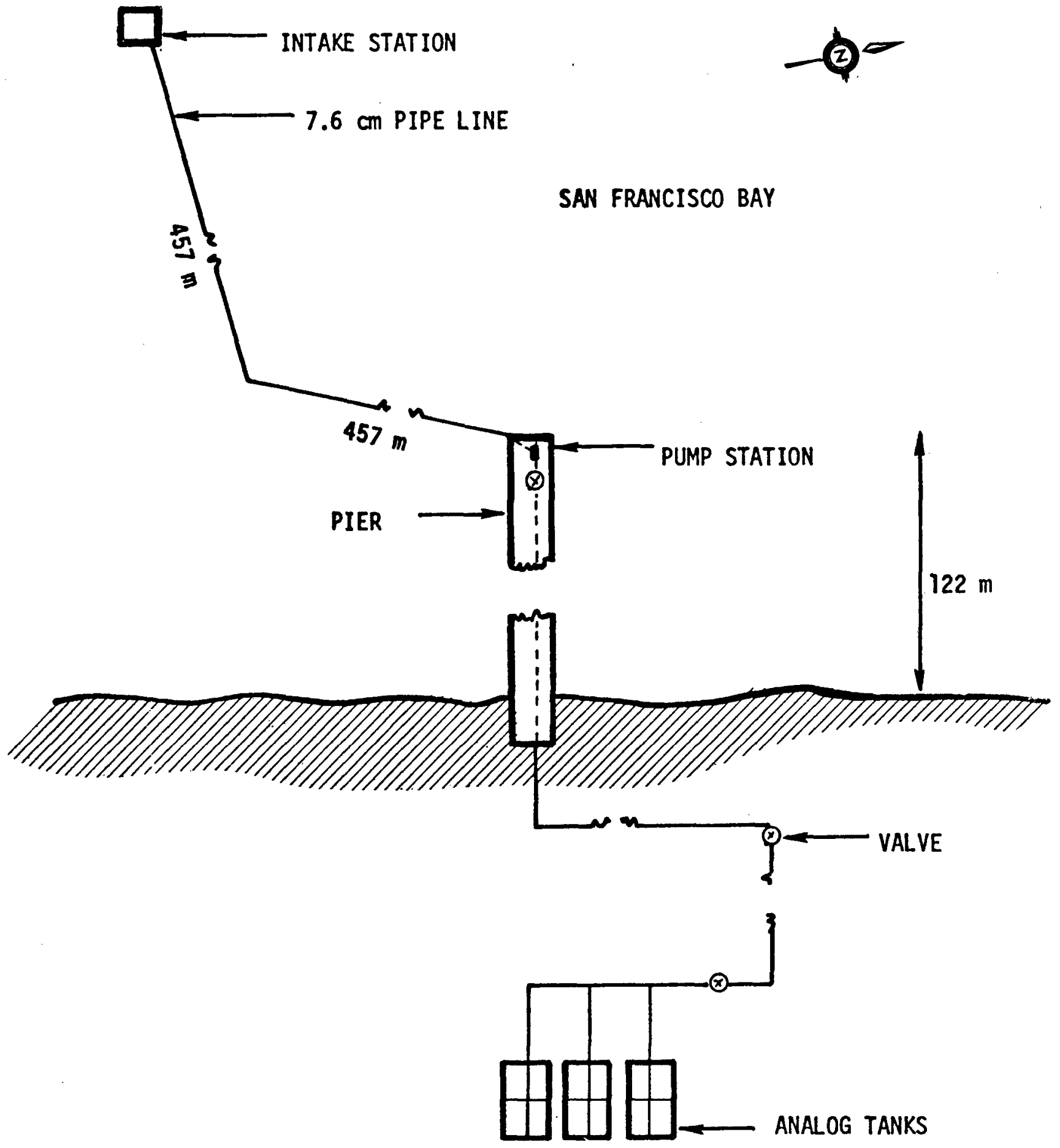

FIGURE 7. BAY WATER SUPPLY SYSTEM FOR ANALOG TANKS 
Wisconsin, was used in spil1 studies. MMH was analyzed by the method of Watt and Chrisp (1952) as modified by Reynolds and Thomas (1964) to allow a 30-min color development period. Percent transmittance was read at $485 \mathrm{~nm}$ on a Spectronic 70 .

\section{1, 1-DIMETHYLHYDRAZINE (UDMH)}

UDMH of $99 \%$ purity was supplied by $\mathrm{K}$ and $\mathrm{K}$ Laboratories, Inc. of Plainview, $\mathrm{N}$. Y. Its toxicity was assessed in spill studies. UDMH was analyzed by the method of Pinkerton et al. (1961) in which a buffered sample is reacted with crisodium pentacyanoaminoferrate. After $1 \mathrm{hr}$ the optical density was read at $500 \mathrm{~nm}$.

\section{DECAY RATE OF THE HYDRAZINES}

The rate of decay of hydrazine, MMH, and UDMH in Bay water was measured by preparing $10 \mathrm{mg} / 1$ solutions of each in Bay water, aerating gently ( 1 bubble per sec) and withdrawing samples over a period of time. The results of 3 replicate experiments (Figure 8 ) indicate that a very rapid decay of $\mathbb{M} M$ and UDMH occurred. There was a less rapid, but still substantial, decay of hydrazine.

\section{FISH}

The toxicity of the hydrazines was assessed using the 3-spine stickleback (Gasterosteus aculeatus). This fish is native to Central San Francisco Bay and is a commonly used indicator species for saline water bioassays.

\section{MUSSEL}

The toxicity of hydrazine to the bay mussel (Mytilus edulis) was examined in continuous-flow studies. Mussels were collected from rocks along the shoreline of the Richmond Inner Harbor.

\section{CRAB}

The mud-flat crab, Hemigrapsus oregonensis, was examined in continuousflow studies of hydrazine. Crabs were collected from the same location as the musse1s.

\section{AUFWUCHS}

Attached periphyton growths, or aufwuchs, were examined for their reponse to the hydrazines. The basic procedure was to suspend a growth rack $50 \mathrm{~cm}$ beneath the water surface in each analog tank (Figure 9). Each rack accomodated 30 growth units consisting of roughened tygon tubing $5 \mathrm{~cm}$ long and $1.2 \mathrm{~cm}$ diameter. After a growth period of approximately 2 weeks, a number of growth units (usually 4 to 8 ) were removed from each tank at the following times:

$$
\begin{aligned}
& \text { a. Prior to toxicant addition (to establish variation between tanks). } \\
& \text { b. Two days after addition of the toxicant. } \\
& \text { c. Four days after addition of the toxicant. }
\end{aligned}
$$

Growth units were examined for metabolic response, chlorophyll a content, and biomass.

Metabolic response (photosynthesis and respiration) was assessed by a 


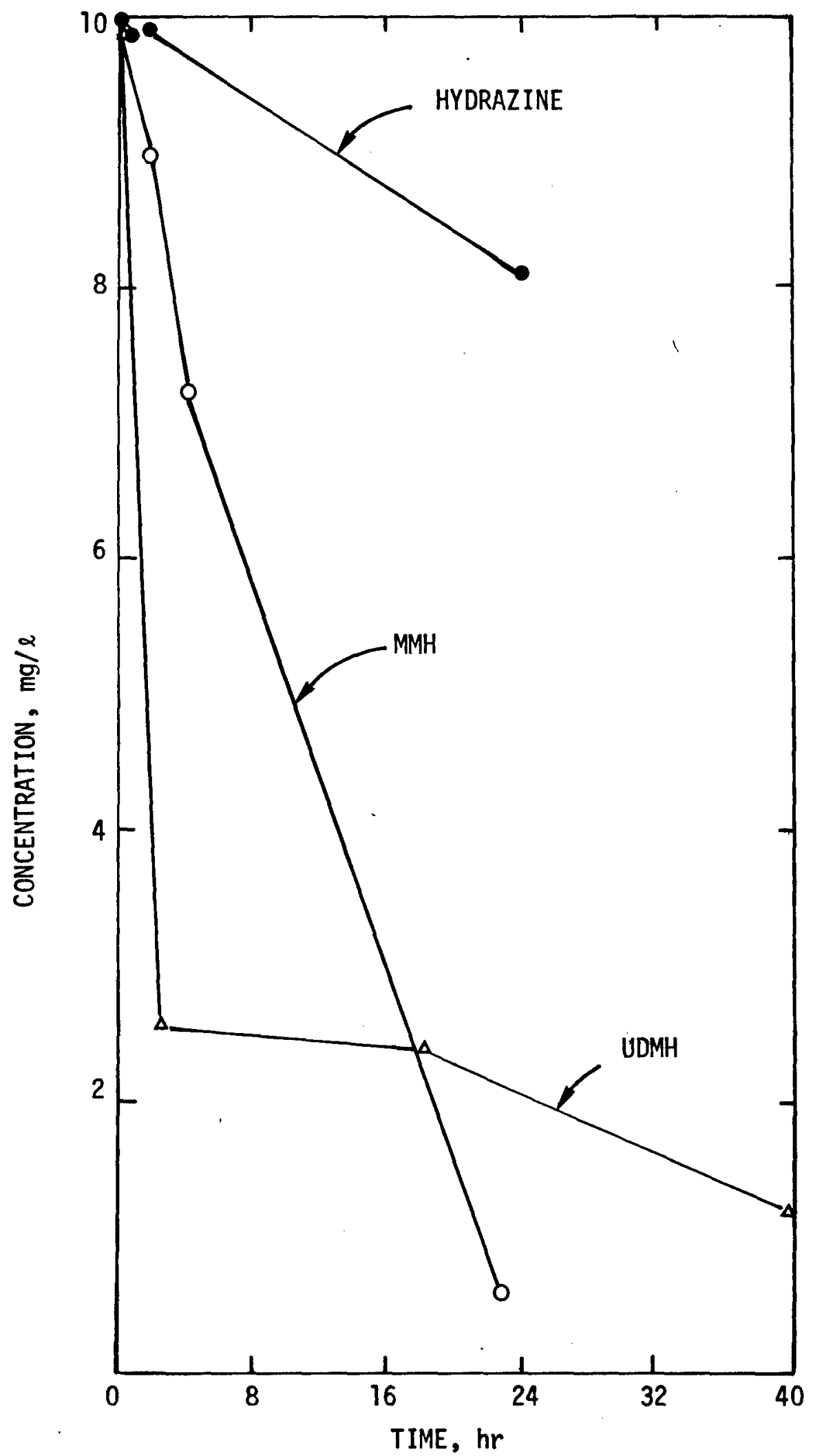

FIGURE 8. DECAY OF THE HYDRAZINES IN AERATED BAY WATER 

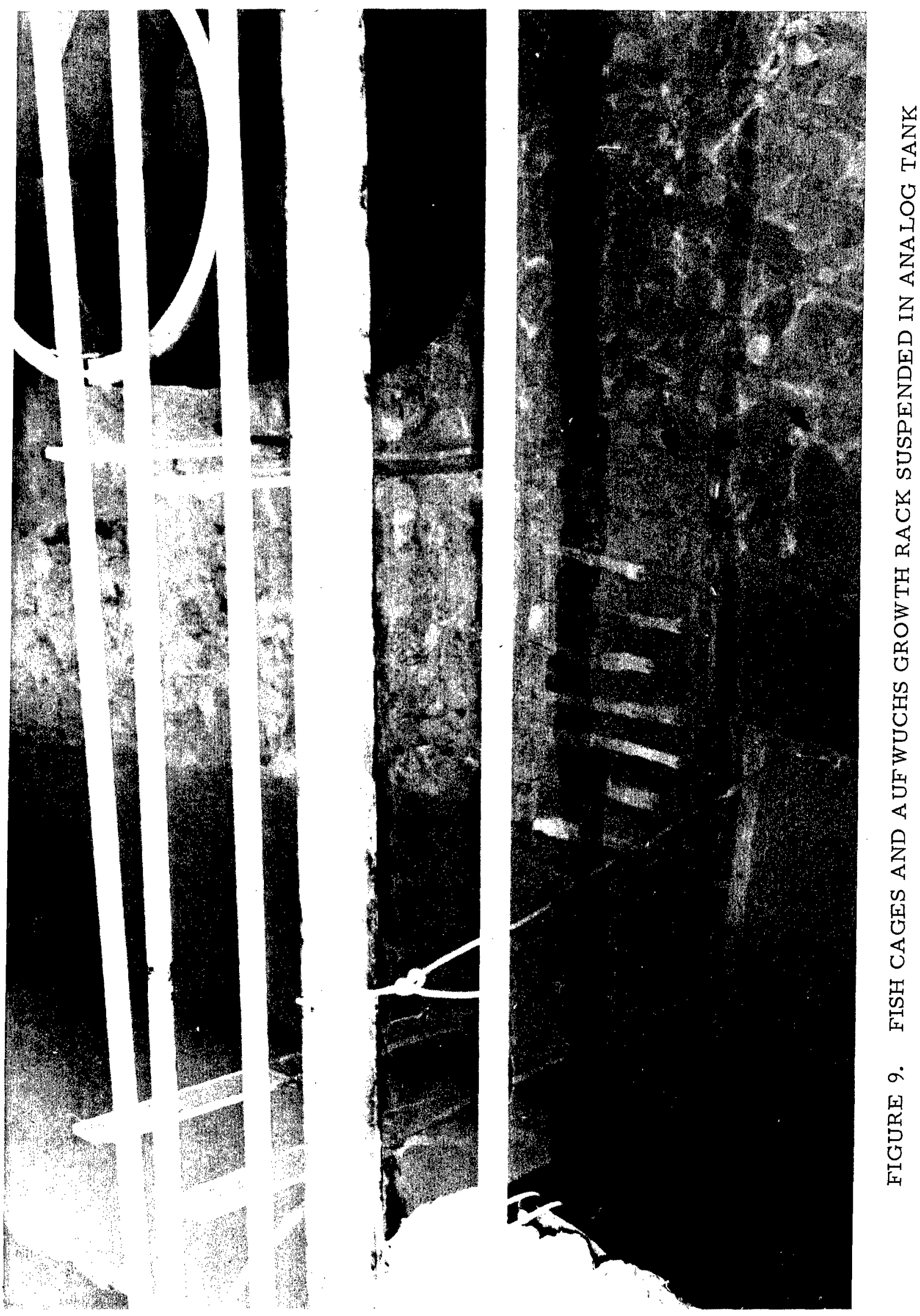
light/dark bottle technique. Four aufwuchs were placed in 4 individual opaque BOD bottles, and 4 aufwuchs were placed in 4 clear BOD bottles. The BOD bottles contained water taken from the same tank as the aufwuchs. Two more BOD bottles were set up containing water only. The Do was measured and a11 10 bottles were placed in a 15C water batch and illuminated at approximately $1500 \mathrm{ft-candles}$ with cool white fluorescent lights. After $2 \mathrm{hr}$ the opaque bottles were removed and their DO was similarly determined.

Metabolic response to the light and dark treatment was calculated by the Standard Methods (1975) technique as follows:

Net photosynthesis = light bottle DO, mg/1 - initial DO, mg/1

Respiration = initial $\mathrm{DO}, \mathrm{mg} / 1$ - dark bottle $\mathrm{DO}, \mathrm{mg} / 1$

Gross photosynthesis = light bottle DO, mg/1/hr - dark bottle Do, $\mathrm{mg} / 1 / \mathrm{hr}$

Photosynthetic Index $=\frac{\text { Gross Photosynthesis, mg } 0_{2}}{\text { Organic Mass, g Dry Wt. }}$

For biomass and chlorophyll a analyses the growth units were removed from BOD bottles, and the growth separated from the substrate by passing the tygon tubing through a rubber stopper holed to the same diameter as the tubing. Aufwuchs growth that had separated while in the BOD bottle was recovered by filtering the bottle contents through a tared $5 \mu \mathrm{m}$ glass fiber filter. The filter, also containing the growth from the tygon tubing, was placed in a plastic bottle. An aqueous solution of $90 \%$ acetone by volume was added to the plastic bottle and the contents were stored at $4 \mathrm{C}$ overnight. The filter was then removed from the bottle with forceps, placed on the filtration apparatus, and the bottle contents filtered through it. The filtrate was analyzed for chlorophy11 a by the Trichromatic Method, Standard Methods (1975). On occasion, when immediate chlorophy11 analysis was not possible, the filtrates were preserved by adding $0.05 \mathrm{ml}$ of a $10 \mathrm{~g} \mathrm{MgCl}_{2} / 1$ solution prior to filtration, then freezing the filtrate until the determination could be made. The filter was saved for biomass determinations.

Biomass was determined gravimetrically using the Standard Methods (1975) techniques for estimation of plankton biomass.

\section{CAGES}

Cylindrical cages, open at the top, were used to contain fish, mussels and crabs during analog tank studies. Each species was isolated for ease of monitoring and to protect aufwuchs. The cages, $30.5 \mathrm{~cm}$ in diameter and $38 \mathrm{~cm}$ in height, were constructed of a $1.3 \mathrm{~cm}$ PVC pipe frame work supporting $18 \times 16$ mesh fiberglass netting. The top $10 \mathrm{~cm}$ of the cages was kept above the water surface to prevent fish from escaping and to facilitate removal of dead fish.

\section{CHRONIC BIOASSAY FLAGFISH EXPOSED TO JP-4}

A long-term continuous-flow bioassay was conducted to determine the chronic toxicity of the WSF of JP-4 to flagfish. Toxicity was assessed by the effect of WSF on egg hatchability, fry growth and development, fry survival, and fuel accumulation in whole-body tissue.

\section{PROCEDURE}

Five duplicate concentrations of WSF were used in 10 stainless steel 
tanks. The percent dilutions of the WSF of JP-4 studied were $0,12,20,32$, and $50 \%$ corresponding to measured $\mathrm{JP}-4$ concentrations of $0,1.5,3.0,4.7$, and $7.3 \mathrm{mg} / 1$. The tanks were operated at a water depth of $20.3 \mathrm{~cm}$ yielding a total tank volume of 80L. The mean hydraulic residence time was maintained at $6 \mathrm{hr}$ by using a total water-flcw rate of $220 \mathrm{ml} / \mathrm{min}$. The desired percent dilutions of WSF were provided using the fuel and dilution water flow rates shown in Table 3 .

Table 3

WSF and Dilution Water Flow Rates to Achieve Desired Percent Dilutions for Continuous-Flow Bioassay

\begin{tabular}{ccc}
$\begin{array}{c}\text { Tank } \\
\text { No. }\end{array}$ & $\begin{array}{c}\text { WSF } \\
\text { ml/min }\end{array}$ & $\begin{array}{c}\text { Dilution } \\
\text { Water } \\
\mathrm{m} 1 / \mathrm{min}\end{array}$ \\
\cline { 2 - 3 } 1 & & 220 \\
2 & 0 & 194 \\
3 & 26 & 176 \\
4 & 44 & 150 \\
5 & 70 & 110
\end{tabular}

Each bank of 5 tanks received the WSF of JP-4 from a separate fuel solubilizer. A water flow of $450 \mathrm{ml} / \mathrm{min}$ was fed to each solubilizer to yield a total WSF flow of $900 \mathrm{ml} / \mathrm{min}$. This flow was sufficient for experimental purposes and was low enough to prevent fuel displacement from the solubilizers which can occur at more rapid water flow rates.

An overview of the study is depicted in the form of a flow diagram (Figure 10). This figure shows that the bioassay consisted of three stages: egg cup, fry chamber, and open tank. The two banks of 5 tanks have been designated as Bank $A$ and Bank B. Within each bank of tanks, the tanks were numbered 1 through 5 to correspond to the successively increasing percent WSF of $\mathrm{JP}-4$ levels of $0,12,20,32$ and 50 respectively.

The study started with the placement of eggs into egg cups (158 eggs into the cups of the Bank A tanks and 144 eggs into the cups of the Bank B tanks). By Day 6 hatching was complete and on Day 11 the surviving fry were transferred from egg cups to fry chambers. The fry were kept in the fry chambers until Day 39. On Day 32 those tanks that contained more than 50 fry were thinned so that a maximum of 50 fry were present in each chamber. On Day 39 the fry were released from the fry chamber into the open tank where they remained for the rest of the 195-day duration of the bioassay. At the conclusion of the study the size of individual fry was assessed by length and wet weight measurements. Fuel accumulation was determined by analyzing whole-body tissue. During the fry chamber period, growth was measured weekly by determining the fish length from photographs. Concentrations of WSF of JP-4 in each tank were measured frequently (usually once per week) in each tank as well as on the solubilizer produce ( $100 \%$ WSF of JP-4).

\section{RESULTS OF JP-4 CONCENTRATION MEASUREMENTS}

\section{JP-4 Quantitation}

The JP-4 concentrations measured in the exposure tanks during the bioassay are tabulated in Table 4. Staggered starts, one week apart, were used to 


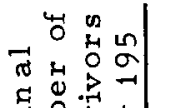

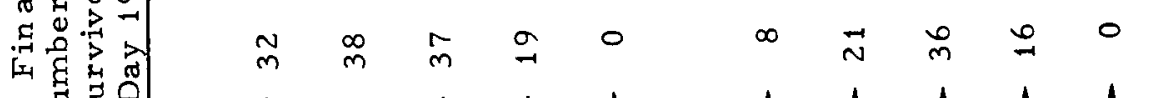

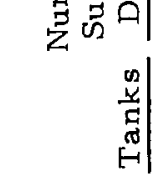

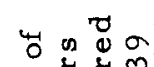

t 0 \& 8 in

$\stackrel{0}{0} \rightarrow \begin{array}{cc}0 \\ \rightarrow\end{array}$

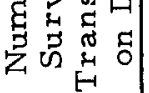

|

$\prod_{1}^{1} \prod_{1}^{1} \prod_{1}^{1}$

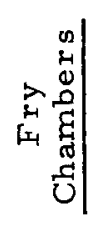

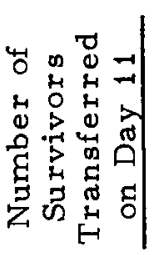

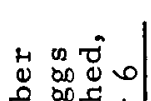

年

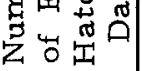

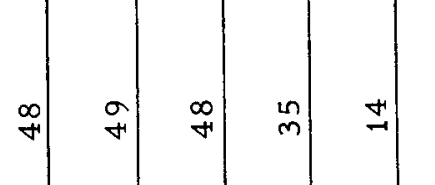

+4 a $m$ m

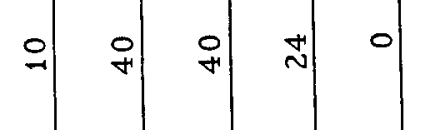

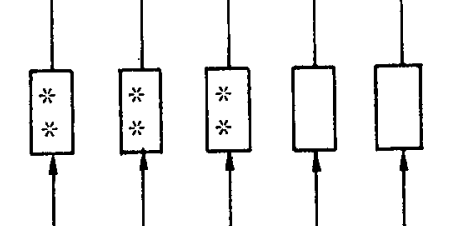

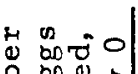

然哭

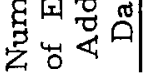

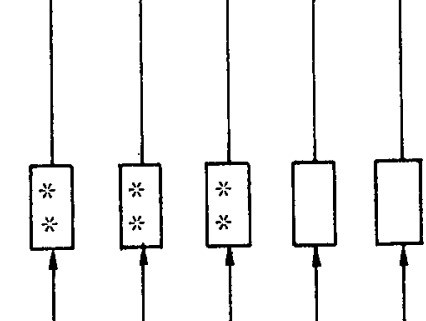

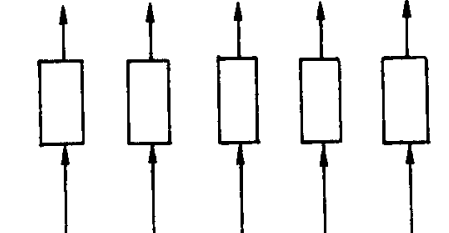

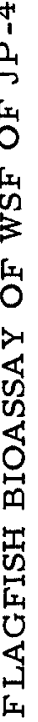

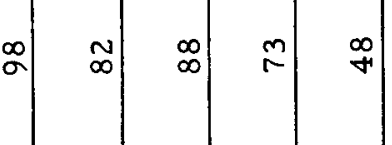

$\stackrel{n}{\stackrel{*}{N}} \stackrel{2}{\sim} \quad \quad$

U

希

。 空

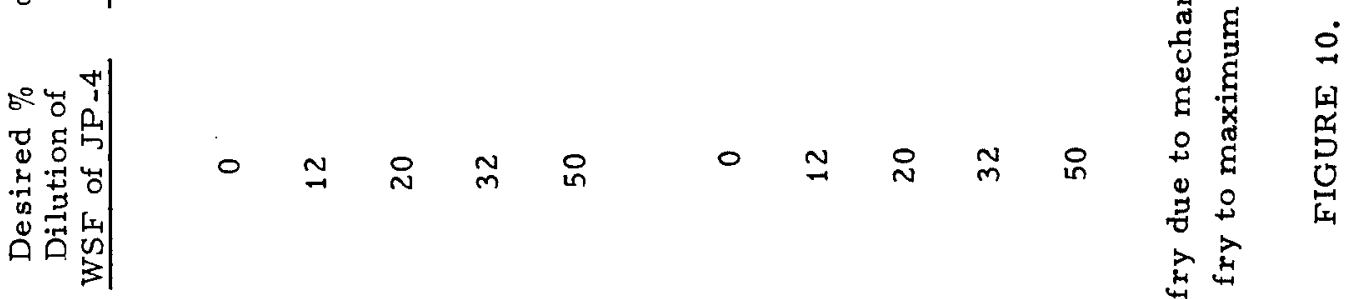

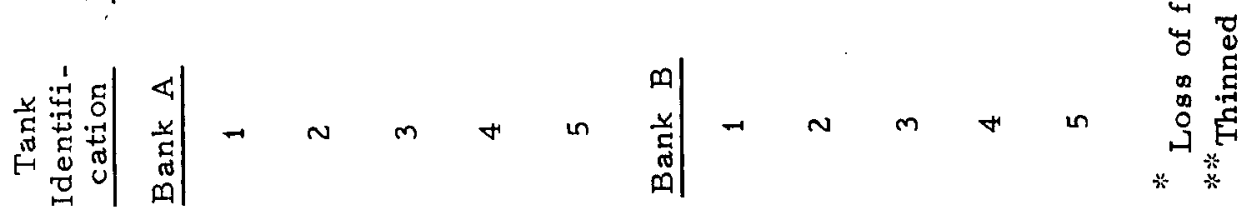




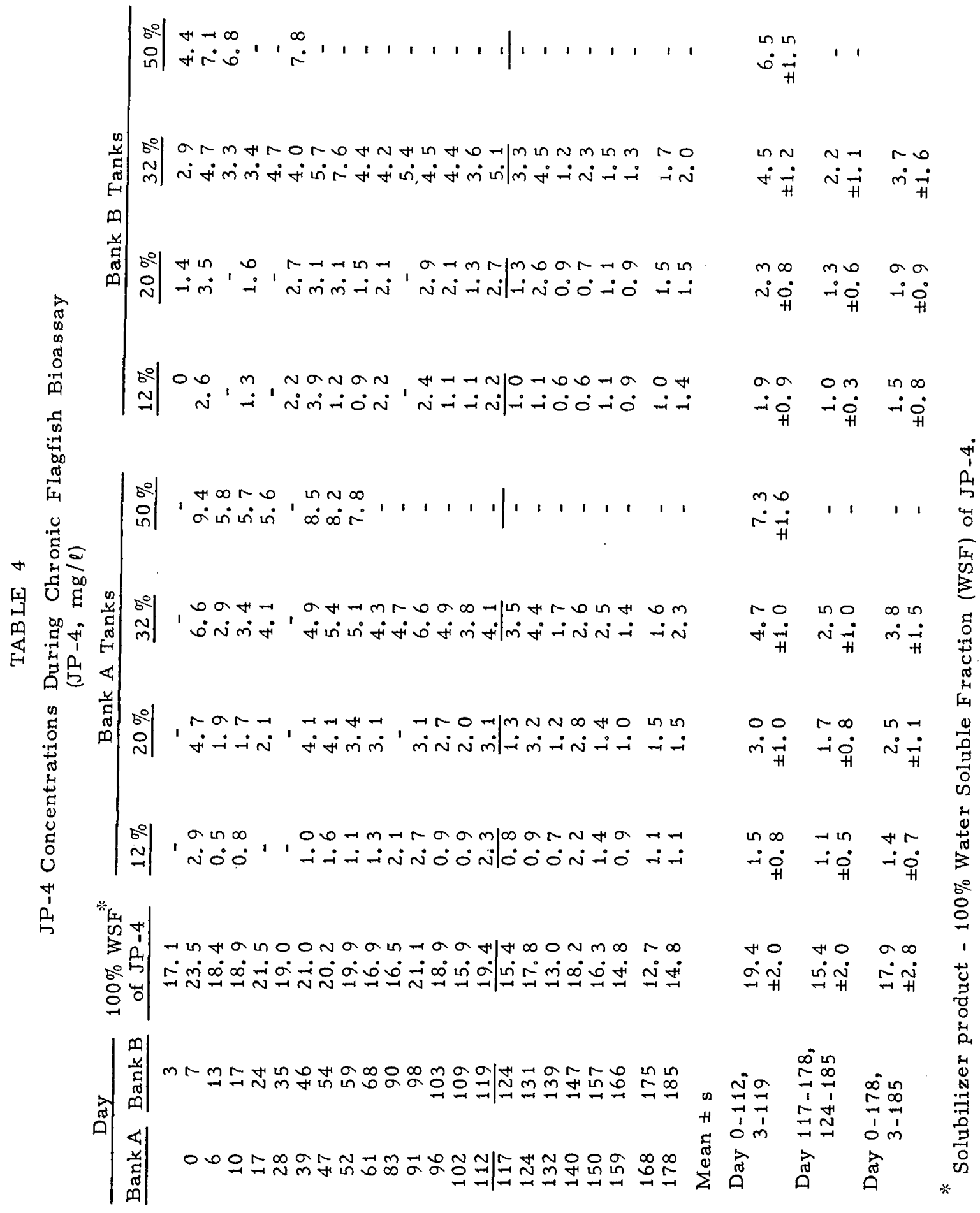


initiate the bioassay in the two banks of tanks. Thus, the sampling day for Bank B tanks was consistently 7 days later than for the Bank A tanks. On each sampling day, duplicate samples of the solubilizer produce (100\% WSF of $\mathrm{JP}-4)$ were taken. The mean of these duplicates is reported. The results of the samples from the control tanks ( $0 \%$ concentration) are omitted since they were always zero.

The means and standard deviations are reported for three periods - the first 4 months, the last 2 months, and the entire 6 months. The reason for isolating the final period is that there was a marked decrease in JP-4 concentration both in the solubilizer produce and, because of this, in the individual tanks. The reason for the decrease is not known with certainty but it coincides with a change in the fuel drums from which the JP-4 to charge the solubilizer was taken.

As shown in Table 4, the average decrease of concentrations of WSF of $\mathrm{JP}-4$ in the $100 \%$ solubilizer product was $4.0 \mathrm{mg} \mathrm{JP}-4 / 1$ (from 19.4 to 15.4 $\mathrm{mg} / 1$ ). During the first 4 months, which embodies the crucial portion of the study (eggs and young fry are most sensitive to toxicants), the mean measured JP-4 concentrations in Banks A and B exposure tanks were, respectively, 1.5 and $1.9 \mathrm{mg} / 1$ at $12 \%$ dilution, 3.0 and $2.3 \mathrm{mg} / 1$ at $20 \%$ dilution, 4.7 and $4.5 \mathrm{mg} / 1$ at $32 \%$ dilution, and 7.3 and $6.5 \mathrm{mg} / 1$ at $50 \%$ dilution. If the data from the entire experimental period are included, these values are reduced by about 10-15\% (similar in magnitude to the drop in solubilizer produce concentration).

Results of mean measured JP -4 concentrations may be used to compute the actual percent WSF of JP-4 relative to the mean solubilizer output of 19.4 $\mathrm{mg} / 1$. The computed percentages for each tank are presented, in Table 5 .

Table 5

Actual vs. Nominal Percent WSF of JP-4

\begin{tabular}{l} 
Nominal $\%$ \\
of WSF \\
of JP-4 \\
\hline
\end{tabular}

12

20

32

50
Actual $\%$ WSF of JP-4

\begin{tabular}{cc}
\hline Day $0-112$ & Day 3-119 \\
Bank A & Bank B \\
\hline
\end{tabular}

7. 7

9.8

15. 5

11. 9

24.2

23. 2

37.6

Note: Difference between Nominal and Actual represents loss due to volatility and biodegradation.

The actual result in each case is lower than the desired (or nominal) value, This difference is due either to volatility loss, biodegradation, or a combination of these two. The magnitude of the difference is $4.3 \%$ (Bank A) and 
$2.2 \%$ (Bank B) at a nominal dilution of $12 \%$. The difference, which becomes greater at higher nominal percent dilutions, is $12.4 \%$ (Bank $A$ ) and $16.5 \%$ (Bank B) at a nominal dilution of $50 \%$. The values shown are for the first 4 months' data, but there is little change in these values if the data from the entire experiment are used.

\section{Effect of Fuel Age on JP-4 Concentration}

Fuel age is defined as the time that "neat fuel" (JP-4) has been present in the solubilizer since it was last replenished with fresh neat fuel. The neat JP-4 fuel in the solubilizers was changed regularly once per week. Before replenishment the apparatus was thoroughly cleaned to remove bacterial slimes. The effect of fuel age on JP-4 concentration was determined repeatedly throughout the bioassay by taking samples of the 100\% WSF of JP-4 (solubilizer product) $18 \mathrm{hr}$ after replenishment and comfaring them to samples taken $168 \mathrm{hr}$ after replenishment.

The mean concentration of the 18-hr samples, based on 13 pairs of duplicates, was $19.2 \mathrm{mg} / 1 \pm 3.7 \mathrm{mg} / 1$. The mean concentration of the 168-hr samples, based on 9 pairs of duplicates, was $16.1 \mathrm{mg} / 1 \pm 1.3 \mathrm{mg} / 1$. Thus, there was a mean reduction of $3.1 \mathrm{mg} / 1$ during this period.

\section{Effect of Fuel Age on Qualitative Nature of WSF of JP-4}

An investigation was made to determine whether the decline in JP-4 concentration during the period between weekly replenishment of the fuel in the solubilizers was due to preferential dissolution of individual fuel components or whether there was a general decline in the concentration of all WSF components either through physical depletion or biodegradability. The solubilizer product and the product of some static (jar) solubilizers were analyzed with the purge gas analyzer.

Four sets of 18-hr samples were compared qualitatively with 4 sets of 168-hr samples from the continuous solubilizer (Table 6). In each case, a $2 \mathrm{ml}$ sample of a 1:10 dilution of the solubilizer effluent was purged and analyzed by the qualitative analytical procedure. The change in JP-4 composition is reflected by two peaks which have retention times of 440 and $820 \mathrm{sec}$, respectively. On the basis of the standards it is judged that these peaks represent compounds in the $\mathrm{C}_{6}-\mathrm{C}_{7}$ range (Table 1 ). The 18-hr results indicate that these two peaks each represent a substantial proportion of the total fuel present (the 440-sec peak constitutes $22 \%$ of the total JP-4 while the $820-\mathrm{sec}$ peak represents $16 \%$ of the total JP-4). After $168 \mathrm{hr}$ the fuel composition changed so that the peak at $440 \mathrm{sec}$ is reduced from $22 \%$ to $2 \%$ of the total area. The peak at $820 \mathrm{sec}$ is reduced from $20 \%$ to $9 \%$ of the total area. Figure 11 shows the difference in the chromatograms.

Whether the peak depletion was due to biodegradation or selective solubilization may be ascertained from the results of "static" jar tests. One liter of JP-4 and 161 of water was placed in each of 2 stoppered jars and mixed continuously by magnetic stirring. Each day for 7 days the mixing was stopped and, after a $5-\mathrm{hr}$ period to permit layer separation, the entire water layer was siphoned off and a sample taken for purge-and-trap analysis. The $j$ ar was then replenished with fresh water. The time frame in the static test was the same as in a 7-day period of continuous-flow solubilizer operation but the 
Table 6

Depletion of Selected JP-4 Components During the Seven-Day Period of Solubilizer Operation

\begin{tabular}{|c|c|c|c|}
\hline $\begin{array}{c}\text { Week } \\
\text { of } \\
\text { Sample }\end{array}$ & $\begin{array}{c}\text { Peak } \\
\text { Retention } \\
\text { Time } \\
\text { sec } \\
\end{array}$ & $\begin{array}{c}18 \mathrm{hr} \\
\text { Peak Area as } \\
\text { \% of Total Area }\end{array}$ & $\begin{array}{c}168 \mathrm{hr}^{* *} \\
\text { Peak Area as } \\
\text { \% of Total Area } \\
\end{array}$ \\
\hline \multirow[t]{2}{*}{8} & 440 & 18.6 & 2.5 \\
\hline & 820 & 17.5 & 8.5 \\
\hline \multirow[t]{2}{*}{9} & 440 & 17. 9 & 1.4 \\
\hline & 820 & 14.1 & 3.2 \\
\hline \multirow[t]{2}{*}{10} & 440 & 19.5 & 2.2 \\
\hline & 820 & 16.2 & 12.4 \\
\hline \multirow[t]{2}{*}{11} & 440 & 30.1 & 1. 5 \\
\hline & 820 & 32.2 & 10.9 \\
\hline \multirow{2}{*}{$\begin{array}{c}\text { Mean } \\
\pm \mathrm{s}\end{array}$} & 440 & $21.5 \pm 5.75$ & $1.9 \pm 0.5$ \\
\hline & 820 & $20.0 \pm 8.25$ & $8.8 \pm 4.0$ \\
\hline
\end{tabular}

* At $18 \mathrm{hr}$, dilution ratio (liters $\mathrm{H}_{2} \mathrm{O}$ per liter $\mathrm{JP}-4$ ) $=97$.

*** At $168 \mathrm{hr}$, dilution ratio $=907$. 

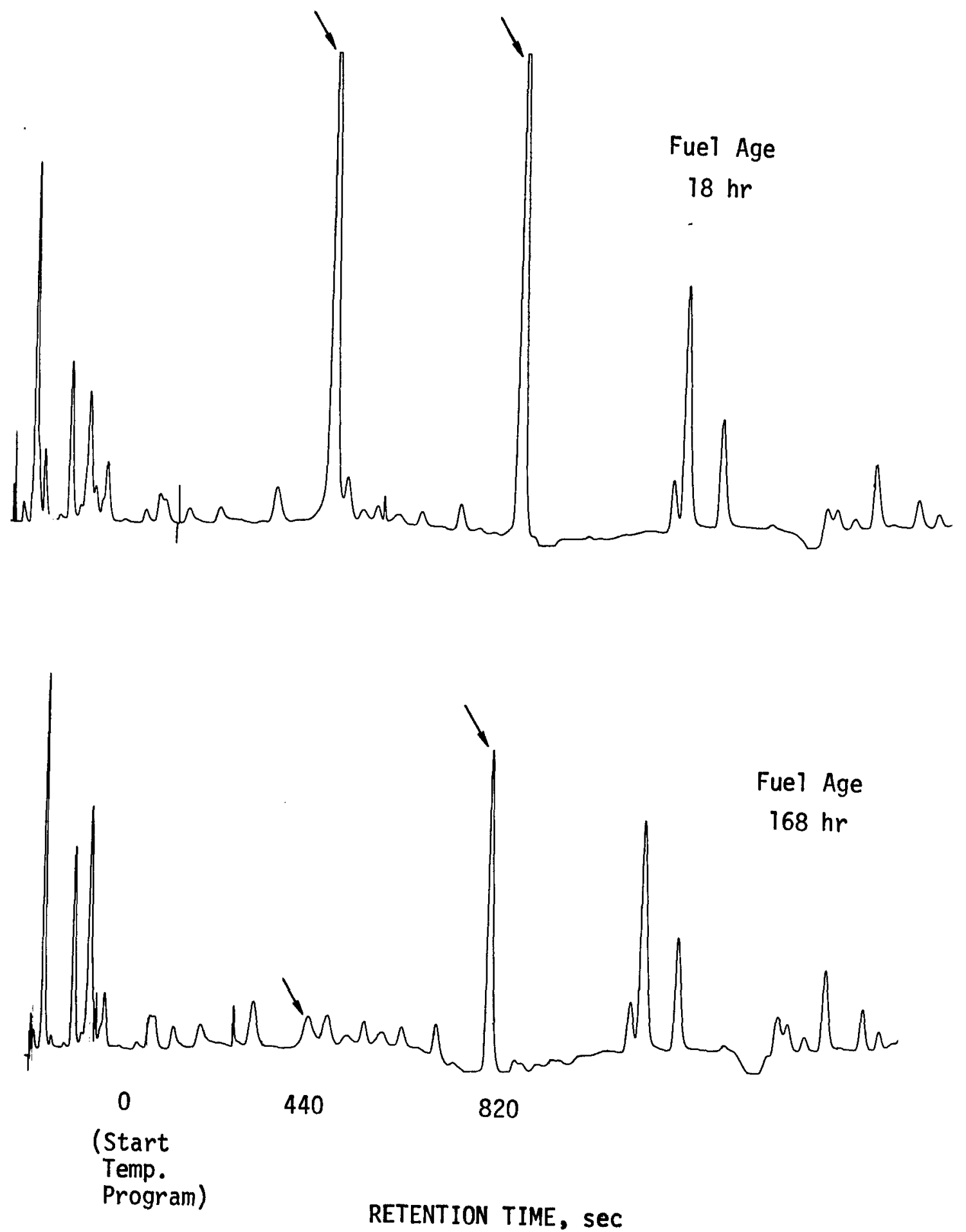

FIGURE 11. PREFERENTIAL DEPLETION OF WSF OF JP-4 COMPONENTS FROM SOLUBILIZER PRODUCT WITH FUEL AGE-PURGE TECHNIQUE (Partial Chromatograms) 
dilution ratio (throughput water volume per volume of JP-4 contacted) was quite different. In the continuous operation this ratio was 97 after $18 \mathrm{hr}$ and 907 after $168 \mathrm{hr}$. In static operation the ratio was 16 after $24 \mathrm{hr}$ and 112 after $168 \mathrm{hr}$.

The results, presented in Table 7 , demonstrate that there was no depletion in the 820-sec peak after $168 \mathrm{hr}$, and only about a 33\% depletion of the 440sec peak. This indicates that the depletions noted in continuous operation were due to preferential solubilization rather than to biodegradation. The $33 \%$ depletion of the 440-sec peak in the static tests occurred between $144 \mathrm{hr}$ and $168 \mathrm{hr}$. To verify that this was probably the onset of depletion rather than the onset of biodegradation, the jars were mixed for an additional $192 \mathrm{hr}$ without replenishment of water and sampled again after a total contact time of $360 \mathrm{hr}$. The dilution ratio remained unchanged during this period and the results indicate no significant change in the peaks.

\section{EGG HATCHABILITY RESULTS}

Eggs used in the study were 0-3 days old and were the product of 5 male and 5-15 female laboratory-reared flagfish. The study was initiated by placing 144 eggs in each of the Bank B egg cups and then one week later placing 158 eggs in each of the Bank A egg cups. The staggered start was necessary because of the limited number of eggs available.

The eggs cups were agitated gently by vertical movement at a rate of 8 strokes per min by a motor-driven pulley system. To combat fungus infection which had been a serious problem in previous studies, the eggs were transferred daily to disinfected egg cups (disinfected by boiling in water for $1 \mathrm{hr}$ ) and Malachite Green was administered just after transfer. Exposure to Malachite Green was for a period of 1-2 min (1ater lengthened to 4-5 min).

\section{Table 7}

Depletion of Selected JP-4 Components in Static Solubilization Tests

\begin{tabular}{|c|c|c|c|}
\hline \multirow{2}{*}{$\begin{array}{c}\text { Contact } \\
\text { Time } \\
\mathrm{hr} \\
\end{array}$} & \multirow{2}{*}{$\begin{array}{c}\text { Volumetric } \\
\text { Dilution } \\
\text { Ratio } \\
\mathrm{H}_{2} \mathrm{O} / \mathrm{JP}-4\end{array}$} & \multicolumn{2}{|c|}{$\begin{array}{c}\text { Peak Area } / \text { Total Area } \\
\%\end{array}$} \\
\hline & & 440 -sec Peak & 820-sec Peak \\
\hline 24 & 16 & 24 & 19 \\
\hline 48 & 32 & 22 & 20 \\
\hline 72 & 48 & 25 & 22 \\
\hline 96 & 64 & 21 & 23 \\
\hline 144 & 96 & 22 & 24 \\
\hline 168 & 112 & 16 & 22 \\
\hline 360 & 112 & 15 & 18 \\
\hline
\end{tabular}


Table 8 shows the total number of eggs hatched and percent egg hatchability of the 158 eggs added to each egg cup in Bank A and of the 144 eggs added to each cup in Bank B. Results indicate that hatching was concluded after 6 days and on the order of $60-75 \%$ of the eggs hatched, except for tank 4B (4.5 mg JP-4/1) in which only $34 \%$ hatchability occurred. The poor hatchability in tank 4B was not supported by the results of its duplicate, tank 4A, nor the fact that hatchability was better in the Number 5 tanks (mean WSF of JP-4 concentration of $6.0 \mathrm{mg} / 1)$ ). There appeared to be a slight decrease in hatchability in the Number 5 tanks compared to the other tanks, but the chisquare test showed it was not significant above the $30 \%$ confidence level. Thus the conclusion is that there was no effect of JP-4 on percent hatchability in the range of concentrations examined.

Table 8

Hatchability of Flagfish Fry in the Presence of JP-4

\begin{tabular}{|c|c|c|c|c|c|c|c|c|c|c|c|}
\hline \multirow{3}{*}{$\begin{array}{r}\text { Tank } \\
\text { Bank A } \\
\end{array}$} & \multirow{3}{*}{$\begin{array}{l}\text { WSF of } \\
\text { JP-4 } \\
\% \text { Dil - } \\
\text { ution }\end{array}$} & \multirow{3}{*}{$\begin{array}{l}\text { Conc. } \\
\mathrm{mg} / \ell \\
\pm \mathrm{s}\end{array}$} & \multirow{3}{*}{$\begin{array}{l}\text { Original } \\
\text { Number } \\
\text { of Eggs }\end{array}$} & \multirow{2}{*}{\multicolumn{6}{|c|}{$\frac{\text { Fry Hatched }}{\text { Number Per Day }}$}} & \multirow{3}{*}{$\begin{array}{c}\text { Total } \\
\text { No. } \\
\end{array}$} & \multirow[b]{3}{*}{$\%$} \\
\hline & & & & & & & & & & & \\
\hline & & & & 1 & $\underline{2}$ & $\underline{3}$ & $\underline{4}$ & $\underline{5}$ & $\underline{6}$ & & \\
\hline 1 & 0 & 0 & 158 & 2 & 18 & 31 & 52 & 17 & 0 & 120 & 75 \\
\hline 2 & 12 & $0.9 \pm 1.1$ & 158 & 5 & 12 & 36 & 42 & 9 & 0 & 104 & 66 \\
\hline 3 & 20 & $2.7 \pm 1.4$ & 158 & 9 & 7 & 21 & 30 & 41 & 0 & 108 & 68 \\
\hline 4 & 32 & $4.1 \pm 1.4$ & 158 & 11 & 9 & 20 & 28 & 24 & 9 & 101 & 64 \\
\hline 5 & 50 & $6.6 \pm 1.9$ & 158 & 3 & 9 & 8 & 33 & 36 & 7 & 96 & 61 \\
\hline
\end{tabular}

Bank B

$\begin{array}{rrrrrrrrrrrr}1 & 0 & 0 & 144 & 6 & 22 & 29 & 26 & 7 & 0 & 90 & 62 \\ 2 & 12 & 2.5 \pm 1.1 & 144 & 3 & 22 & 44 & 23 & 2 & 0 & 94 & 65 \\ 3 & 20 & 2.7 \pm 0.8 & 144 & 19 & 18 & 53 & 16 & 9 & 2 & 107 & 75 \\ 4 & 32 & 4.5 \pm 0.9 & 144 & 1 & 9 & 16 & 9 & 11 & 3 & 49 & 34 \\ 5 & 50 & 5.4 \pm 1.8 & 144 & 4 & 3 & 26 & 15 & 32 & 1 & 82 & 57\end{array}$

* Results of 3 measurements during the 11 -day egg-hatching period.

Using the number of fry surviving on Day 6 as a baseline of $100 \%$, the percent fry hatched was calculated on a daily basis to determine if there was any retardation attributable to WSF of JP-4. The results, presented in Table 9, demonstrate that hatchability was delayed at the higher fuel concentrations. In Tank $3(2.7 \mathrm{mg} \mathrm{JP-4/1)}$ a discernible retardation is evident by Day 4 in the pooled data from Banks $A$ and $B$. At the higher fuel concentrations present in Tanks 4 and 5 ( $\sim 6.0 \mathrm{mg} \mathrm{JP}-4 / 1)$, the retardation caused a one day delay in attaining $100 \%$ hatchability in both the $\mathrm{A}$ and $\mathrm{B}$ banks.

The survival of the fry during the 11-day period that they were in the egg cups is indicated in Table 10. By the end of Day 6 (when hatching was complete) the total number of surviving fry was at maximum. Thereafter, 
there was some mortality of fry in the egg cups until they were transferred to the fry chambers on Day 11 . As noted in Table 10, there was a loss of 56 fry in the control tank of Bank B on Day 11 when a mechanical failure resulted in a spill of the egg cup. The number of surviving hatched fry at the conclusion of the egg cup stage on Day 11 indicates that there was no clearcut correlation between percent survival and WSF concentration. However, in Tank 5 of Bank B the fry were lethargic and deformed (curled tails) and in Bank A Tank 5 there was a notable reduction in percent survival compared to the other four tanks of Bank A. Thús, it can be concluded that at approximately $6 \mathrm{mg}$ WSF of JP-4/1 a toxic effect was evident by Day 11 .

Table 9

Cumulative Percentage Fry Hatched in the Presence of WSF of JP $-4^{*}$

\section{Tank}

\section{$\underline{\text { Bank A }}$}

1

2

3

4

5

Bank B

1

2

3

4

5

Pooled Data for

Banks A + B

1
2
3
5

$\begin{array}{rr}\frac{1}{2} & \frac{2}{1} \\ 5 & 1 \\ 8 & 1 \\ 11 & 20 \\ 3 & 1\end{array}$

Day

$\begin{array}{llrrr}\frac{2}{2} & \frac{3}{4} & \frac{4}{6} & \frac{5}{100} & \frac{6}{100} \\ 17 & 43 & 86 & 100 & 100 \\ 16 & 51 & 91 & 100 & 100 \\ 15 & 34 & 62 & 91 & 100 \\ 20 & 40 & 67 & 93 & 100 \\ 13 & 21 & 55 & & \end{array}$

$\begin{array}{rrrrr}31 & 63 & 92 & 100 & 100 \\ 27 & 73 & 98 & 100 & 100 \\ 25 & 75 & 90 & 98 & 100 \\ 18 & 53 & 71 & 94 & 100 \\ 9 & 41 & 60 & 99 & 100\end{array}$$$
5
$$

7

3

8

2

5

$\begin{array}{ll}4 & 22 \\ 4 & 21 \\ 8 & 20 \\ 8 & 19 \\ 4 & 11\end{array}$

51

89

100

100

21

61

94

100

100

$20 \quad 55$

44

76

100

11

30

68

99

100

100

\footnotetext{
* Based on setting the percentage of fry hatched on Day 6 equal to $100 \%$.
} 
Table 10

Cumulative Survival of Fry in Egg Cups

\begin{tabular}{|c|c|c|c|c|c|c|c|c|c|c|}
\hline \multirow[b]{3}{*}{ Day } & \multicolumn{5}{|c|}{ Bank A Tanks } & \multicolumn{5}{|c|}{ Bank B Tanks } \\
\hline & 1 & 2 & 3 & 4 & 5 & 1 & 2 & 3 & 4 & 5 \\
\hline & $0 \%$ & $12 \%$ & $\underline{20 \%}$ & $\underline{32 \%}$ & $\underline{50 \%}$ & $\underline{0 \%}$ & $12 \%$ & $20 \%$ & $32 \%$ & $50 \%$ \\
\hline 1 & 2 & 5 & 9 & 11 & 3 & 6 & 3 & 9 & 1 & 4 \\
\hline 2 & 20 & 17 & 16 & 19 & 12 & 28 & 24 & 26 & 10 & 7 \\
\hline 3 & 51 & 58 & 36 & 39 & 19 & 57 & 68 & 78 & 23 & 34 \\
\hline 4 & 103 & 92 & 63 & 66 & 54 & 83 & 90 & 93 & 28 & 45 \\
\hline 5 & 119 & 96 & 101 & 87 & 87 & 87 & 89 & 100 & 39 & 77 \\
\hline 6 & 113 & 95 & 101 & 92 & 92 & 85 & 86 & 101 & 39 & 75 \\
\hline 7 & 112 & 95 & 101 & 90 & 83 & 85 & 86 & 101 & 37 & 74 \\
\hline 8 & 102 & 95 & 94 & 77 & 53 & 81 & 83 & 99 & 36 & 71 \\
\hline 9 & 100 & 84 & 92 & 75 & 51 & 80 & 82 & 99 & 34 & 70 \\
\hline 10 & 100 & 84 & 92 & 78 & 51 & 79 & 79 & 93 & 31 & 63 \\
\hline 11 & 98 & 82 & 88 & 73 & 48 & $23^{2 k}$ & 75 & 90 & 30 & 63 \\
\hline \multicolumn{11}{|c|}{$\begin{array}{l}\text { Day } 11 \\
\text { Survival, } \% \quad \text { (based on total eggs hatched) }\end{array}$} \\
\hline & 82 & 79 & 81 & 72 & 50 & $80^{* * * *}$ & 80 & 84 & 61 & 77 \\
\hline
\end{tabular}

FRY SURVIVAL - IN CHAMBER AND TANK.

The numbers of surviving fry were counted weekly during the period between Day 11 and Day 39 while the fry were in the fry chamber. Counts were made on Days 11, 18, 25, 32, and 39 by examining photographs taken of the fry chambers. After the fry were released from the chamber into the open tanks a count could not be taken until the conclusion of the study on Day 195 because it was impossible to keep the fish still enough to count them by eye and there was no means of photographing the entire chamber. Table 11 indicates the number of survivors and percent survival. The concentrations of WSF of JP-4 shown in Table 11 are the mean of the first 4 months of analyses presented in Table 4 . On Day 32 the fry were thinned to a maximum of 50 in each tank; therefore, on Days 32 and 39 percent survival is not presented in Table 11 . The survivals presented for the termination of the study on Day 195 were computed on the basis of 50 , the maximum number of fish present on Day 32 .

Based on fry survival, toxicity (as assessed by percent survival of fry) is clearly indicated in both Number 5 tanks (mean of $6.9 \mathrm{mg}$ WSF of JP-4/1) subsequent to Day 11. By Day 18 there were no survivors in Tank $5 \mathrm{~B}$ and only 
Table 11

Survival of Flagfish Fry Exposed to WSF of JP-4 in the Fry Chamber and Exposure Tank

\begin{tabular}{|c|c|c|c|c|c|c|c|c|c|c|c|}
\hline \multirow{3}{*}{$\begin{array}{c}\text { Tank } \\
\text { Bank A }\end{array}$} & \multirow{3}{*}{$\begin{array}{c}\text { Mean } \pm \mathrm{s} \\
\text { WSF of } \\
\mathrm{JP}-4 \\
\mathrm{mg} / \mathrm{L}\end{array}$} & \multicolumn{10}{|c|}{ Day } \\
\hline & & \multicolumn{2}{|c|}{11} & \multicolumn{2}{|c|}{$\underline{18}$} & \multicolumn{2}{|c|}{25} & \multirow{2}{*}{$\begin{array}{l}\frac{32 *}{\text { No. }} \\
\end{array}$} & \multirow{2}{*}{$\frac{39}{\text { No. }}$} & \multicolumn{2}{|c|}{195} \\
\hline & & No. & $\%$ & No. & $\%$ & No. & $\underline{\%}$ & & & No. & $\%^{* *}$ \\
\hline 1 & r & 98 & 82 & 67 & 56 & 64 & 53 & 50 & 48 & 32 & 64 \\
\hline 2 & $1.5 \pm 0.8$ & 82 & 79 & 66 & 63 & 66 & 63 & 50 & 49 & 38 & 76 \\
\hline 3 & $3.0 \pm 1.0$ & 88 & 81 & 64 & 59 & 57 & 53 & 49 & 48 & 37 & 74 \\
\hline 4 & $4.7 \pm 1.0$ & 73 & 72 & 37 & 37 & 37 & 37 & 36 & 35 & 19 & 38 \\
\hline 5 & $7.3 \pm 1.6$ & 48 & 50 & 17 & 18 & 16 & 17 & 16 & 14 & 0 & 0 \\
\hline
\end{tabular}

$\underline{B a n k ~ B}$

$\begin{array}{rcrrrrrrrrrr}1 & 0 & 23 & * * * & 12 & -- & 10 & -- & 10 & 10 & 8 & -- \\ 2 & 1.9 \pm 0.9 & 75 & 80 & 49 & 52 & 46 & 49 & 45 & 40 & 21 & 42 \\ 3 & 2.3 \pm 0.8 & 90 & 84 & 65 & 61 & 61 & 57 & 50 & 40 & 36 & 72 \\ 4 & 4.5 \pm 1.2 & 30 & 61 & 24 & 49 & 24 & 49 & 24 & 24 & 16 & 32 \\ 5 & 6.5 \pm 1.5 & 63 & 77 & 0 & 0 & 0 & 0 & 0 & 0 & 0 & 0\end{array}$

$*$

$x_{*} * 3$

On Day 32 the fry were thinned to a maximum number of 50 in each fry chamber.

$* 2 * * * ;$

\% survival based on 50 fish (from Day 32 to Day 195).

Severe mortality due to spill, percent survival meaningless.

$18 \%$ survival in Tank 5A. By the end of the study there were no survivors in Tank 5A. During the fry chamber period there was some evidence of a toxic effect as assessed by fry survival in Tanks $4 \mathrm{~A}$ and $4 \mathrm{~B}$ which contained a WSF of JP-4 concentration of approximate $1 \mathrm{y} 4.6 \mathrm{mg} / 1$. This effect became pronounced by the end of the study at which time there was $38 \%$ survival in Tank $4 \mathrm{~A}$ and $32 \%$ survival in Tank $4 \mathrm{~B}$ compared to Tanks $1 \mathrm{~A}, 2 \mathrm{~A}, 3 \mathrm{~A}$, and $3 \mathrm{~B}$, all of which had survivals greater than $64 \%$ at WSF of JP-4 concentrations of up to $3.0 \mathrm{mg} / 1$. To ascertain the significance of the reduced survival in Tanks $4 \mathrm{~A}$ and 4B (WSF of $\mathrm{JP}-4=4.6 \mathrm{mg} / \mathrm{I}$ ) a chi-square test was performed in which the mean survival of fry in Tanks $1 \mathrm{~A}, 2 \mathrm{~A}$ and $3 \mathrm{~A}(36 \%)$ was compared with the survival in Tanks 4A and 4B. With $95 \%$ confidence this test revealed that the survival in Tank $4 \mathrm{~A}$ was less than the survival in Tanks $1 \mathrm{~A}, 2 \mathrm{~A}$, and $3 \mathrm{~A}$.

The conclusion is that a WSF of JP-4 concentration of $4.6 \mathrm{mg} / 1$ (i.e. the mean of $4.7 \pm 1.0 \mathrm{mg} / 1$ for Tank $4 \mathrm{~A}$ and $4.5 \pm \mathrm{mg} / 1$ for Tank $4 \mathrm{~B}$ ) causes a reduction in fry survival. No reduction in survival occurs at WSF of JP-4 concentrations of up to $3 \mathrm{mg} / 1$.

The results were more erratic in the Bank B tanks. Mortality in the controls was high because the egg cup dropped into the tank and spilled the eggs. of the 23 survivors from this accident, there were apparently many injured fry because an additional 11 died within one week. Another factor affecting the Bank $B$ tanks was a fungus infection that occurred during the egg-hatching stage which was probably responsible for the high loss of fry by Day 11 in Tank 4B, and niay have also weakened the fry in Tank $2 B$ so that ultimately there was 
also a poor survival rate in this tank. Thus, of the Bank B tanks only tanks 3B and 5B showed a pattern of mortality throughout the course of the study that was similar to the Bank A tanks. At the conclusion of the study Tank 4B results were similar to Tank 4A, but the mortality pattern was different, i.e. high initial mortality in Tank 4B compared with that in Tank 4A. It is suspected that the reason that Bank A tanks did not become infected with the fungus that attacked the eggs in Bank $B$ tanks was that the period of treatment with Malachite Green was increased from 2 min in Bank B tanks to 5 min in Bank A tanks. This was done because a fungus infection was noted in the Bank $B$ tanks which were started one week earlier than the Bank A tanks.

FRY GROWTH - IN CHAMBER AND TANK

\section{Fry Lengths}

The growth rates of fish in the fry chamber were determined by length measurements from photographs taken on Days $11,18,25,32$, and 39 . The results are presented in Table 12 .

A statistical examination of the measurements in the Bank A tanks shows that:

1. On Day 25, the $\mathrm{F}$ test detected no significant difference in length that could be ascribed to WSF of JP-4 concentration.

2. On Days 32 and 39 the $F$ test showed that there was a high probability ( $>99 \%$ ) of there being a difference in fish length that could be ascribed to WSF of JP-4 concentration. This difference was attributable to Tank $5(7.3 \mathrm{mg}$ WSF of JP-4/1) fish, since the F test did not show a significant difference when Tank 5 fish were omitted.

3. The $T$ test confirmed a difference that was significant at the $99 \%$ confidence level on Days 32 and 39 between Tank 1 (control) vs. Tank 5 (7.3 $\mathrm{mg}$ WSF of JP-4/1) fish and Tanks 1-4 (0-4.7 $\mathrm{mg}$ WSF of $\mathrm{JP}-4 / 1$ ) vs. Tank 5 .

4. On Day 195 the $F$ test showed a high probability (>99\%) of there being a real difference in fish lengths attributable to differences in WSF of JP-4 concentrations in both the Bank a and Bank B tanks.

The replication of fish lengths in corresponding "duplicate" tanks between the Bank $A$ and Bank $B$ tanks can be assessed by examining Figure 12 . The fish in the Bank B tanks were slightly longer than those in the Bank A tanks at any given time because they were one week older. The $F$ test confirmed that on Day 195 there was a high probability (>99\%) that the fish lengths in the A bank of tanks were different from those in the B bank of tanks. This lack of replication could be due to several factors besides the staggered starting time, such as difference in WSF of JP-4 concentrations, different levels of fungus infection at the egg stage, and different feeding competition.

\section{Fry Weights}

At the conclusion of the study, fish were removed from the tanks and weighed to provide another measure of the effect of fuel concentration on growth. The mean wet weights, the sample standard deviation of these means, 


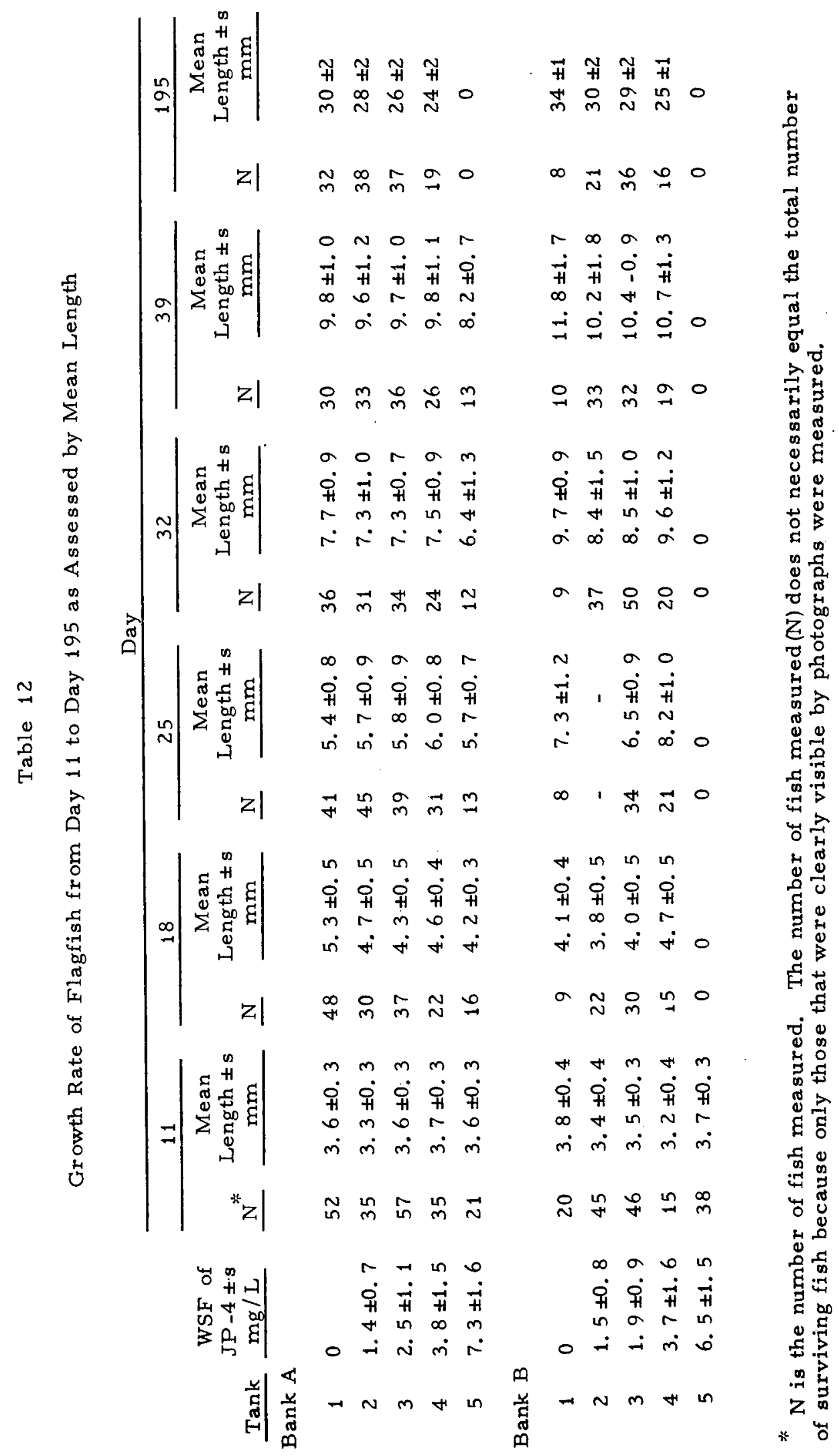




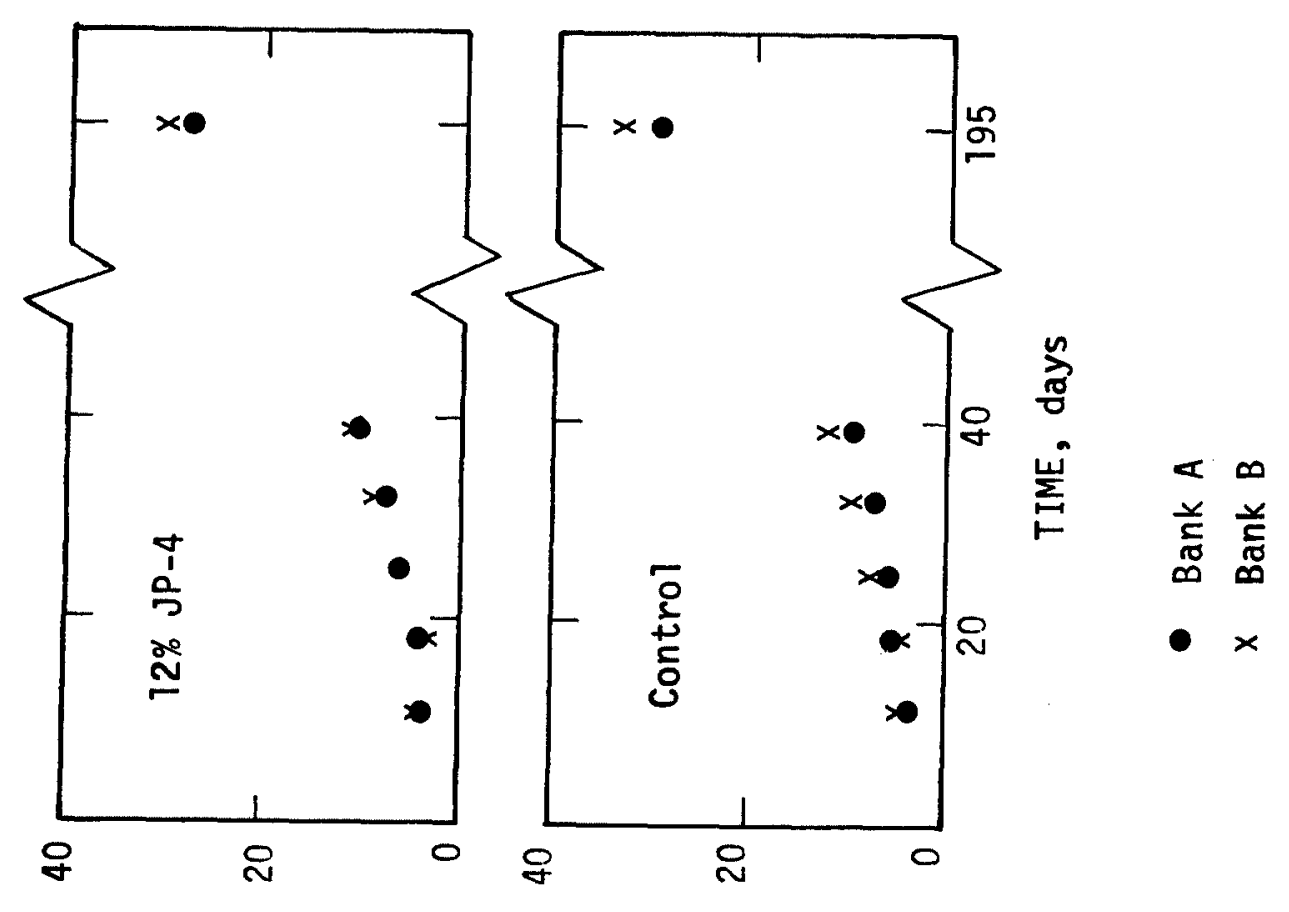



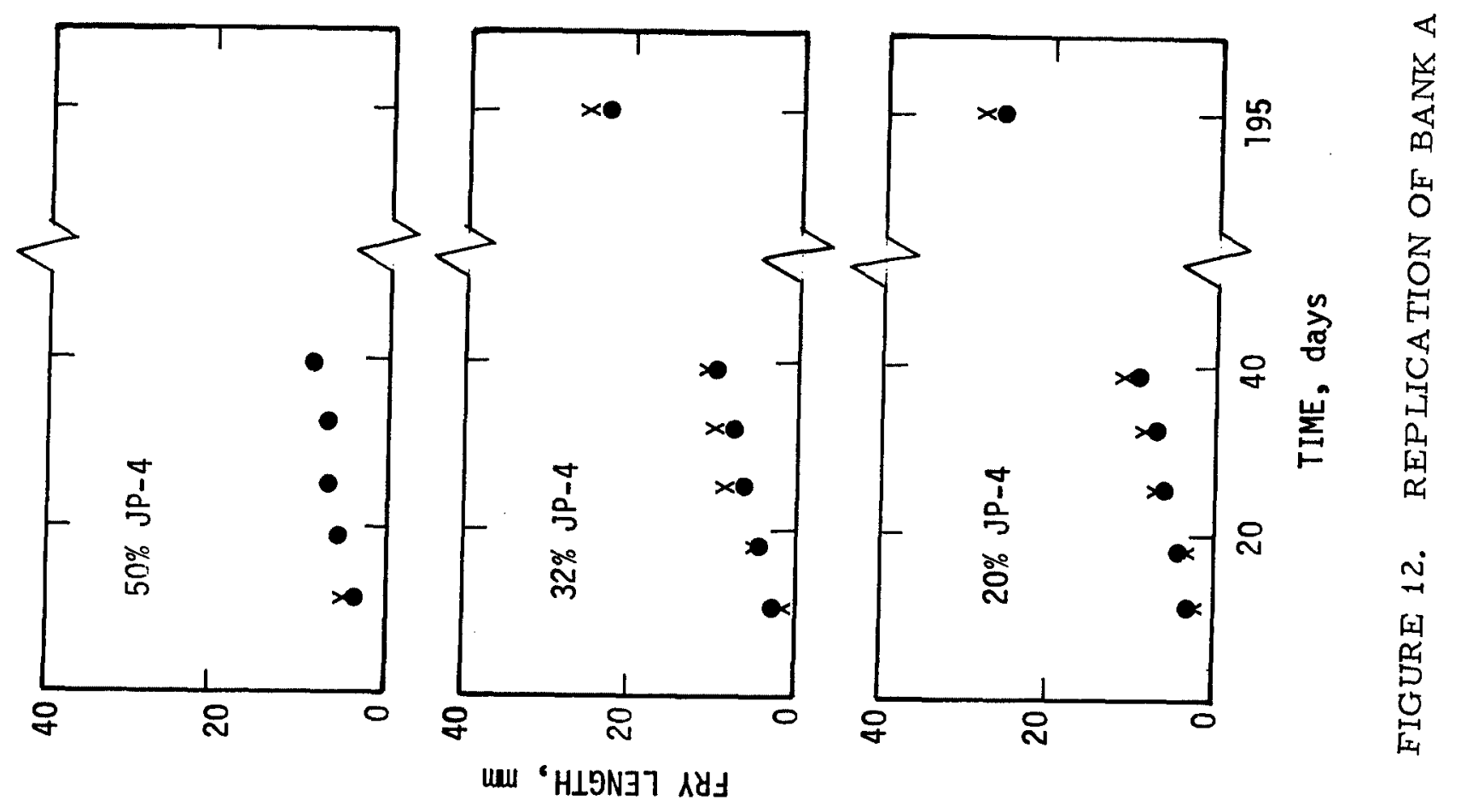


and the standard error of the mean (SE), are reported in Table 13. The mean weights and lengths of fish on Day 195 are plotted against WSF of JP-4 concentration in Figure 13. The weight differences between Bank A fish and Bank $B$ fish emphasize the observation already made with respect to fish length, i.e. that Bank $B$ fish exposed to similar fuel concentrations were heavier than the Bank A fish. There were only $8 \mathrm{fish}$ in the Bank B control tank so that there was much less competition for food in this control than the Bank A control tank. Consequently, these fish were extremely heavy compared to the Bank A control fish ( $700 \mathrm{mg}$ vs. $363 \mathrm{mg}$ ). Other than this anomaly there appeared to be an inverse linear relationship between WSF of JP-4 concentration and fish weight and length.

No-Effect Level of WSF of JP-4 on Fish Weight and Length

A regression analysis of the weight and length data vs. WSF of JP-4 concentration is presented graphically in Figure 14. The 95\% confidence limits are plotted in this figure and from these limits an estimate was made of the maximum no-effect level of WSF of JP-4 concentration on fish growth. Figure 14 shows a maximum predicted no-effect level of $0.40 \pm 0.15 \mathrm{mg}$ WSF of JP-4/1 based on the fry lengths in Bank A tanks, a value of $0.60 \pm 0.20 \mathrm{mg}$ WSF of $\mathrm{JP}-4 / 1$ based on the fry lengths in Bank B, a value of $0.65 \pm 0.25 \mathrm{mg}$ WSF of $\mathrm{JP}-4 / 1$ for the fry weights in Bank A tanks and a value of $0.70 \pm 0.30 \mathrm{mg}$ WSF of JP-4/1 for the fry weights in Bank B tanks. The mean maximum no-effect level of all of these values is $0.6 \pm 0.2 \mathrm{mg}$ WSF of JP-4/1. Therefore, the no-effect level is likely to be in the range between $0-0.6 \mathrm{mg}$ WSF of JP-4/1.

An examination of the linear correlation of the regressions leads one to believe that the no-effect level is at the lower end of this concentration range. Table 14 shows the correlation coefficient, $r$, for the four sets of data pertaining to flagfish lengths and weights vs. WSF of JP-4 concentration to be between -0.67 and -0.815 . These regression coefficients are highly significant as indicated by the calculated $t$ being much greater than the tabular $t$ at the $99.9 \%$ level of significance. The degree of correlation is such that there is little, if any, skewing at the extremes indicating that the no-effect level could be determined by repeating the bioassay at a WSF of JP-4 concentration range between 0 and $1 \mathrm{mg} / 1$, but the precision $( \pm 0.85 \mathrm{mg} / 1)$ of the WSF of JP-4 analysis would make it very dubious whether a meaningful bioassay could be conducted at this low concentration range.

\section{JP-4 ACCUMULATION IN FLAGFISH WHOLE-BODY TISSUE}

At the conclusion of the bioassay the accumulated fuel was measured in whole-body tissue. The fish were too small to permit dissection - therefore no measurements of the accumulation in specific tissues could be made.

The results (Table 15) show that the JP-4 accumulation ratio (ratio of WSF of JP-4 concentration in fish to WSF of JP-4 concentration in water) was approximately 300 (range 171 to 389 ). The mean ratio was $272 \pm 90$. This accumulation ratio was significantly higher than the mean ratio of 159 previously found in the study of the effect of WSF of JP-8 on flagfish indicating that lower molecular weight hydrocarbons, which are more predominant in JP-4, were more readily absorbed into the fish tissue.

The mean concentrations of WSF of JP-4 reported in Table 15 are the means of the final 61 days of the bioassay. As shown in previous work on the effect 

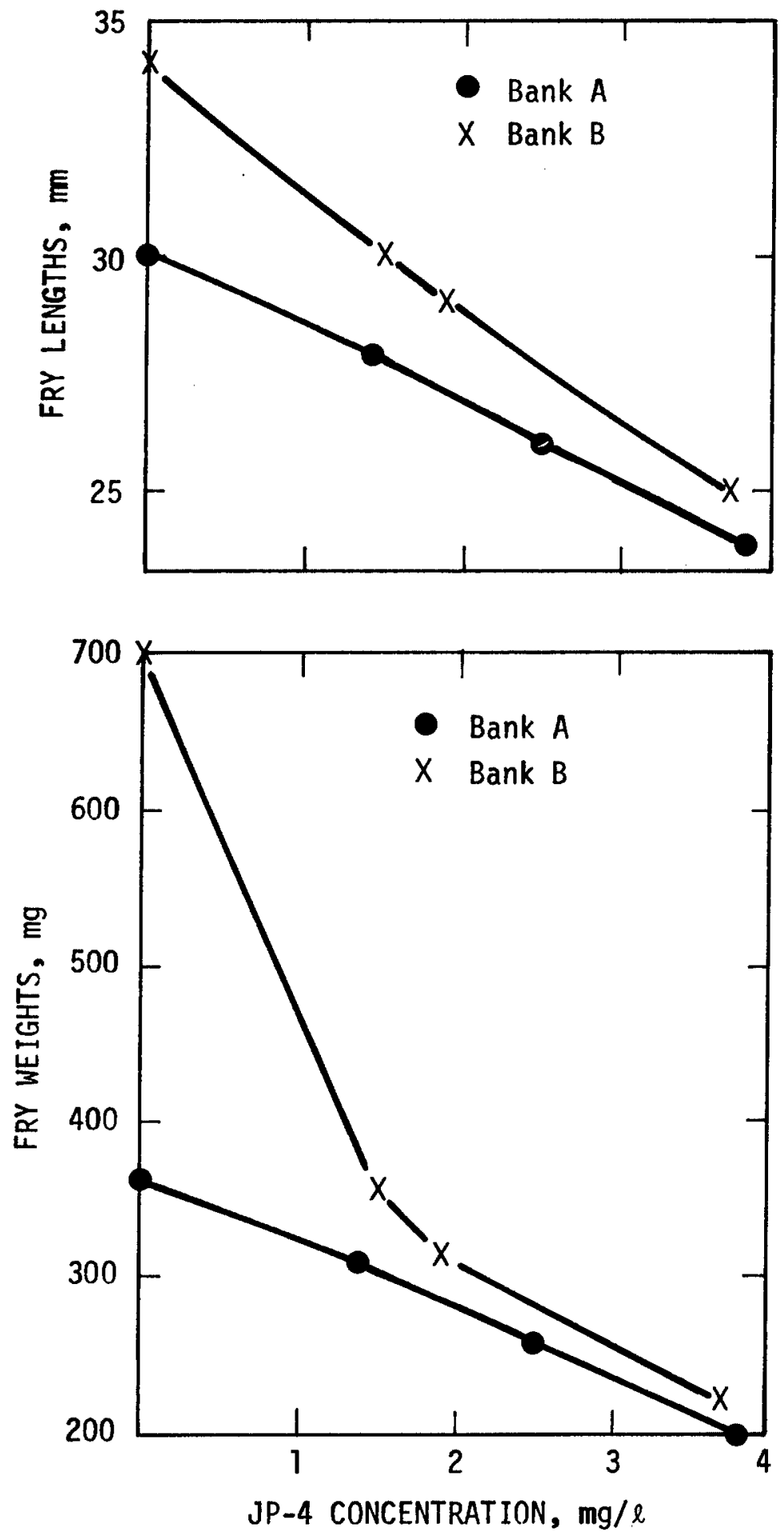

FIGURE 13. EFFECT OF JP-4 CONCENTRA TION ON FR Y WEIGHT AND LENGTH (CONCLUSION OF STUDY DAY 195) 

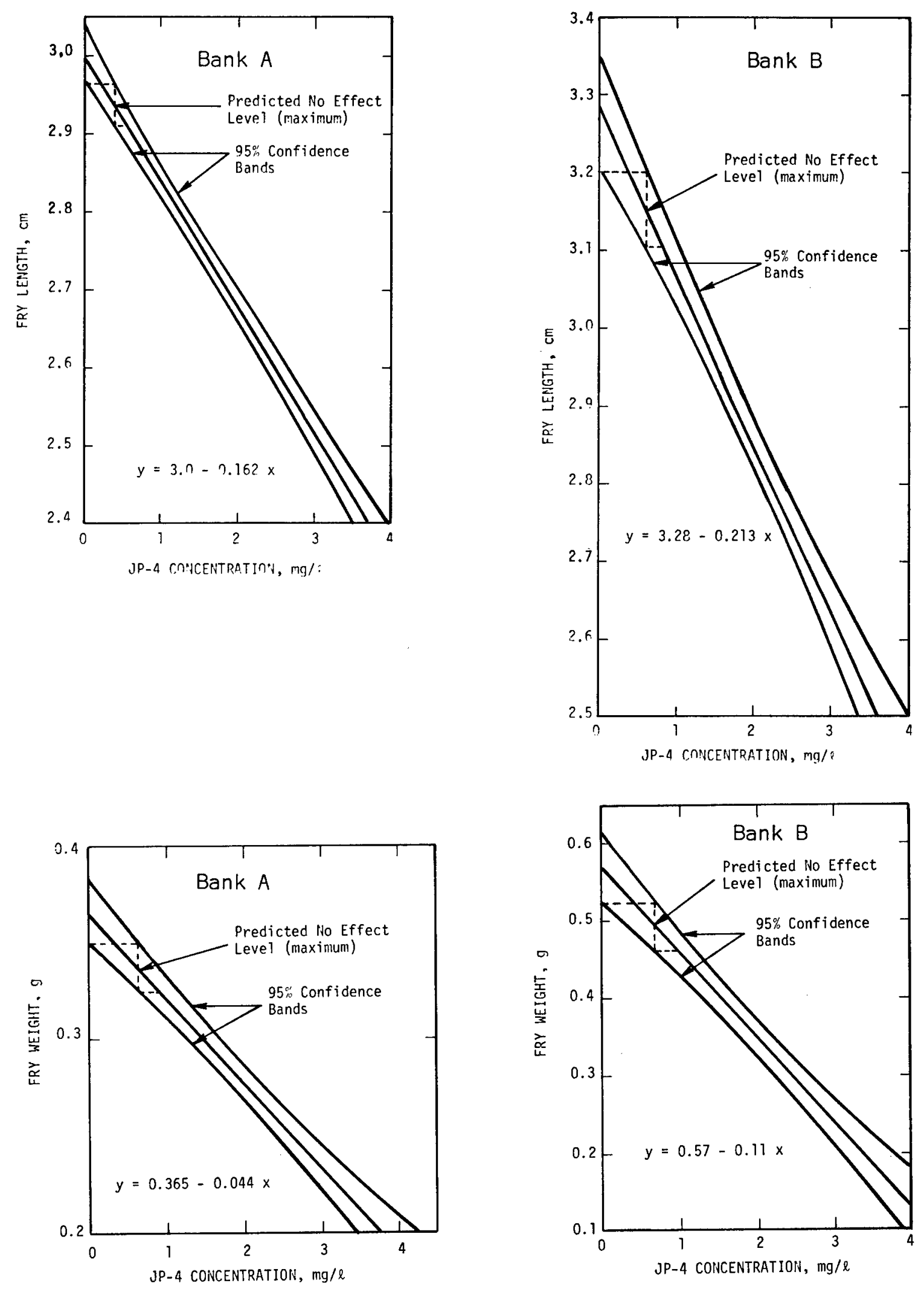

FIGURE 14. REGRESSION ANALYSES OF FRY WEIGHTS AND LENGTHS 
Table 13

Effect of WSF of JP-4 on Flagfish Wet Weights (Day 195)

\begin{tabular}{cccccc} 
Tank & $\begin{array}{c}\text { Mean } \\
\text { WSF of } \\
\text { JP-4 } \\
\text { Bank A }\end{array}$ & $\begin{array}{c}\text { Number } \\
\text { of Fish } \\
\text { Weighed }\end{array}$ & $\begin{array}{c}\text { Mean Wet } \\
\text { Weight } \\
\text { mg }\end{array}$ & $\begin{array}{c}\text { Standard } \\
\text { Deviation } \\
\text { mg }\end{array}$ & $\begin{array}{c}\text { Standard } \\
\text { Error of } \\
\text { Mean } \\
\text { mg }\end{array}$ \\
\hline 2 & 0 & 31 & 363 & 0.08 & 0.01 \\
3 & 1.4 & 38 & 306 & 0.07 & 0.01 \\
4 & 3.5 & 37 & 255 & 0.05 & 0.01
\end{tabular}

Bank B

$\begin{array}{lccccc}1 & 0 & 8 & 700 & 0.16 & 0.06 \\ 2 & 1.5 & 21 & 356 & 0.10 & 0.02 \\ 3 & 1.9 & 20 & 313 & 0.05 & 0.01 \\ 4 & 3.7 & 16 & 218 & 0.05 & 0.01\end{array}$

Table 14

Analysis of Variance and Linear Correlation

(Length and Weight Data vs. JP-4 Concentration)

\begin{tabular}{|c|c|c|c|c|c|}
\hline \multirow[b]{3}{*}{$\begin{array}{c}\text { Data } \\
\text { Source } \\
\end{array}$} & \multirow{2}{*}{\multicolumn{2}{|c|}{ Variance }} & \multicolumn{3}{|c|}{ Linear Correlation } \\
\hline & & & \multirow[b]{2}{*}{$\begin{array}{c}\text { Coef. } \\
r \\
\end{array}$} & \multicolumn{2}{|c|}{ Significance of $r$} \\
\hline & $\begin{array}{c}\text { Calculated } \\
\text { F }\end{array}$ & $\begin{array}{l}\text { Tabular } \\
F(0.01)\end{array}$ & & Calc. $t$ & $\begin{array}{c}\text { Tabular } \mathrm{t} \\
(0.001)\end{array}$ \\
\hline \multicolumn{6}{|l|}{ Bank A } \\
\hline Length & 40.85 & 3. 94 & -0.815 & 15.67 & 3.37 \\
\hline Weight & 32.60 & 3. 94 & -0.670 & 10.01 & 3.37 \\
\hline
\end{tabular}

Bank B

$\begin{array}{lrrrrr}\text { Length } & 41.67 & 4.58 & -0.779 & 11.18 & 3.42 \\ \text { Weight } & 55.50 & 4.13 & -0.722 & 9.38 & 3.42\end{array}$


Table 15

Ratio of WSF of JP-4 Concentrations in Flagfish Whole-Body Tissue

To Aqueous WSF of JP-4 Concentration After 195 Days Exposure

\begin{tabular}{|c|c|c|c|c|}
\hline $\begin{array}{l}\text { Exposure } \\
\text { Tank }\end{array}$ & $\begin{array}{c}\text { WSF of JP-4* } \\
\mathrm{mg} / 1 \pm \mathrm{s}\end{array}$ & $\begin{array}{c}\text { Tissue } \\
\text { Wet Wt. } \\
\mathrm{g}\end{array}$ & $\begin{array}{l}\text { WSF of } \\
\text { JP-4 in } \\
\text { Tissue, } \\
\text { mg/kg } \\
\text { Wet Wt. }\end{array}$ & $\begin{array}{l}\begin{array}{c}\text { Accumula- } \\
\text { tion Ratio } \\
\text { mg/kg, Wet Wt. }\end{array} \\
\frac{\mathrm{mg} / 1}{}\end{array}$ \\
\hline $2 \mathrm{~A}$ & $1.1 \pm 0.5$ & 10.75 & 400 & 360 \\
\hline $2 \mathrm{~B}$ & $1.0 \pm 0.3$ & 7.30 & 270 & 290 \\
\hline $3 A$ & $1.7 \pm 0.8$ & 8.74 & 300 & 180 \\
\hline $3 \mathrm{~B}$ & $1.3 \pm 0.6$ & 11.20 & 220 & 170 \\
\hline $4 \mathrm{~A}$ & $2.5 \pm 1.0$ & 3.52 & 970 & 390 \\
\hline $4 B$ & $2.2 \pm 1.1$ & 3.27 & 580 & 260 \\
\hline
\end{tabular}

* Mean concentrations of final 61 days of the study.

of WSF of JP-8 on flagfish, the fuel accumulation was a linear function of the aqueous concentration. The mean of the final period of the bioassay (which was lower than the mean of the preceding 4 months) governed the uptake of fuel present in the fish at the conclusion of the study when the fish were analyzed.

The accumulation ratio for the fish in Tanks $2 \mathrm{~A}, 2 \mathrm{~B}, 4 \mathrm{~A}$, and $4 \mathrm{~B}$ are in good agreement. The ratios for the fish in Tanks $3 \mathrm{~A}$ and $3 \mathrm{~B}$ are low by comparison because all previous work on accumulation has indicated an excellent correlation between aqueous fuel concentration and fuel accumulation.

\section{JP-4 ACCUMULATION IN GOLDEN SHINERS}

Two accumulation studies were conducted on fish larger than the $3 \mathrm{~cm}$ size flagfish available for analysis at the conclusion of the chronic bioassay. The fish were of sufficient size to be dissected and allow the analysis of fuel accumulation in specific tissues. In the first study, golden shiners, approximately $10 \mathrm{~cm}$ in length, were exposed to a 32\% dilution of WSF of JP-4 ( 2.5 $\mathrm{mg} / 1$ ). In the second study golden shiners were exposed to a $12 \%$ dilution of WSF of JP-4 ( $1.0 \mathrm{mg} / 1)$. In both cases, following the accumulation period, the fish were held in fuel-free water to examine the rate at which fuel was purged from the various tissues.

ACCUMULATION IN $32 \%$ DILUTION OF WSF OF JP-4 ( $2.5 \mathrm{mg} / 1)$

Fifteen golden shiners (mean length of $10.2 \pm 1.0 \mathrm{~cm}$ ) were exposed to the $32 \%$ dilution of WSF of JP-4 (approximately $2.5 \mathrm{mg}$ WSF of JP-4/1). Fish were periodically sacrificed and examined for fuel uptake during a 17-day accumulation period and a 36-day purge period. The tissues evaluated were whole body, muscle, liver, and "innards" (which included the stomach, intestinal tract, etc.). 
The livers were too small to obtain good accumulation data, and therefore during the purge period the livers were combined with the innards. Table 16 presents the results of samples analyzed on Days 3, 10, and 17 of the accumu1ation period and Days 8,17 , and 36 of the purge period. The innards appear to be responsible for most of the WSF of JP -4 present in the fish. Thus, after 17 days of exposure to approximately $2.5 \mathrm{mg}$ WSF of JP-4/1 the innards contained $3400 \mathrm{mg} \mathrm{JP}-4 / \mathrm{kg}$ wet weight compared to $180 \mathrm{mg} / \mathrm{kg}$ wet weight in the muscle tissue.

The fact that the innards retained a substantial level of JP-4 (1500 $\mathrm{mg} / \mathrm{kg}$ wet weight) after 8 days purging indicates that accumulation was probably not just due to ingested water in the intestinal tract. This water, it would be expected, would be rapidly flushed out during purging. Thus, it might be concluded that there is a real incorporation of fuel in the tissues of the innards. After 36 days of purging the fish were virtually free of fuel.

\section{ACCUMULATION IN $12 \%$ DILUTION OF WSF OF JP-4 ( $1.0 \mathrm{mg} / 1)$}

Twenty golden shiners (mean length $=10.9 \pm 1.0 \mathrm{~cm}$ ) were exposed to the $12 \%$ dilution of WSF of JP-4 (WSF of JP-4 = approximately $1.0 \mathrm{mg} / 1$ ). In this study fuel accumulation was measured not only in the innards but also in the gastro-intestinal (GI) tract, To check the results, measurements were taken of samples of the innards from which the GI tract was removed, Other samples were taken of whole body, muscle tissue, and carcass (head, tail, and other remains). Duplicate, and occasionally triplicate, samples were taken of each tissue. During the accumulation period samples were taken on Days 3, 10, and 17. During purging in fuel-free water, samples were taken on Days 7,17 and 35.

Samples were taken of the various tissues of fish in tanks containing no WSF of JP-4. All of these samples showed negligible amounts of $\mathrm{JP}-4(<3 \mathrm{mg} / \mathrm{kg})$ wet wt.) except for the innards ( $8 \mathrm{mg} / \mathrm{kg}$ wet wt.) and the GI tract (13 $\mathrm{mg} / \mathrm{kg}$ wet wt.). Results reported for innards and GI tract for exposed fish are net values obtained by subtraction of control values from the measured concentration. The controls appeared to contain JP-4 because organics extracted from fish tissue chromatographed in the JP-4 region.

The results (Table 17) indicate that maximum accumulation of WSF of JP-4 occurred by Day 10, since no increase was noted on Day 17 . Based on the averaged data, accumulation was highest in the innards (more specifically in the GI tract) which had a mean concentration of $1337 \pm 310 \mathrm{mg} / 1$. The mean concentration of the innards minus the GI tract was $567 \pm 220 \mathrm{mg} / 1$. This value indicates that the uptake in the internal organs was much less than in the GI tract.

Comparing these results with those of the previous study demonstrated that fuel accumulation is proportional to aqueous WSF of JP-4 concentration. Thus, at an aqueous WSF of JP-4 concentration of $2.5 \mathrm{mg} / 1$ the uptake in the innards was about $3500 \mathrm{mg} / \mathrm{kg}$ yielding an accumulation ratio $\mathrm{mg} / \mathrm{kg}$ of 1400 . This value is similar to the GI tract accumulation ratio of $[\mathrm{mg} / 1] 1337$ found in the fish exposed to an aqueous WSF of JP-4 concentration of $1 \mathrm{mg} / 1$.

The fuel uptake in muscle tissue from the $1 \mathrm{mg} / 1$ WSF of JP-4 solution was $64 \pm 34 \mathrm{mg} / \mathrm{kg}$; in the carcass the uptake was $317 \pm 115 \mathrm{mg} / \mathrm{kg}$. 
Table 16

Accumulation and Purging Rate of $32 \%$ Dilution of WSF of JP-4 in Golden Shiner Body Tissues

\begin{tabular}{|c|c|c|c|c|}
\hline \multirow[b]{2}{*}{$\begin{array}{l}\text { Time } \\
\text { Days }\end{array}$} & \multicolumn{4}{|c|}{ WSF of JP-4 } \\
\hline & $\begin{array}{l}\text { Whole } \\
\text { Body }\end{array}$ & Muscle & Innards & $\underline{\text { Liver }}$ \\
\hline & \multicolumn{4}{|c|}{ Accumulation Period } \\
\hline 3 & 440 & 58 & 200 & 0 \\
\hline 10 & 1000 & 120 & 2800 & 640 \\
\hline \multirow[t]{2}{*}{17} & 990 & 180 & 3400 & 570 \\
\hline & \multicolumn{3}{|c|}{ Purge Period } & \\
\hline 8 & 220 & 97 & 1500 & 5 \\
\hline 17 & 150 & 130 & 380 & - \\
\hline 36 & 9 & - & - & - \\
\hline
\end{tabular}

Table 17

Accumulation and Purging Rate of $12 \%$ Dilution of WSF of JP-4 in Golden Shiner Body Tissues

WSF of JP-4 Concentration, $\mathrm{mg} / \mathrm{kg}$ Wet Wt.

\begin{tabular}{|c|c|c|c|c|c|c|}
\hline $\begin{array}{l}\text { Time } \\
\text { days }\end{array}$ & $\begin{array}{l}\text { Whole } \\
\text { Body } \\
\end{array}$ & Muscle & Carcass & Innards & $\begin{array}{c}\text { GI } \\
\text { Tract } \\
\end{array}$ & $\begin{array}{c}\text { Innards } \\
(-) \\
\text { GI Tract } \\
\end{array}$ \\
\hline & \multicolumn{6}{|c|}{ Accumulation Period } \\
\hline 3. & 150 & 9 & 140 & 600 & 1400 & 650 \\
\hline 10 & 310 & 81 & 320 & - & - & - \\
\hline \multirow[t]{2}{*}{17} & 170 & 46 & 270 & 1600 & 1200 & 400 \\
\hline & \multicolumn{6}{|c|}{ Purge Period } \\
\hline 7 & 170 & 0 & 130 & 730 & 710 & - \\
\hline 17 & 14 & 2 & 30 & 4 & 6 & - \\
\hline 35 & 0 & - & - & - & - & - \\
\hline
\end{tabular}


The purge results again indicated that a substantial amount of JP-4 remained in the innards and GI tract (about $700 \mathrm{mg} / \mathrm{kg}$ ) after 7 days. After 17 days of purging there was a negligible amount of JP-4 left in all of the tissues.

On the basis of the two studies performed with large golden shiners, the following conclusions may be drawn:

1. WSF of JP-4 is accumulated primarily in the innards; accumulation is greatest in the GI tract.

2. The accumulation ratio in the GI tract was similar at aqueous WSF of $\mathrm{JP}-4$ concentrations of $1 \mathrm{mg} / 1$ and $2.5 \mathrm{mg} / 1$ with a value between $1300-1400$.

3. The close agreement between the accumulation ratios at the two WSF of JP-4 concentrations indicates that JP-4 accumulation in fish innards (GI tract) is proportional to the aqueous WSF of JP-4 concentration.

4. There is very little accumulation of WSF of JP-4 in muscle tissues.

\section{THE HYDRAZINES}

Studies were conducted to assess the toxicity of the hydrazines (1-methy1hydrazine (MMH), 1, 1-dimethylhydrazine (UDMH), and hydrazine) to plant and animal species indigenous to the Central San Francisco Bay. Aufwuchs and 3spine stickleback were exposed to MMH and UDMH in "spill" studies conducted in analog tanks and in range-finding laboratory jar tests. "Spill" studies and jar tests pertaining to hydrazine toxicity have been previously reported (November 1977 Second Annual Report, AMRL-TR-77-54). Recent work on hydrazine toxicity, reported here, includes a 14-day continuous-flow analog study of aufwuchs, 96-hr continuous-flow analog bioassay. Continuous-flow studies with UDMH and MMH are planned for the near future.

\section{UDMH STUDIES}

\section{Jar Test}

Based on the results of a range-finding study, a static acute 96-hr bioassay was conducted in duplicate for UDMH concentrations of $0,0.32,0.56,1.0$, and $3.2 \mathrm{mg} / 1$. Ten stickleback (mean length $=3.16 \pm 0.26 \mathrm{~cm}$, mean wet weight $=0.44 \pm 0.5 \mathrm{~g}$ ) were placed in a 20 liter jar containing 18 liters of toxicant solution for each duplicate concentration of UDMH. The UDMH solutions were renewed every $24 \mathrm{hr}$ because of the rapid UDMH decay rate in Bay water (approximately two-thirds of the initial UDMH was lost in the first $2.5 \mathrm{hr}$ ). The jars were covered with aluminum foil and were gently aerated. Throughout the bioassay the $\mathrm{pH}$ of the dilutions averaged 7.8 and the DO was in the range $5.4-6.8 \mathrm{mg} / 1$ - both acceptable values for this species.

Table 18 indicates that short-term mortalities occurred in the range of initial UDMH concentrations of between 1.0 and $3.2 \mathrm{mg} / 1$. The mean $96-\mathrm{hr} \mathrm{LC} 50$ for the duplicate bioassays was $1.63 \mathrm{mg} / 1$, and satisfactory replication was achieved. The LC 50 was somewhat higher than predicted from the range-finding study, possibly because the water temperature was lower (13-15C). than in the range-finding test (16-18C). 
Effect of UDMH on Stickleback: Static Acute Bioassay with 24 -hr Renewal of UDMH

\begin{tabular}{|c|c|c|c|c|c|c|c|c|c|c|}
\hline \multirow{3}{*}{$\begin{array}{c}\text { Initial UDMH } \\
\text { Concentration } \\
\mathrm{mg} / \mathrm{L} \\
\end{array}$} & \multicolumn{10}{|c|}{ Time, $h r$} \\
\hline & \multicolumn{2}{|c|}{0} & \multicolumn{2}{|c|}{24} & \multicolumn{2}{|c|}{48} & \multicolumn{2}{|c|}{72} & \multicolumn{2}{|c|}{96} \\
\hline & $\underline{A}$ & B & $\underline{A}$ & $\underline{\mathrm{B}}$ & $\underline{\mathrm{A}}$ & $\underline{B}$ & $\underline{A}$ & B & $\underline{A}$ & $\underline{B}$ \\
\hline 0 & 10 & 10 & 10 & 10 & 10 & 10 & 10 & 10 & 10 & 10 \\
\hline 0.32 & 10 & 10 & 10 & 10 & 10 & 10 & 10 & 10 & 10 & 10 \\
\hline 0.56 & 10 & 10 & 10 & 10 & 10 & 10 & 10 & 10 & 10 & 10 \\
\hline 1.0 & 10 & 10 & 10 & 10 & 10 & 10 & 10 & 9 & 10 & 8 \\
\hline 3.2 & 10 & 10 & 10 & 10 & 9 & 9 & 5 & 7 & 0 & 0 \\
\hline
\end{tabular}

* $A$ and $B$ indicate duplicate tests.

Analog Study

A UDMH spill study was performed at initial concentrations of $0,1.0$, and $3.2 \mathrm{mg} \mathrm{UDMH} / 1$ in duplicate and at concentrations of 10.0 and $19.3 \mathrm{mg} \mathrm{UDMH} / 1$ without duplication.

Aufwuchs growths were developed during an 11-day period in the analog tanks which each received a continuous-flow of $4.81 / \mathrm{min}$ of Bay water. Upon introduction of sticklebacks ( 10 per tank) and UDMH, the Bay water pumps were shut down and the analog tanks operated in a static mode for the ensuing 96-hr bioassay period. Aufwuchs were removed from the tanks after $24 \mathrm{hr}$ exposure to UDMH. During the bioassay the water temperature was in the range 13-19C, the $\mathrm{pH}$ was approximately 7.8 , and the chlorosity was $17.6 \mathrm{~g} / 1$.

The data in Table 19 indicate that all fish died within $96 \mathrm{hr}$ in the tanks. containing initial UDMH concentrations of $10 \mathrm{mg} / 1$ and $19.3 \mathrm{mg} / 1$. Significant fish mortality occurred in the tank containing an initial UDMH concentration of $10.0 \mathrm{mg} / 1$ even after all measurable UDMH had disappeared from solution. Examination of UDMH concentration in the system by withdrawal of samples from a depth of $20 \mathrm{~cm}$ showed that UDMH had virtually all disappeared from solution within $7 \mathrm{hr}$ of its introduction.

The concentrations of UDMH after $1 \mathrm{hr}$ in several of the analog tanks ( $G, E$, and $A$ ) were higher than would be expected if complete mixing had occurred. This demonstrated that the UDMH was stratifying on the surface. Such stratification has important implications for the environment. In a real spill the organisms staying near the surface would be more seriously affected than bottom dwellers. Based on initial UDMH concentrations the 96-hr no-effect.1evel on survival was between 3.2 and $10 \mathrm{mg} / 1$. 
Table 19

Effect of UDMH Spill on Stickleback Survival in Analog Tanks

\begin{tabular}{|c|c|c|c|c|c|c|c|c|c|c|}
\hline \multirow{3}{*}{$\begin{array}{c}\text { Analog } \\
\text { Tank }\end{array}$} & \multirow{3}{*}{$\begin{array}{c}\text { Initial UDMH } \\
\text { Concentration } \\
\mathrm{mg} / \mathrm{L} \\
\end{array}$} & \multirow{2}{*}{\multicolumn{2}{|c|}{$\begin{array}{c}\begin{array}{c}\text { Measured } \\
\text { UDMH } \\
\text { Concentration } \\
\text { mg/L }\end{array} \\
\text { Time, hr }\end{array}$}} & \multicolumn{7}{|c|}{ Number of Fish Surviving } \\
\hline & & & & \multicolumn{7}{|c|}{ Time, $\mathrm{hr}$} \\
\hline & & 1 & 7 & $\underline{0}$ & $\underline{6}$ & $\underline{7}$ & 24 & 48 & 72 & 96 \\
\hline $\mathrm{H}$ & 0 & 0 & 0 & 10 & 10 & 10 & 10 & 10 & 10 & 10 \\
\hline $\mathrm{D}$ & 0 & 0 & 0 & 10 & 10 & 10 & 10 & 10 & 10 & 10 \\
\hline $\mathrm{C}$ & 1. 0 & 0 & 0 & 10 & 10 & 10 & 10 & 10 & 10 & 10 \\
\hline$G$ & 1. 0 & 2.6 & 0 & 10 & 10 & 10 & 10 & 10 & 10 & 10 \\
\hline B & 3. 2 & 0.8 & 0 & 10 & 10 & 10 & 10 & 10 & 10 & 10 \\
\hline$F$ & 3.2 & 2. 5 & 0 & 10 & 10 & 10 & 10 & 10 & 10 & 9 \\
\hline $\mathrm{E}$ & 10.0 & 21 & 0.8 & 10 & 10 & 10 & 9 & 6 & 1 & 0 \\
\hline A & 19.3 & 39 & 2.8 & 10 & 10 & 0 & 0 & 0 & 0 & 0 \\
\hline
\end{tabular}

The effect of the spill on aufwuchs is shown in Table 20. There was a significant reduction in photosynthetic index ( $P I^{\prime} s$ ) for aufwuchs in the tanks containing initial UDMH concentrations of 10 and $19.3 \mathrm{mg} / 1$. This indicates that UDMH is toxic to aufwuchs at these levels. There was also a noticeable reduction in the organic matter content of aufwuchs subjected to these two initial UDMH concentrations but it is not possible to conclude that this reduction is caused by the toxicant since the values are within the normally expected range of values. The data indicate that the no-effect level for aufwuchs is between an initial level of $3.2-10.0 \mathrm{mg} \mathrm{UDMH} / 1$.

MMH STUDIES

Jar Test

A static acute bioassay was conducted to determine the $96-\mathrm{hr}$ LC 50 of MMH to the 3-spine stickleback. Based on the findings of a preliminary study, the range of initial toxicant concentrations investigated was 0 to $3.2 \mathrm{mg} \mathrm{MMH} / 1$. Six initial concentrations, $0,0.32,0.56,1.0$, and $3.2 \mathrm{mg} / 1$, were studied in duplicate in 20-1 capacity jugs, each containing 161 of Bay water. In one set of jugs, $10 \mathrm{fish}$ were exposed to each concentration. Because of the previously determined high rate of MMH loss (65\% in $6.5 \mathrm{hr})$, the MMH solutions were renewed daily. The jugs were covered with aluminum foil and gently aerated with house air.

Aeration was sufficient to maintain a minimum DO of $6 \mathrm{mg} / 1$ throughout 


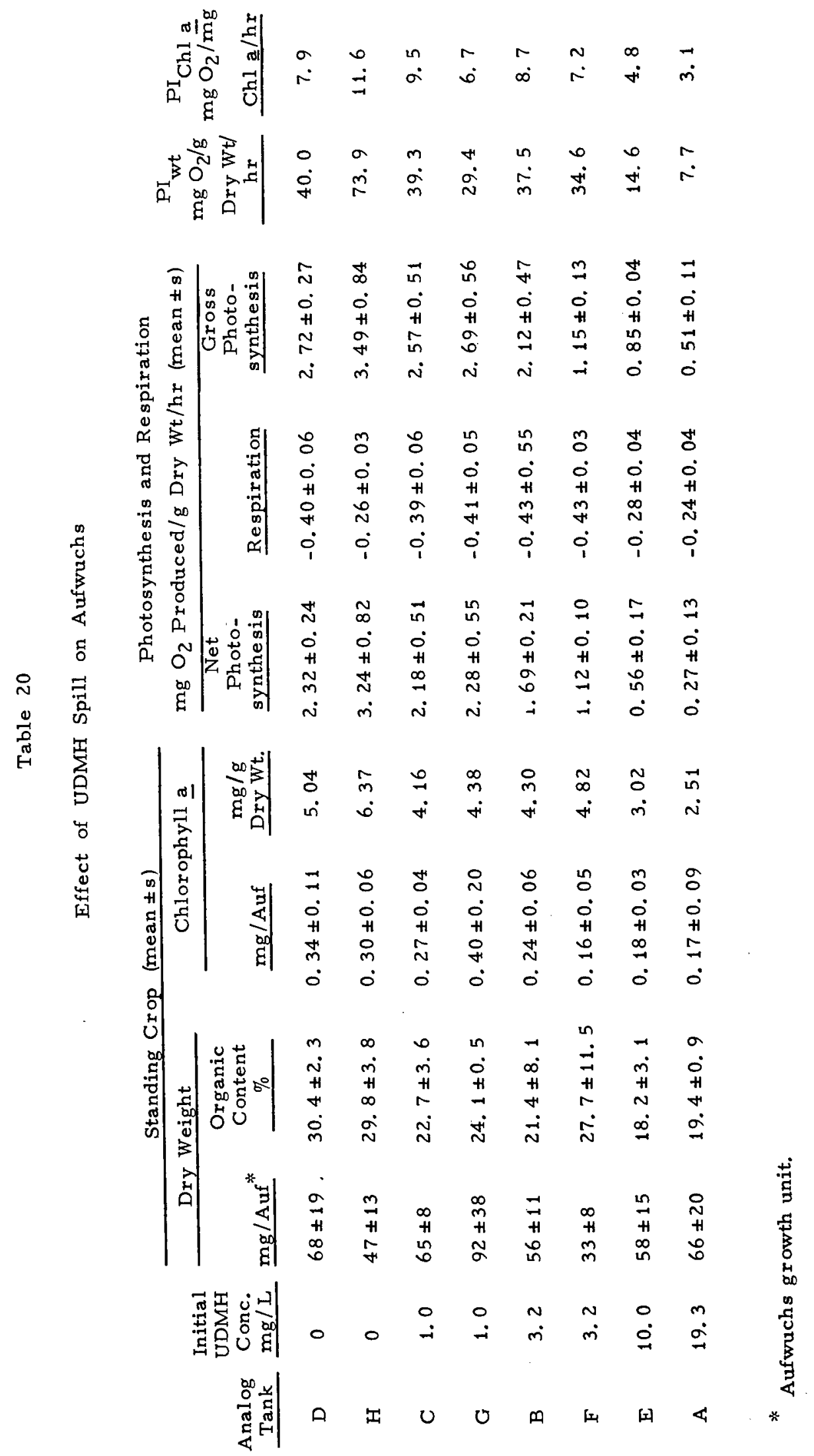


the bioassay. Water temperatures were in the range 19-21C, the pH was 8.95, and the chlorosity was $14.9 \mathrm{~g} / 1$. The mean standard length of the fish was 2.89 $\pm 0.197 \mathrm{~cm}$ and the mean weight was $332 \pm 61 \mathrm{mg}, \mathrm{n}=10$.

Results (Table 21) show that no fish survived the first day of exposure in the jar containing an initial $\mathrm{MMH}$ concentration of $3.2 \mathrm{mg} / 1$; in fact, all of the fish were dead within $6 \mathrm{hr}$. In the jar containing an initial MMH level of $1.0 \mathrm{mg} / 1$ there were no survivors after $48 \mathrm{hr}$ of exposure.

The LC 50's of the duplicate samples, expressed as initia1 MMH concentration were $1.4 \mathrm{mg}$ and $1.9 \mathrm{mg} / 1$ at $24 \mathrm{hr}, 0.60$ and $0.46 \mathrm{mg} / 1$ at $48 \mathrm{hr}$, and 0.32 and $0.40 \mathrm{mg} / 1$ at $96 \mathrm{hr}$. Table 22 shows that during each $24 \mathrm{hr}$ period between MMH renewals, MMH disappeared rapidly and was completely gone before the subsequent 24-hr renewa1. In view of the rapid decay of MMH, there is no doubt that in a continuous-flow bioassay where steady levels of MMH could be maintained, the LC-50 values would be considerably lower than those indicated above.

\section{Analog Study}

A spill study on the toxicity of $\mathrm{MMH}$ to stickleback and aufwuchs was conducted following the general procedures described earlier for the UDMH study. The aufwuchs growth units were developed in the analog tanks over a period of 17 days prior to the addition of MMH. Growth units were examined $24 \mathrm{hr}$ after MMH addition to determine the effect on metabolic response, chlorophyll a content, and biomass. Initial $\mathrm{MH}$ concentrations of $0 ., 0.56,1.0$, and $\overline{3} .2$ $\mathrm{mg} / 1$ were used in duplicate sets of analog tanks. The possibility of toxicity caused by MMH degradation to ammonia was assessed by routine monitoring of ammonia levels.

Results of fish survival are presented in Table 23 and show that significant mortality occurred only within the initial $24 \mathrm{hr}$ following MMH addition and only in the tanks containing an initial MMH concentration of $3.2 \mathrm{mg} / 1$. The no-effect level to stickleback for a spill situation is therefore between 1.0-3.2 mg MMH/1. As would be expected, MMH toxicity to sticklebacks was less in the analog tank spill situation than in the jar test where the solutions were renewed daily.

There was no increase in $\mathrm{NH}_{3}-\mathrm{N}$ concentration corresponding to the decline in MMH concentration (Table 24). ${ }^{3}$ The rapid decrease in MMH concentration levels that were below the limit of detection $(0.01 \mathrm{mg} / 1)$ by $5.5 \mathrm{hr}$ indicates why no significant fish toxicity was observed after one day of exposure.

The results of the aufwuchs study are presented in Table 25 . There were no significant differences in the metabolic response of aufwuchs as assessed by photosynthetic index (PI) at any of the initial MMH levels examined. This result was unexpected, since previous experiments with hydrazine showed that aufwuchs were more sensitive than sticklebacks to these types of toxicant. It is possible that the extremely brief contact period allowed the aufwuchs to recover from the initial MMH doses.

To investigate this possibility the aufwuchs portion of the bioassay was repeated using a modified procedure in which fully-developed aufwuchs growths were exposed to the desired $\mathbf{M M H}$ concentrations during the metabolic reponse test. 


\section{Table 21}

Survival of Stickleback Exposed to $\mathrm{MMH}$ in a

Static 24-hr Renewal Bioassay

Initial $\mathrm{MMH}$

Concentration $\mathrm{mg} / \mathrm{L}$

0

0

0.32

0.32

0.56

0.56

1. 0

1. 0

3. 2

3. 2
Number of Fish Surviving

\begin{tabular}{rrrrr}
\hline \multicolumn{5}{c}{ Time, hr } \\
\hline 0 & $\underline{24}$ & $\underline{48}$ & $\underline{72}$ & $\underline{96}$ \\
9 & 9 & 9 & 9 & 9 \\
8 & 8 & 8 & 8 & 8 \\
10 & 10 & 10 & 7 & 5 \\
8 & 8 & 8 & 8 & 7 \\
10 & 10 & 6 & 1 & 0 \\
8 & 8 & 2 & 0 & 0 \\
10 & 6 & 0 & 0 & 0 \\
8 & 6 & 0 & 0 & 0 \\
10 & 0 & 0 & 0 & 0 \\
8 & 0 & 0 & 0 & 0
\end{tabular}

Table 22

Decline in $\mathrm{MMH}$ Concentration During a $24 \mathrm{hr}$ Period Under Static Bioassay Conditions

Initial $\mathrm{MMH}$

Concentration $\mathrm{mg} / \mathrm{L}$

0

0.32

0.56

1. 0

3. 2

Measured MMH Concentration, $\mathrm{mg} / \mathrm{L}$

Time, $\mathrm{hr}$

\begin{tabular}{llll}
\hline 1.5 & $\frac{3.5}{0}$ & $\underline{6.5}$ & $\frac{24}{0}$ \\
0.25 & 0 & 0 & 0 \\
0.33 & 0.06 & 0.01 & 0 \\
0.75 & 0.08 & 0.07 & 0 \\
- & - & 0.33 & 0
\end{tabular}


Table 23

Survival of Sticklebacks in a Simulated MMH Spill in Central San Francisco Bay Water

Initial $\mathrm{MMH}$ Number of Fish Surviving

Concentration $\mathrm{mg} / \mathrm{L}$

\begin{tabular}{rrrrrrr}
\hline \multicolumn{7}{c}{ Timie, hr } \\
\hline 10 & $\underline{2.5}$ & $\underline{4.5}$ & $\underline{24}$ & $\underline{48}$ & $\underline{72}$ & $\underline{96}$ \\
10 & 10 & 10 & 10 & 10 & 10 & 10 \\
10 & 10 & 10 & 10 & 10 & 9 & 8 \\
10 & 10 & 10 & 10 & 10 & 9 & 9 \\
10 & 10 & 10 & 10 & 10 & 10 & 10 \\
10 & 10 & 10 & 10 & 10 & 10 & 10 \\
9 & 9 & 9 & 9 & 9 & 9 & 9 \\
10 & 9 & 5 & 1 & 0 & 0 & 0
\end{tabular}

Table 24

$\mathrm{MMH}$ and $\mathrm{NH}_{3}-\mathrm{N}$ Concentrations During $\mathrm{MMH}$ Spill Study

Initial $\mathrm{MMH}$

Concentration $\mathrm{mg} / \mathrm{L}$

0

0.56

0.56

1. 0

1. 0

3. 2

3. 2

\begin{tabular}{|c|c|c|}
\hline \multicolumn{3}{|c|}{ Time, $\mathrm{hr}$} \\
\hline 1 & 3.5 & 5.5 \\
\hline
\end{tabular}

$$
0
$$

0

0.1

0.1

0.4

0.4

2. 2

2. 1
0

0.1

0. 1

0

0

0.2

0.2 $\underline{5.5}$

$-$

-

-

-24
$-\quad 43$

43

35

51

32

44

14

30

0

$\frac{\mathrm{NH}_{3}-\mathrm{N}, \mu \mathrm{g} / \mathrm{L}}{\frac{\mathrm{Time}, \mathrm{hr}}{1}}$

28

63

24

21

57

46

84 


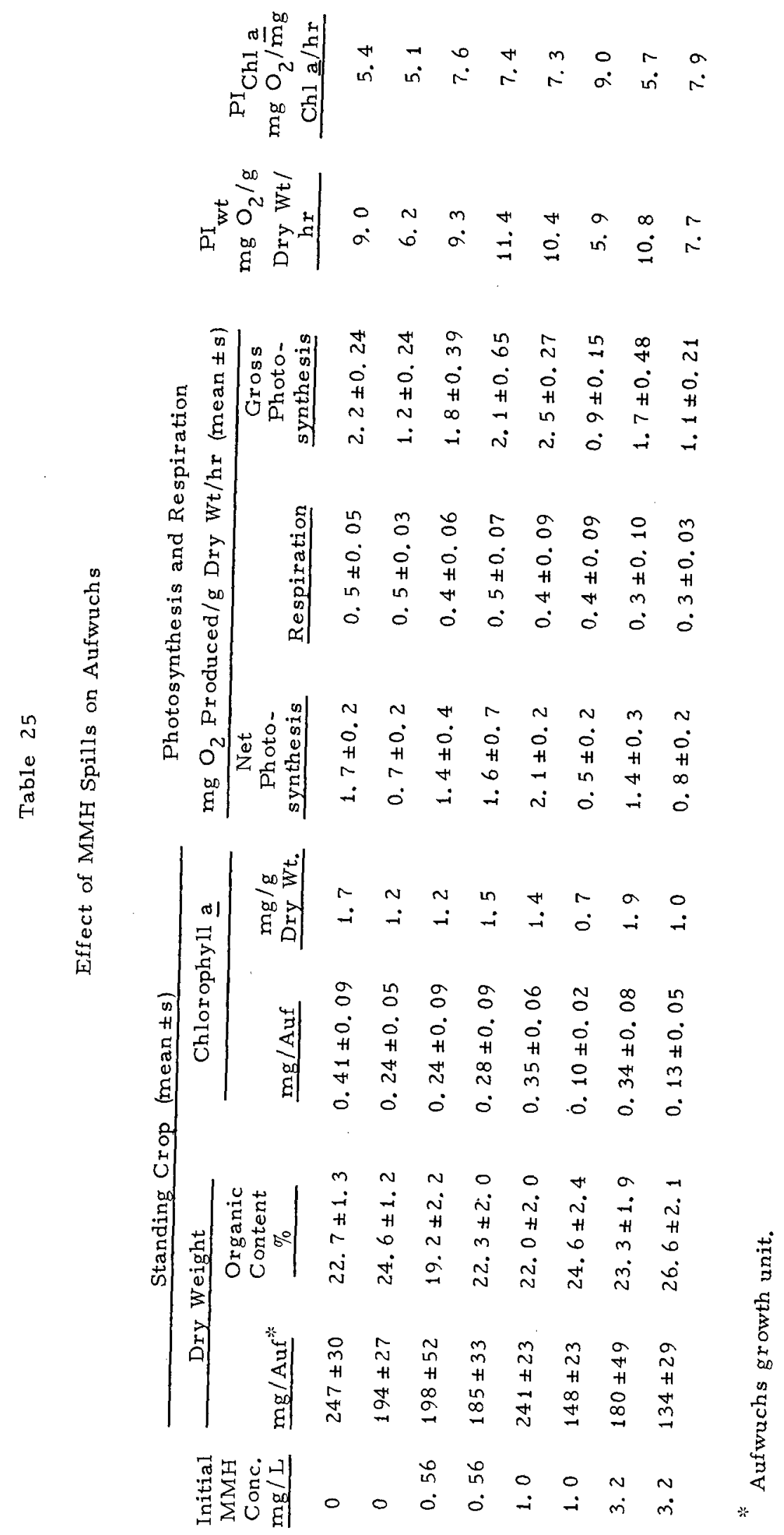


Aufwuchs were grown for 18 days in one of the analog tanks used for the spill studies. At the end of the growth period, MMH solutions were prepared in sea water (filtered through $5 \mu \mathrm{m}$ porosity glass fiber filters) with initial concentrations of $0,0.32$, and $3.2 \mathrm{mg} \mathrm{MMH} / 1$. The MMH solutions were siphoned into BOD bottles. Five light bottles and 5 dark bottles were used for each MMH concentration. One aufwuchs substrate was placed into each bottle. The aufwuchs were incubated and oxygen determined as for the spill studies. MMH concentrations were measured following the 2-hr light bottle incubation and the 4-hr dark bottle incubation periods.

The results of the aufwuchs study are presented in Table 26. Aufwuchs incubated in the $3.2 \mathrm{mg} \mathrm{MMH} / 1$ solution had substantially lower photosynthetic indices and much greater oxygen depletions than the aufwuchs receiving lower MMH doses. Much of the oxygen depletion in the $3.2 \mathrm{mg}$ MM/1 solution was probably caused by a chemical reaction between MMH and oxygen. There was a rapid depletion of $\mathrm{MMH}$ from its initial concentration of $3.2 \mathrm{mg} / 1$ (Table 27) indicating that the MMH oxidizes rapidly using up displaced oxygen. A $3.2 \mathrm{mg}$ MMH/1 solution made with filtered seawater and placed in a BOD bottle without aufwuchs substrate rapidly used up dissolved oxygen (Table 28). Because of this phenomenon, the actual dark respiration and net photosynthesis of the aufwuchs in the $3.2 \mathrm{mg} \mathrm{MMH} / 1$ solution was probably higher than indicated. However, the gross photosynthesis (used for photosynthetic index determinations) should only reflect the effect of the aufwuchs since the oxygen consumed in MMH oxidation will cancel out in the gross photosynthesis calculations. The no-effect level of MMH on aufwuchs in this system, as determined by the photosynthetic index, was between $0.32-3.2 \mathrm{mg} \mathrm{MMH} / 1$.

\section{HYDRAZINE STUDIES}

\section{Introduction}

Previously reported work has indicated that the $96-\mathrm{hr}$ no-effect level of hydrazine (initial concentration) to stickleback in a spill situation was between 3.2 and $5.6 \mathrm{mg} / 1$. In the same type of spill situation, aufwuchs were more sensitive to hydrazine than stickelback since they were shown to demonstrate an acute toxic response at initial hydrazine concentrations of less than $3.2 \mathrm{mg} / 1$. In a jar test, utilizing $24 \mathrm{hr}$ renewal of hydrazine concentrations, the 96-hr LC 50 of hydrazine to stickleback was found to be $3.4 \mathrm{mg} / 1$. Further work has been completed on hydrazine toxicity and is presented here.

The 96-hr Continuous-Flow Bioassay - Analog Tanks

A $96-\mathrm{hr}$ continuous-flow study was conducted to determine the LC 50 of hydrazine to the stickleback, the bay mussel (Mytilus edulis), and the mud-flat crab (Hemigrapsus oregonensis). In addition, the experiment at tempted to determine changes in the metabolic rate (productivity), chlorophy11 a, $\underline{\mathrm{b}}$, and c, pheophytin a, and biomass (standing crop) of the aufwuchs community.

Procedure. Approximately 100 mussels and 100 crabs were collected; the mussels were scrubbed clean of epiphytic growth and pooled into 8 sets of 10 mussels each. Each set was placed in a $50 \mathrm{~cm} \times 15 \mathrm{~cm}, 4.0 \mathrm{~mm}$ mesh Nytex bag and suspended in Bay water $50 \mathrm{~cm}$ below the surface in a holding tank. The crabs were also pooled into 8 sets of 10 crabs each and placed into cylindrical fish cages. The 8 cages were covered with aluminum foil and suspended $28 \mathrm{~cm}$ below the water surface in a holding tank. The two types of organisms were acclimated for 9 days. 


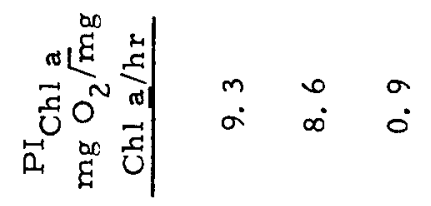

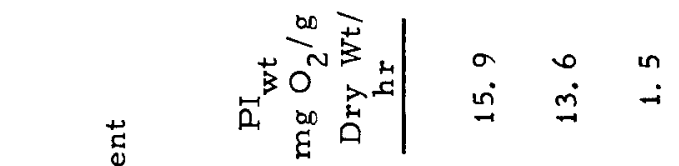

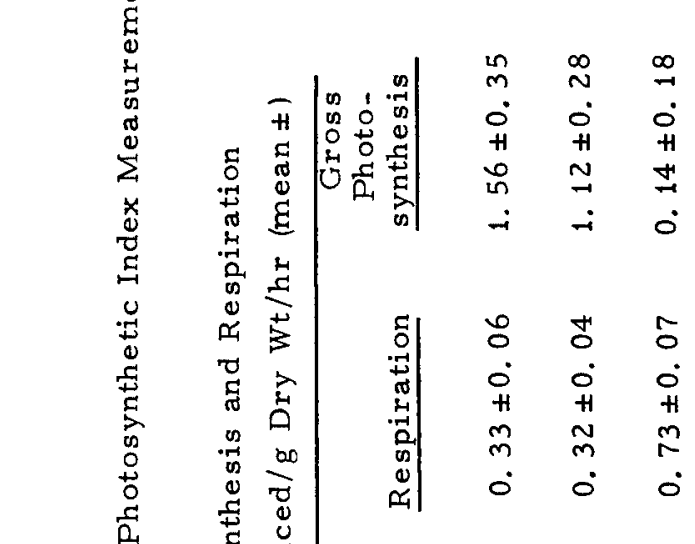

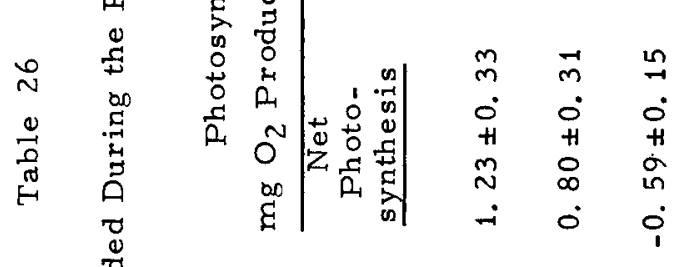

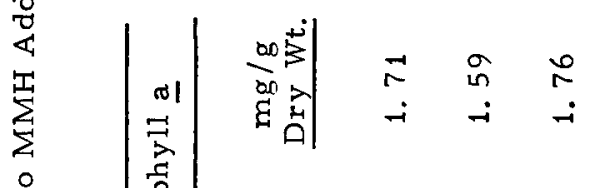

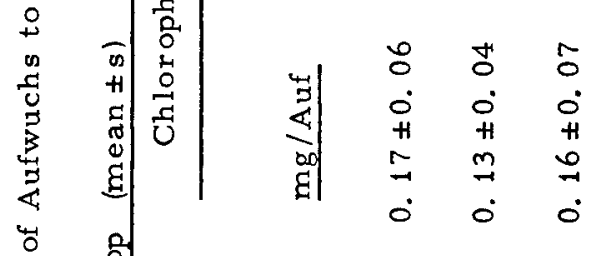

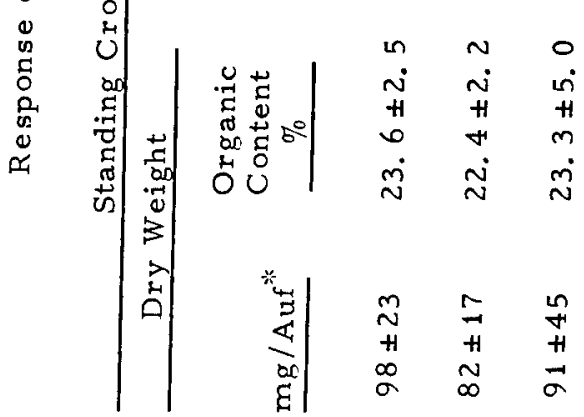

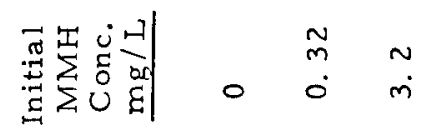

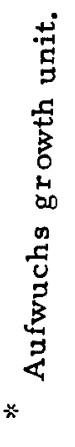


Table 27

MMH Concentration Profile in Central San Francisco Bay

Water in the Presence of Aufwuchs

\begin{tabular}{c}
$\begin{array}{c}\text { Time } \\
\mathrm{hr}\end{array}$ \\
\hline 0 \\
2 \\
4
\end{tabular}

$\mathrm{MMH}$ Concentration
$\mathrm{mg} / \mathrm{L}$

3. 2

1. 5

. 0.6

Table 28

Dissolved Oxygen Concentration Profile in a Solution of 3. $2 \mathrm{mg} / \mathrm{L} \mathrm{MMH}$ in Central San Francisco Bay Water (No Aufwuchs Present in Seawater)

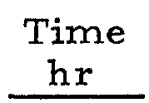

0

2

3
Dissolved Oxygen Concentration $\mathrm{mg} / \mathrm{L}$

5. 4

3. 2

2. 0

Stickleback were divided into 8 sets of $30 \mathrm{fish}$ each, placed in fish cages, and acclimated for 12 days in aholding tank. Size measurements for the stickleback, crabs, and mussels were $38.0 \pm 3.6,14.7 \pm 3.5$ (carapace width), and $35.3 \pm 6.8 \mathrm{~mm}$, respectively.

Eight aufwuchs racks, each containing 30 substrates, were suspended $50 \mathrm{~cm}$ below the water surface in a holding tank. Aufwuchs growths developed during a period of 12 days prior to exposure to hydrazine.

Al1 3 test organisms and the aufwuchs communities were maintained in Bay water at a flow rate of $4.01 / \mathrm{min}$. The nominal hydraulic residence time for an analog tank at this flow rate was estimated to be about $17.4 \mathrm{hr}$.

The organisms and aufwuchs community were exposed in duplicate to hydrazine concentrations of 0 (control); $1.0 ; 1.8$; and $3.2 \mathrm{mg} / 1$. Hydrazine was pumped at a rate of $1.0 \mathrm{ml} / \mathrm{min}$ by Buchler polystaltic pumps into the seawater inflow pipes of each of the 6 tanks. The tanks were equilibrated for $120 \mathrm{hr}$ prior to the commencement of the experiment.

At the start of the experiment the fish, mussels, and crabs were placed in each of the 8 analog tanks. The organisms were checked at 24-hr intervals for mortality; dead animals were removed immediately. Animals were considered dead when they no longer responded to probing. 
At the start of the experiment, 6 aufwuchs substrates from each of the 8 growth racks were analyzed for metabolic rate, chlorophylls, pheophytin, and biomass to establish the baseline values and their variation between the growth racks. The racks were then placed in each of the analog tanks. Aufwuchs were sampled after $48 \mathrm{hr}$ and $96 \mathrm{hr}$.

For analysis of the chemical parameters of the Bay water, a $300 \mathrm{ml}$ sample was collected at 0,24 and $96 \mathrm{hr}$ from one of the head tanks.

Bay Water Characteristics. The characteristics of the saline water utilized in the study are compiled in Table 29.

Hydrazine and Ammonia Nitrogen Concentrations. These concentrations were measured initially and then daily during the bioassay in each analog tank using a $300 \mathrm{ml}$ water sample collected approximately $50 \mathrm{~cm}$ beneath the water surface in the middle of each of the tanks.

Table 30 indicates that hydrazine and ammonia nitrogen concentrations showed considerable excursions. Moreover, while there was reasonable agreement between pairs of duplicate hydrazine concentrations, the measured hydrazine concentrations were much higher than desired. A variety of factors contributed to this variation in hydrazine level including problems with Bay water pumping, with hydrazine solution pumping due to short-circuiting of control devices in heavy rain, uncertainty of hydrazine losses by degradation and volatilization, and overcompensation in the addition of extra hydrazine in attempts to adjust for the shutdown periods when the hydrazine solution pumps were not operating.

Nevertheless, the hydrazine concentrations do show a progressive gradient from one dilution to another.

Mortality Results for the Fish, Crab, and Mussels. Tables 31, 32, and 33, respectively show that high mortality of both fish and crabs occurred at the highest hydrazine concentration $(5.7 \mathrm{mg} / 1)$. The average percent mortality at $96 \mathrm{hr}$ at $5.7 \mathrm{mg}$ hydrazine/1 was $55 \% ; 26 \%$ of the surviving fish displaying "stressed" behavior, such as erratic swimming, disorientation, and increased respiration rates. All of the crabs were dead in both duplicates of the highest hydrazine concentration $(5.7 \mathrm{mg} / 1)$. The crabs appeared to be more sensitive to hydrazine than the stickleback since a mortality of $80-100 \%$ occurred after $48 \mathrm{hr}$ of exposure (see Table 32). The mussels were the most tolerant of the organisms tested. Only a 5\% mortality ( 1 mussel) occurred at one of the highest hydrazine concentrations (see Table 33). The experiment appeared to be too short to elicit significant mortalitites of this organism.

The 96-hr LC 50's for both stickleback and crab were calculated by the best fit line from the mortality results plotted on logarithmic-probability paper. The $96-\mathrm{hr}$ LC 50 for stickleback was $5.4 \mathrm{mg} / 1$ with $95 \%$ confidence limits of 4.5 to $6.6 \mathrm{mg} / 1$. The $96-\mathrm{hr}$ LC 50 for crab was $3.6 \mathrm{mg} / 1$ (95\% confidence limit could not be computed).

The amount of growth on the aufwuchs substrates was small compared with that obtained in previously-reported San Francisco Bay water ana!.og studies. Thus, in the present work the maximum dry weight of the growth on each aufwuchs was 8-9 $\mathrm{mg}$ (in the controls) and ranged downwards to 3-4 $\mathrm{mg}$ on the aufwuchs 
Table 29

Physical and Chemical Characteristics of Central San Francisco Bay Water During Continuous-Flow Bioassay of Hydrazine
Salinity, \%o
$20.9 \pm 0.4$
Chlorosity, g/ 1
$8.02 \pm 0.47$
Temperature, C
13. $1 \pm 1.4$
$\mathrm{pH}$
$8.05 \pm 0.06$
$\mathrm{DO}, \mathrm{mg} / \mathrm{I}$
$7.6 \pm 0.4$
Alkalinity, mg as $\mathrm{CaCO}_{3} / 1$
$90.7 \pm 1.2$
Total Dissolved Solids, g/ 1
$16.6 \pm 0.7$

Table 30

Hydrazine and Ammonia-Nitrogen Concentrations in the 96-hr Continuous-Flow Bioassay

\begin{tabular}{|c|c|c|c|c|c|}
\hline \multirow[b]{2}{*}{$\begin{array}{c}\text { Analog } \\
\text { Tank } \\
\end{array}$} & \multicolumn{3}{|c|}{ Hydrazine $, \pm \mathrm{s}, \mathrm{mg} / \mathrm{1}$} & \multicolumn{2}{|c|}{$\mathrm{NH}_{3}-\mathrm{N}^{* * *} \pm \mathrm{s}, \mu \mathrm{g} / 1$} \\
\hline & $\begin{array}{c}\text { Desired } \\
\text { Conc. } \\
\end{array}$ & $\begin{array}{c}\text { Measured } \\
\text { Conc. } \\
\end{array}$ & $\begin{array}{c}\text { Avg. of } \\
\text { Measured } \\
\text { Conc. } \\
\end{array}$ & $\begin{array}{c}\text { Measured } \\
\text { Conc. } \\
\end{array}$ & $\begin{array}{c}\text { Avg. of } \\
\text { Measured } \\
\text { Conc. } \\
\end{array}$ \\
\hline A & 0 & 0.0 & & $30.9 \pm 29.4$ & \\
\hline $\mathrm{B}$ & 0 & 0.0 & 0.0 & $34.6 \pm 35.8$ & $32.7 \pm 30.4$ \\
\hline G & 1.0 & $2.1 \pm 2.2$ & & $53.3 \pm 27.5$ & \\
\hline $\mathrm{H}$ & 1. 0 & $2.2 \pm 2.0$ & $2.2 \pm 2.0$ & $57.7 \pm 32.7$ & $55.5 \pm 28.1$ \\
\hline $\mathrm{E}$ & 1.8 & $2.9 \pm 2.4$ & & $44.9 \pm 20.5$ & \\
\hline$F$ & 1. 8 & $2.9 \pm 2.8$ & $2.9 \pm 2.5$ & $52.0 \pm 29.1$ & $48.4 \pm 23.6$ \\
\hline $\mathrm{C}$ & 3.2 & $5.3 \pm 4.1$ & $5.7 \pm 4.0$ & $51.1 \pm 29.9$ & $51,6 \pm 27,2$ \\
\hline $\mathrm{D}$ & 3.2 & $6.0 \pm 4.3$ & & $52.1 \pm 28.8$ & \\
\hline
\end{tabular}


Table 31

Toxicity of Hydrazine to Sticklebacks in Central San Francisco Bay Water

\begin{tabular}{|c|c|c|c|c|c|c|c|}
\hline \multirow{2}{*}{$\begin{array}{c}\text { Analog } \\
\text { Tank } \\
\end{array}$} & \multirow{2}{*}{$\begin{array}{c}\text { Avg. of } \\
\text { Measured } \\
\text { Hydrazine } \\
\text { Conc. } \\
\text { mg/1 } \\
\end{array}$} & \multirow{2}{*}{$\begin{array}{l}\text { Number } \\
\text { of Test } \\
\text { Organ- } \\
\text { isms }\end{array}$} & \multicolumn{4}{|c|}{$\begin{array}{c}\text { Cumulative Number of Test } \\
\text { Organisms Dead After: }\end{array}$} & \multirow{2}{*}{$\begin{array}{c}\% \\
\text { Mortality } \\
\text { at } 96 \mathrm{hr} \\
\end{array}$} \\
\hline & & & $24 \mathrm{hr}$ & $48 \mathrm{hr}$ & $72 \mathrm{hr}$ & $96 \mathrm{hr}$ & \\
\hline $\mathrm{A}$ & \multirow{2}{*}{$\stackrel{0.0}{\text { (control) }}$} & 30 & 0 & 0 & 0 & 0 & 0 \\
\hline B & & 30 & 0 & 0 & 0 & 0 & 0 \\
\hline G & \multirow{2}{*}{2.2} & 30 & 0 & 0 & 1 & 1 & 3.3 \\
\hline $\mathrm{H}$ & & 30 & 0 & 0 & 0 & 0 & 0 \\
\hline$E$ & \multirow{2}{*}{2.9} & 30 & 0 & 0 & 0 & 0 & 0 \\
\hline $\mathrm{F}$ & & 30 & 0 & 0 & 1 & 1 & 3.3 \\
\hline C & \multirow[t]{2}{*}{5.7} & 30 & \multirow{2}{*}{$\begin{array}{c}0 \\
(4) * \\
0 \\
(1) *\end{array}$} & \multirow{2}{*}{$\begin{array}{l}10 \\
(5) * \\
5 \\
(6) *\end{array}$} & \multirow{2}{*}{$\begin{array}{l}16 \\
(4) * \\
14\end{array}$} & \multirow{2}{*}{$\begin{array}{l}17 \\
(3) * \\
16 \\
(4) *\end{array}$} & 56.7 \\
\hline D & & 30 & & & & & 53.3 \\
\hline
\end{tabular}

( )* designates the number of stressed sticklebacks at indicated time.

Table 32

Toxicity of Hydrazine to Hemigrapsus oregonensis (Crabs)

in Central San Francisco Bay Water

Avg. of

Measured

Hydrazine

Analog

Conc.

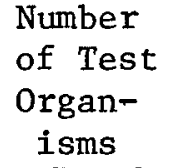

Cumulative Number of Test Organisms. Dead After:

Tank $\mathrm{mg} / 1$

isms

\begin{tabular}{|c|c|c|c|}
\hline $24 \mathrm{hr}$ & $48 \mathrm{hr}$ & $72 \mathrm{hr}$ & $96 \mathrm{hr}$ \\
\hline
\end{tabular}

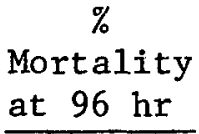

$\begin{array}{ccc}\text { A } & 0.0 & 10 \\ \text { B } & \text { (contro1) } & 10 \\ \text { G } & & 10 \\ \text { H } & 2.2 & 10 \\ \text { E } & & 10 \\ \text { F } & 2.9 & 10 \\ \text { C } & & 10 \\ \text { D } & 5.7 & 10\end{array}$

10

0

0

0

0

0

10

0

0

0

0

0

10

0

0

0

0

0

10

0

0

0

0

0

$10 \quad 0$

0

1

1

10

0

0

0

0

0

104

10

(2) *

(1) *

10

100

(4) *

10

$10 \quad 10$

100

( )* designates the number of stressed crabs at indicated time. 
Table 33

Toxicity of Hydrazine to Mytilus edulis (Mussels) in

Central San Francisco Bay Water

\begin{tabular}{|c|c|c|c|c|c|c|c|}
\hline \multirow{2}{*}{$\begin{array}{c}\text { Analog } \\
\text { Tank } \\
\end{array}$} & \multirow{2}{*}{$\begin{array}{c}\text { Avg. of } \\
\text { Measured } \\
\text { Hydrazine } \\
\text { Conc. } \\
\text { mg/L } \\
\end{array}$} & \multirow{2}{*}{$\begin{array}{l}\text { Number } \\
\text { of Test } \\
\text { Organ- } \\
\text { isms } \\
\end{array}$} & \multicolumn{4}{|c|}{$\begin{array}{c}\text { Cumulative Number of Test } \\
\text { Organisms Dead After: }\end{array}$} & \multirow{2}{*}{$\begin{array}{c}\% \\
\text { Mortality } \\
\text { at } 96 \mathrm{hr} \\
\end{array}$} \\
\hline & & & $24 \mathrm{hr}$ & $48 \mathrm{hr}$ & $72 \mathrm{hr}$ & $96 \mathrm{hr}$ & \\
\hline A & \multirow{2}{*}{$\begin{array}{l}0.0 \\
\text { (control) }\end{array}$} & 10 & 0 & 0 & 0 & 0 & 0 \\
\hline B & & 10 & 0 & 0 & 0 & 0 & 0 \\
\hline$G$ & \multirow[t]{2}{*}{ 2. 2} & 10 & 0 & 0 & 0 & 0 & 0 \\
\hline $\mathrm{H}$ & & 10 & 0 & 0 & 0 & 0 & 0 \\
\hline$E:$ & \multirow{2}{*}{2.9} & 10 & 0 & 0 & 0 & 0 & 0 \\
\hline$F$ & & 10 & 0 & 0 & 0 & 0 & 0 \\
\hline $\mathrm{C}$ & \multirow[t]{2}{*}{5.7} & 10 & 0 & 0 & 0 & 1 & 10 \\
\hline $\mathrm{D}$ & & 10. & 0 & 0 & 0 & 0 & 0 \\
\hline
\end{tabular}

exposed to various concentrations of hydrazine. Previous studies have shown dry weight of biomass on each aufwuchs growth unit of up to $100-300 \mathrm{mg}$. The causes for the small amount of growth in the present study may have been: 1) the presence of large amounts of low-nutrient content fresh water in the Bay system due to the high runoff from heavy rains, 2) the absence of the previously used vigorous aeration/mixing. This was reduced to keep hydrazine losses down to an acceptable level. Nutritional level and low salinity have been reported to stress aufwuchs communities (Krock and Mason, 1971) and affect biological communities (Pearson et al., 1970).

Because of the very small amount of growth the conclusions from this study must be made with some degree of caution.

The data in Table 34 and Figures 15-18 show a severe toxic effect after $48 \mathrm{hr}$ and a more pronounced effect after $96 \mathrm{hr}$ on aufwuchs exposed to hydrazine at all concentrations examined. The aufwuchs exposed to a hydrazine concentration had a sharply reduced biomass, chlorophyl1 a, b, and $\underline{\text {, }}$ gross photosynthesis and photosynthetic indices ( $\mathrm{PI}_{\mathrm{wt}}$ and $\left.\mathrm{PI} \mathrm{Ih}_{\mathrm{1}}\right)$ compared to the control aufwuchs. The gross photosynthesis, a sensitive indicator of toxicity, shows 96-hr values at the $2.2 \mathrm{mg}$ hydrazine/1 level (the lowest level tested) that are about $10 \%$ of the control. In the two higher levels $(2.9$ and $5.7 \mathrm{mg} / 1)$ 


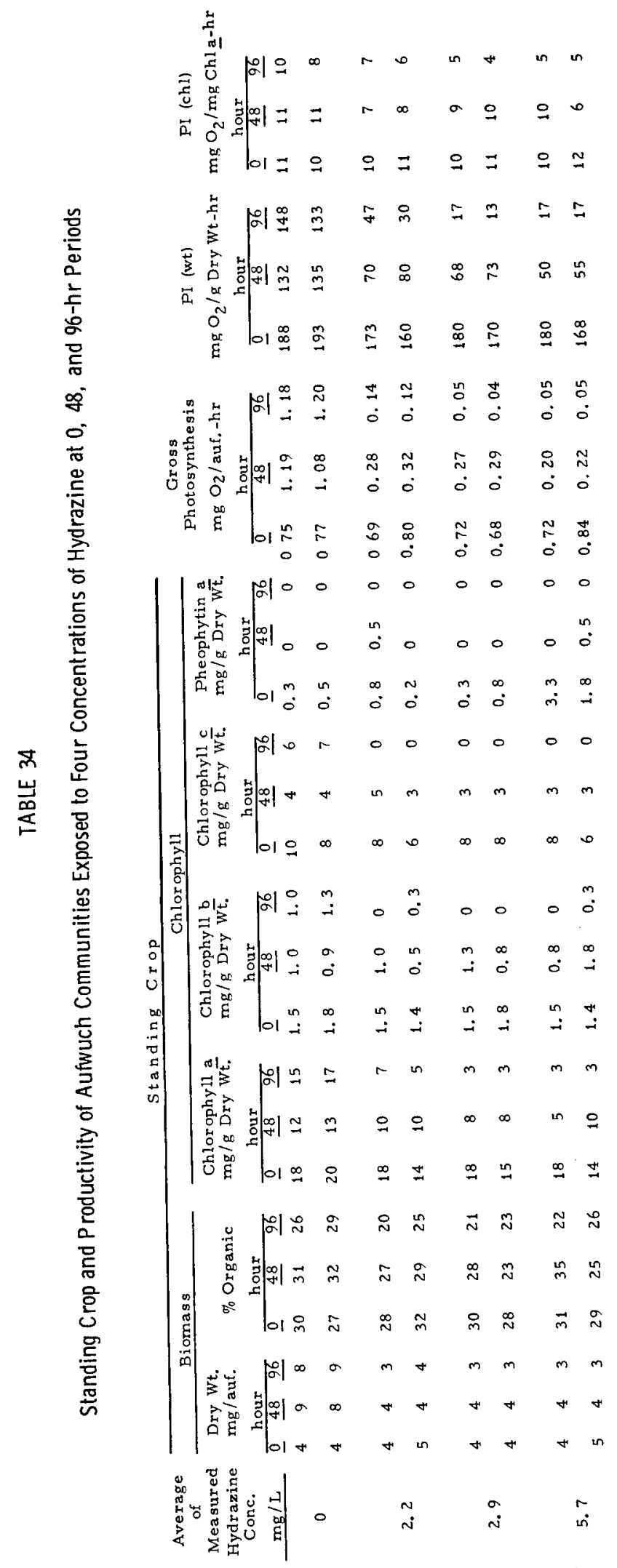



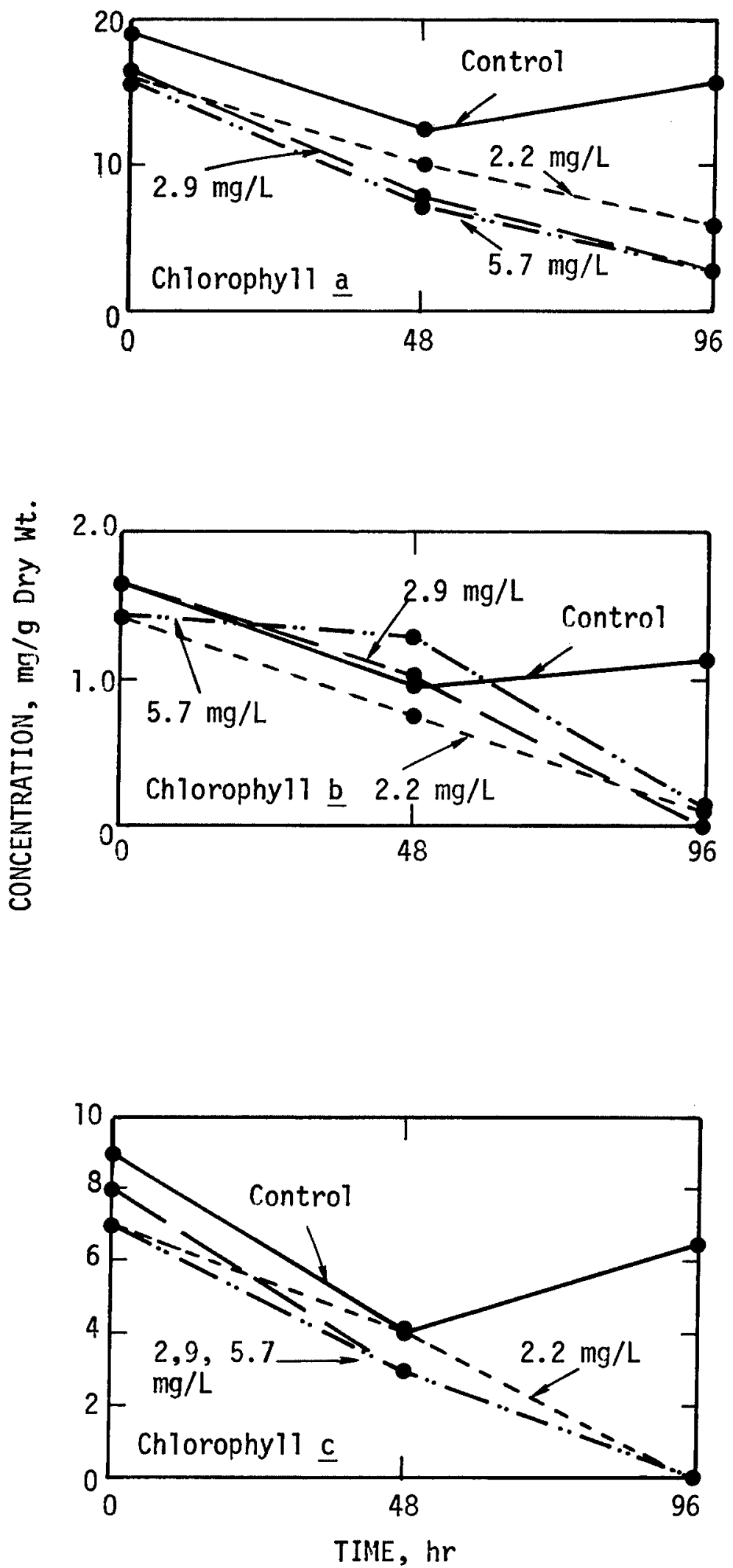

FIGURE 15. CHLOROPHYLL a, b, AND c CONCENTRATIONS

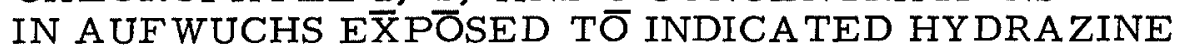
CONCENTRA TIONS AT 0, 48, AND 96-HOUR INTERVALS IN CONTINUOUS-FLOW SALT WATER BIOASSAYS 


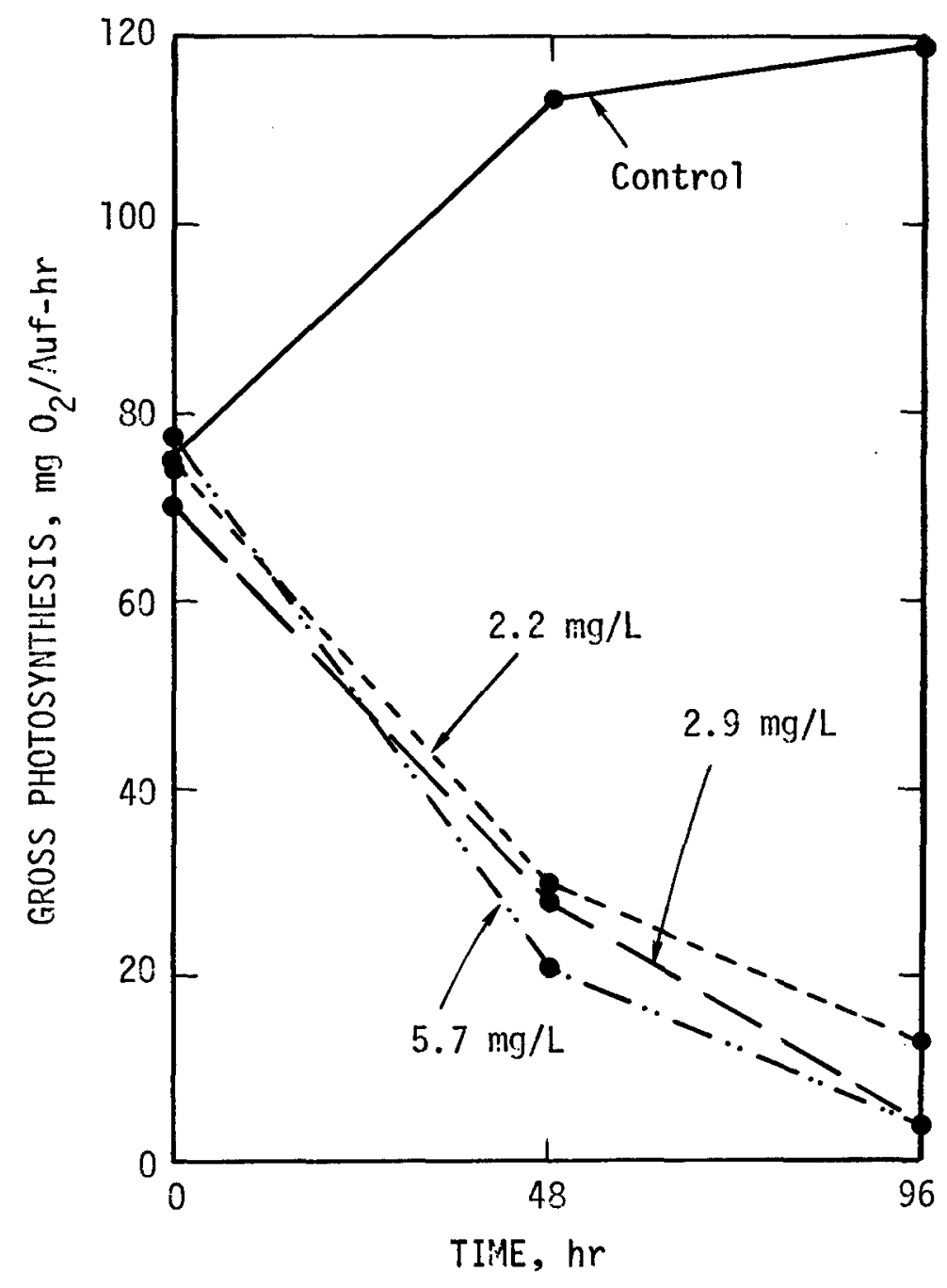

FIGURE 16. GROSS PHOTOSYNTHESIS OF AUFWUCHS COMMUNI TIES EXPOSED TO INDICA TED HYDRAZINE CONCENTRA TIONS A T 0, 48, AND 96-HOUR INTERVALS IN CONTINUOUSFLOW SALT WATER BIOASSAYS 


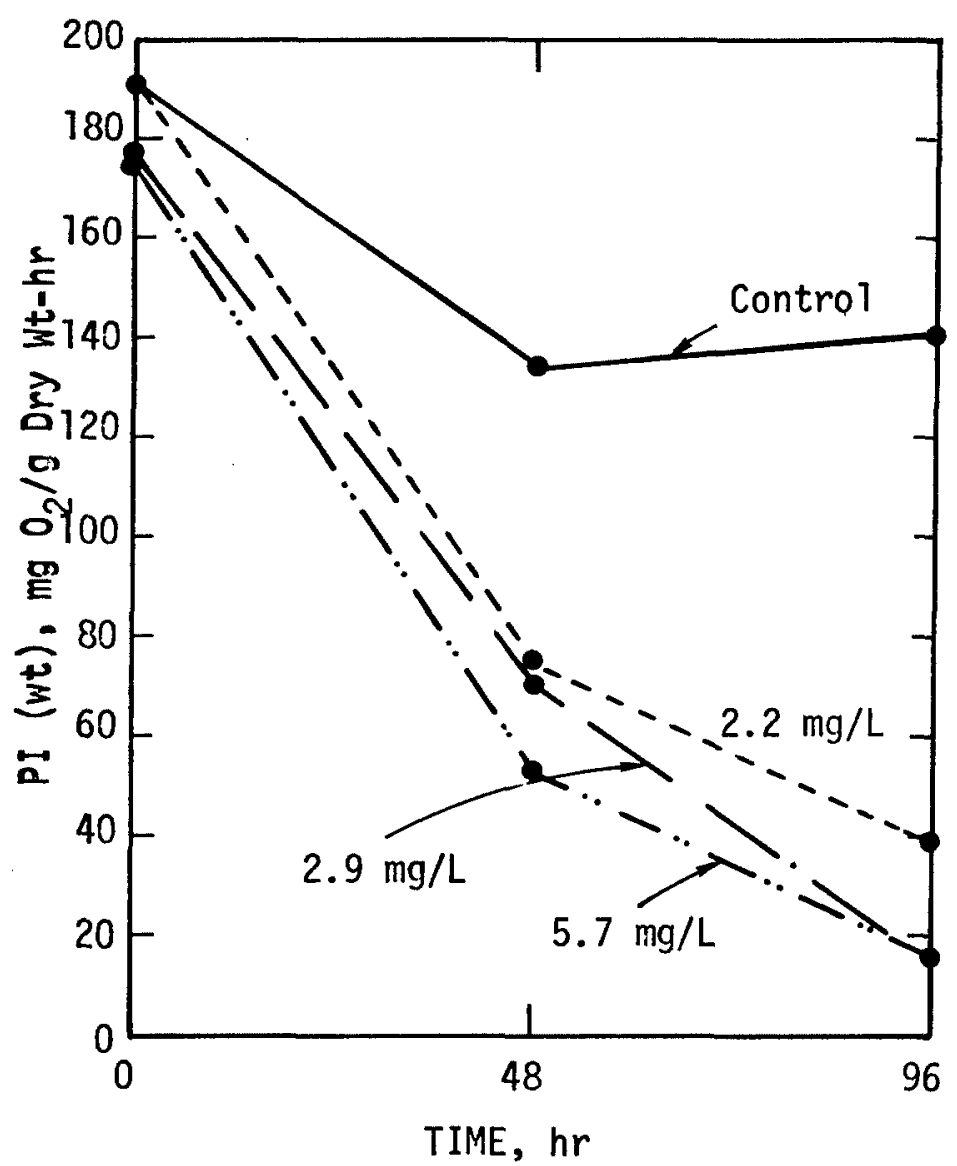

FIGURE 17. PHOTOSYNTHE TIC INDEX [PI (wt)] OF AUFWUCHS COMMUNITIES EXPOSED TO INDICA TED HYDRAZINE CONCENTRA TIONS AT 0, 48, AND 96-HOUR INTERVALS IN CONTINUOUS-FLOW SALT WATER BIOASSAYS

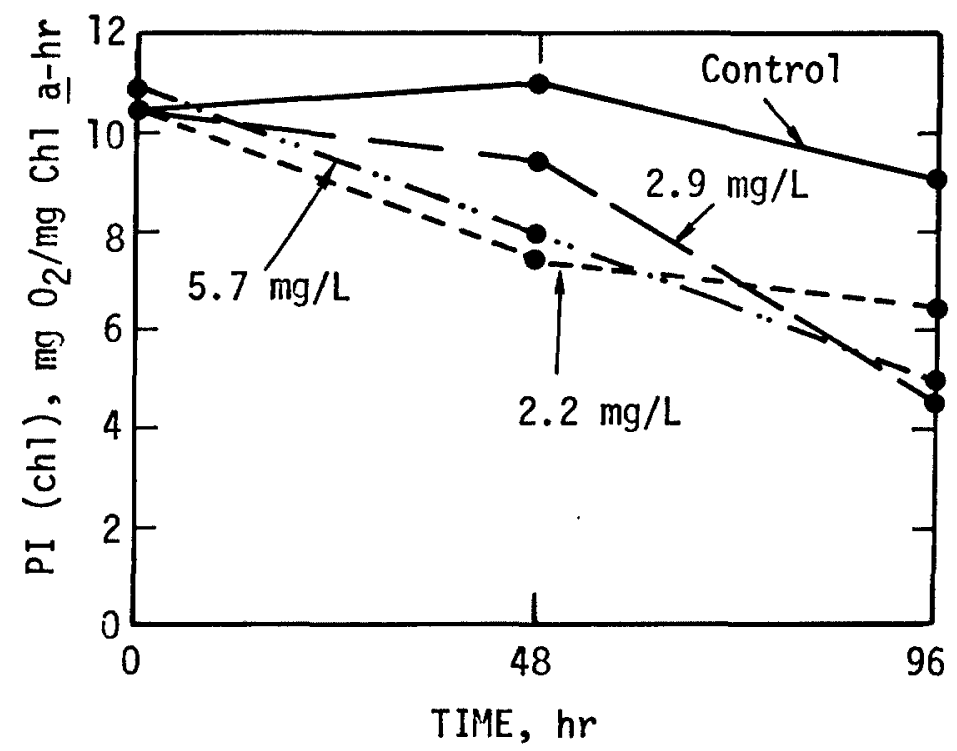

FIGURE 18. PHOTOSYNTHE TIC INDEX [ PI (ch1)] OF AUFWUCHS COMMUNITIES EXPOSED TO INDICATED HYDRAZINE CONCENTRA TIONS A T 0, 48, AND 96-HOUR INTERVALS IN CONTINUOUS-FLOW SALT WATER BIOASSAYS 
of hydrazine tested there was over $95 \%$ reduction in these parameters compared with the control aufwuchs. Pheophytin a content was negligible or absent in all aufwuchs including the controls. These results indicate that the aufwuchs are much more sensitive indicators of hydrazine toxicity than stickleback.

The 14-Day Continuous-Flow Bioassay - Analog Tanks

Procedure. A 14-day continuous-flow study was conducted on the same species, obtained from the same sources, studied in the preceding $96-\mathrm{hr}$ bioassay. The sizes of the stickleback, crabs, and mussels were $38.4 \pm 3.6 \mathrm{~mm}, 16.9 \pm 2.0$ $\mathrm{mm}$ (carapace width), and $33.3 \pm 3.3 \mathrm{~mm}$, respectively.

An aufwuchs growth rack containing 24 substrates was placed in each of the 8 analog tanks at the start of the experiment to observe the effect of hydrazine on aufwuchs development. This was different from the previous 96-hr study where the aufwuchs were developed before being exposed to hydrazine. The aufwuchs were examined after 7 days (168 hr) and after 14 days (336 hr) of exposure to hydrazine.

The target hydrazine concentrations were 0 (control), $0.75,1.35$, and $2.4 \mathrm{mg}$ hydrazine/1. Stock solutions of hydrazine were pumped into the analog tanks for a 24-hr period of equilibration before initiating the study. Test organisms were observed each day for mortality, and dead animals were immediately removed.

Bay Water Characteristics. During the study a $300 \mathrm{ml}$ Bay water sample was collected daily from one of the head tanks and analyzed for alkalinity, chloride, total dissolved solids, salinity, temperature, and Do. Hydrazine, $\mathrm{NH}_{3}-\mathrm{N}$, and $\mathrm{pH}$ were measured daily in a $300 \mathrm{ml}$ sample taken at midpoint $50 \mathrm{~cm}$ below the water surface. The characteristics of the Bay water utilized in the study are presented in Table 35.

Results of the Hydrazine, $\mathrm{NH}_{3}-\mathrm{N}$ and $\mathrm{pH}$ Measurements. These results are presented in Table 36. The measured hydrazine concentrations were, in each case, about $28 \%$ lower than the target values. This constant percentage (rather than absolute quantity) decrease indicates that the loss of hydrazine can be accounted for by volatilization, degradation, and perhaps operational procedures (e.g. Bay water continues to flow after the float switch has shut off hydrazine pumps) rather than by analytical error. $\mathrm{NH}_{3}-\mathrm{N}$ concentrations were not significantly different between the analog tanks except that one control tank (Analog Tank F) showed a significantly lower $\mathrm{NH}_{3}-\mathrm{N}$ value. No explanation can be offered to account for this low value. The $\mathrm{pH}$ values in both control tanks were higher than in the tanks containing hydrazine. This was kecause the presence of hydrazine suppressed the photosynthetic activity of the aufwuchs which tends to raise $\mathrm{pH}$ by extracting $\mathrm{CO}_{2}$ from the water.

Mortality Results for Stickleback and Crab. Bioassay results are presented in Tables 37 and 38, respectively. The mortality of both organisms increased with increasing hydrazine concentrations. At the highest hydrazine concentration $(1.72 \mathrm{mg} / 1)$ the average mortality was $80 \%$. "Stressed" behavior, such as disorientation of swimming, increased respiration rate, and 1ying sideways, was observed in $60-86 \%$ and $25-38 \%$ of the surviving fish at the highest ( 1.72 $\mathrm{mg} / 1)$ and the next highest $(0.98 \mathrm{mg} / 1)$ hydrazine concentrations, respectively. 
Table 35

Physical and Chemical Characteristics of Central San Francisco Bay Water During 14-Day Continuous-Flow Bioassay of Hydrazine

Parameter and Unit

of Expression

Concentration

Salinity, \%o

17. $5 \pm 1.9$

Temperature, C

$15.6 \pm 1.5$

DO, $\mathrm{mg} / \mathrm{L}$

$8.8 \pm 0.5$

Alkalinity, $\mathrm{mg}$ as $\mathrm{CaCO}_{3} / \mathrm{L}$

$95.2 \pm 6.8$

Clorosity, g/L

10. $17 \pm 1.44$

Total Dissolved Solids, g/L

$24.8 \pm 6.9$

Table 36

Hydrazine, $\mathrm{NH}_{3}-\mathrm{N}$, and $\mathrm{pH}$ Concentrations in

the 14-Day Continuous-Flow Bioassay

Concentration, mean $\pm s$

\begin{tabular}{|c|c|c|c|c|c|c|}
\hline \multirow{2}{*}{$\begin{array}{c}\text { Analog } \\
\text { Tank } \\
\end{array}$} & \multicolumn{3}{|c|}{ Hydrazine ${ }^{*}, \mathrm{mg} / \mathrm{L}$} & \multicolumn{2}{|c|}{$\mathrm{NH}_{3}-\mathrm{N}^{*}, \mu \mathrm{g} / \mathrm{L}$} & \multirow{2}{*}{$\begin{array}{c}\mathrm{pH}^{*} \\
\text { Measured } \\
\end{array}$} \\
\hline & Target & Measured & Average & Measured & Average & \\
\hline $\mathrm{E}$ & 0.0 & 0.0 & \multirow{2}{*}{0.0} & $42.6 \pm 12.7$ & \multirow[b]{2}{*}{$31.7 \pm 15.3$} & $8.28 \pm 0.24$ \\
\hline$F$ & 0.0 & 0.0 & & $20.9 \pm 8.5$ & & $8.32 \pm 0.24$ \\
\hline I & 0.75 & & \multirow{2}{*}{$0.53 \pm 0.19$} & & \multirow{2}{*}{$37.0 \pm 9.8$} & $8.10 \pm 0.08$ \\
\hline $\mathrm{J}$ & 0.75 & $0.57 \pm 0.19$ & & $34.5 \pm 5.8$ & & $8.11 \pm 0.06$ \\
\hline $\mathrm{K}$ & 1. 35 & $1.03 \pm 0.48$ & \multirow{2}{*}{$0.98 \pm 0.36$} & $47.1 \pm 13.0$ & \multirow{2}{*}{$41.6 \pm 13.4$} & $8.12 \pm 0.05$ \\
\hline L & 1.35 & $0.92 \pm 0.16$ & & $36.2 \pm 11.7$ & & $8.13 \pm 0.07$ \\
\hline $\mathrm{C}$ & 2.4 & $1.75 \pm 0.33$ & \multirow{2}{*}{$1.72 \pm 0.30$} & $36.7 \pm 7.8$ & \multirow{2}{*}{$34.6 \pm 7.8$} & $8.15 \pm 0.07$ \\
\hline $\mathrm{D}$ & 2.4 & $1.69 \pm 0.26$ & & $32.4 \pm 7.5$ & & $8.16 \pm 0.06$ \\
\hline
\end{tabular}




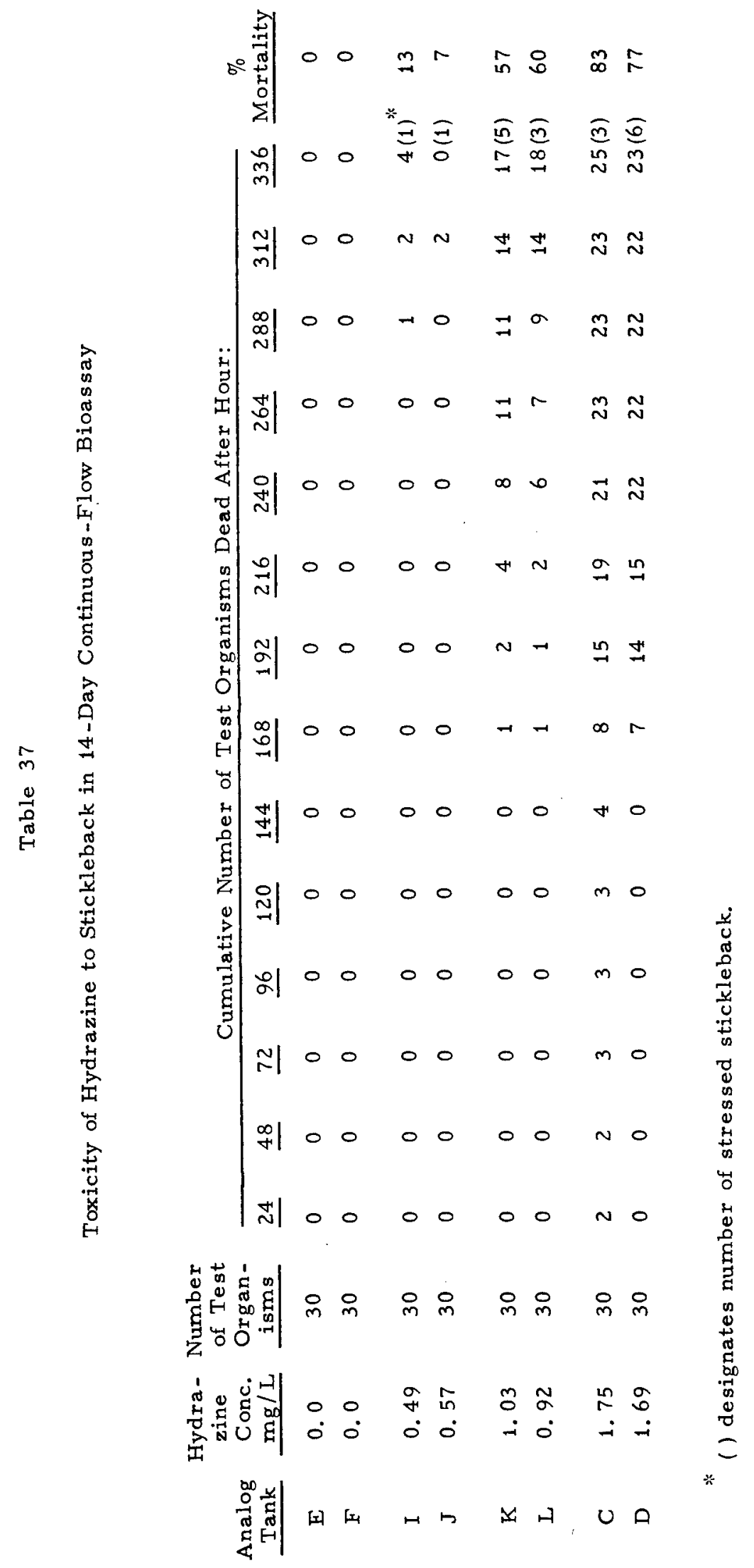




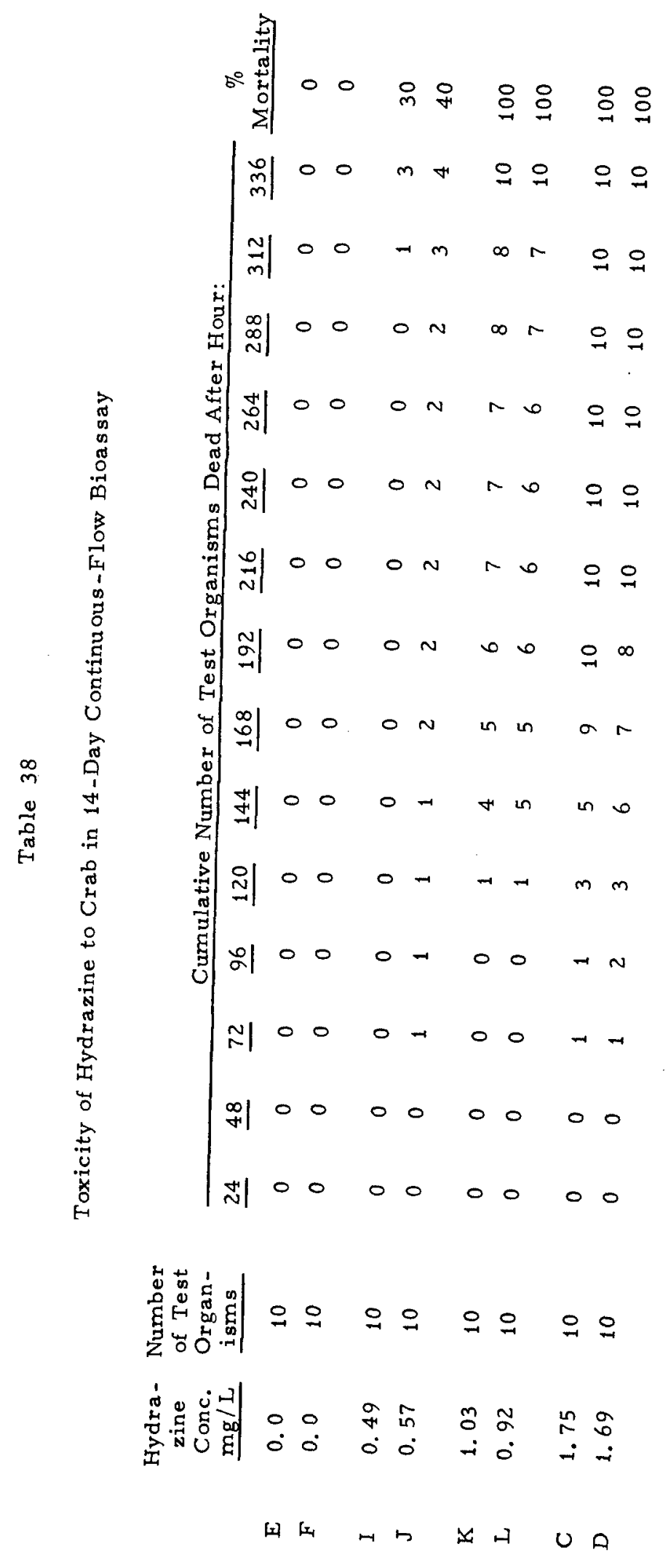


At the highest hydrazine concentration $(1.72 \mathrm{mg} / 1)$ all crabs were dead by $216 \mathrm{hr}$ ( 9 days). At a hydrazine concentration of $0.98 \mathrm{mg} / 1$ all crabs were dead by $336 \mathrm{hr}$ (14 days) (see Table 38).

The 336-hr LC 50's and their 95\% confidence limits were calculated by the log-probit method (Litchfield and Wilcoxon, 1949) for stickleback and crab. The 336-hr (14-day) LC 50 for stickleback was $1.07 \mathrm{mg} / 1$ (95\% confidence limits of 0.78 to $1.47 \mathrm{mg} / 1$ ); the value for crab was estimated to be $0.56 \mathrm{mg} / 1$. Confidence limits could not be calculated because of the high mortalities at the two highest hydrazine concentrations. For crab the 216-hr (9-day) LC 50 was $0.85 \mathrm{mg} / 1$ ( $95 \%$ confidence limits of 0.33 to $2.17 \mathrm{mg} / 1$ ).

Mussels. There was no toxic response in the range of hydrazine concentrations tested.

Aufwuchs Results. As in the 96-hr Bay water analog study, and for probably the same reasons, the amount of growth on the aufwuchs was very smal1. Therefore, again the conclusions drawn on hydrazine toxicity must be somewhat tentative.

In a11 aufwuchs exposed to hydrazine, growth, as assessed by dry weight, was severely reduced over that observed in the control (Table 39 and Figure 19). Neither the control aufwuchs nor the aufwuchs exposed to the two lowest hydrazine concentrations $(0.53 \mathrm{mg} / 1$ and $0.98 \mathrm{mg} / 1)$ exhibited any increase in dry weight between the 7-day and the 14-day measurements (Figure 19). The aufwuchs exposed to $1.72 \mathrm{mg}$ hydrazine/1 showed a decrease in biomass dry weight between Days 7 and 14. Perhaps these results are an indication that the control aufwuchs and aufwuchs exposed to the two lowest hydrazine concentrations reached some steady-state level of growth which could be maintained in the presence (or absence) of the given hydrazine concentration. Further experiments are needed to justify this contention.

The organic matter content of the growth that occurred on a11 aufwuchs was similar and in the range of $26-50 \%$ of the dry weight. Because of the extremely low dry weights of aufwuchs growth in this study, the amounts of the chlorophylls $\underline{a}, \underline{b}$, and $\underline{c}$ were also extremely small and pheophytin was not detected (Table $3 \overline{9}$ ). These low values may have contributed to the somewhat inconsistent response of the concentrations of the various chlorophylls to different hydrazine concentrations (Figure 20). In the chlorophyl1 a data (the chlorophy11 species with the greatest mass) there is evidence of a consistent response to the various levels of hydrazine. Both at $168 \mathrm{hr}$ and 336 $\mathrm{hr}$ the aufwuchs exposed to increasing levels of hydrazine between 0 and 1.72 $\mathrm{mg} / 1$ contained decreasing amounts of chlorophy11 a.

Results of photosynthetic rate measurements show distinct evidence of the toxicity of hydrazine (Figures 21 and 22) as indicated by both gross photosynthesis (mg $\mathrm{O}_{2}$ /aufwuch substrate-hr) and photosynthetic index based on dry weight (mg $\mathrm{O}_{2} / \mathrm{g}$ dry wt. $-\mathrm{hr}$ ). In both of these expressions of photosynthetic activity there is a suggestion that at each of the lower levels of hydrazine ( 0.53 and $0.98 \mathrm{mg} / 1$ ) a recovery from the toxic effects of hydrazine was occurring (Figure 21 and 22). At the $1.72 \mathrm{mg}$ hydrazine/1 level, no such recovery was evident. Further experiments with more significant aufwuchs growths and for a longer duration than 14 days are necessary to determine whether these data are truly representative of the situation. 


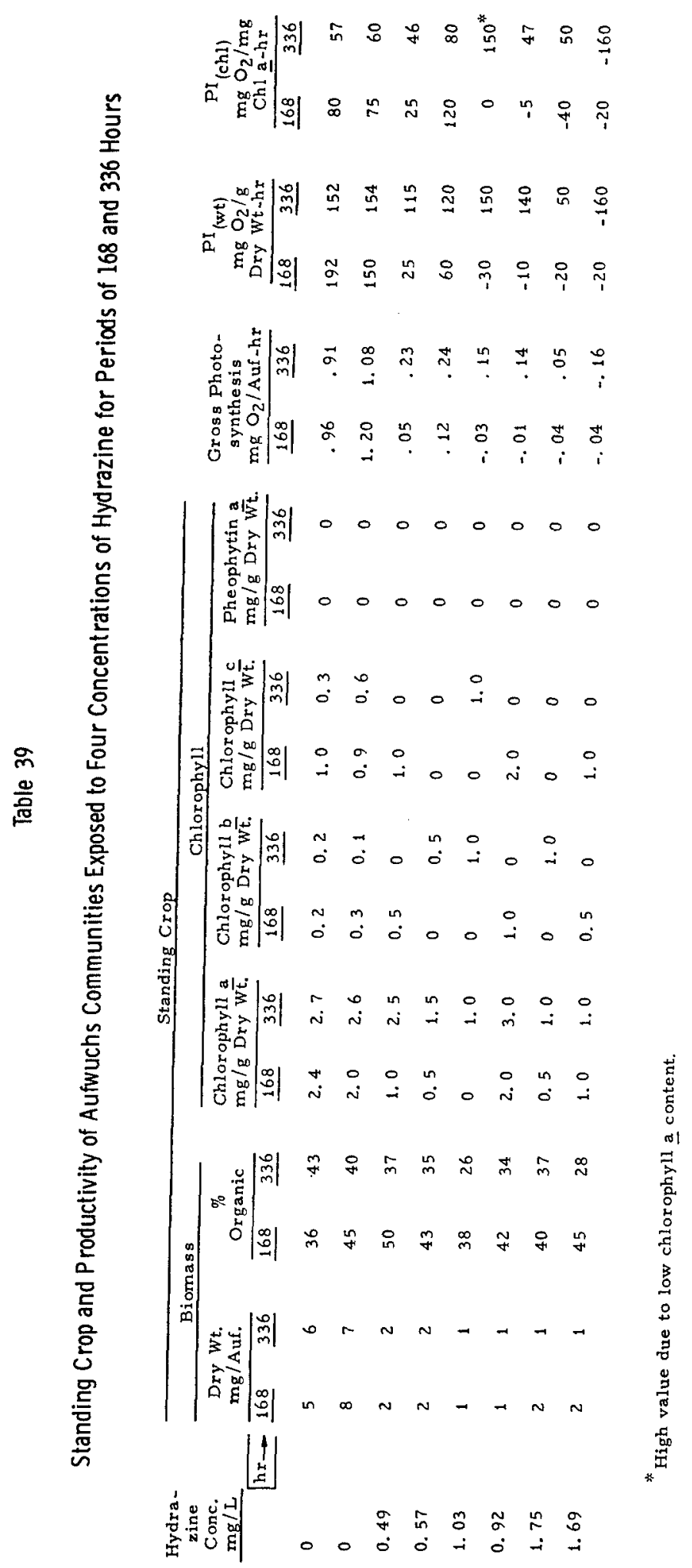




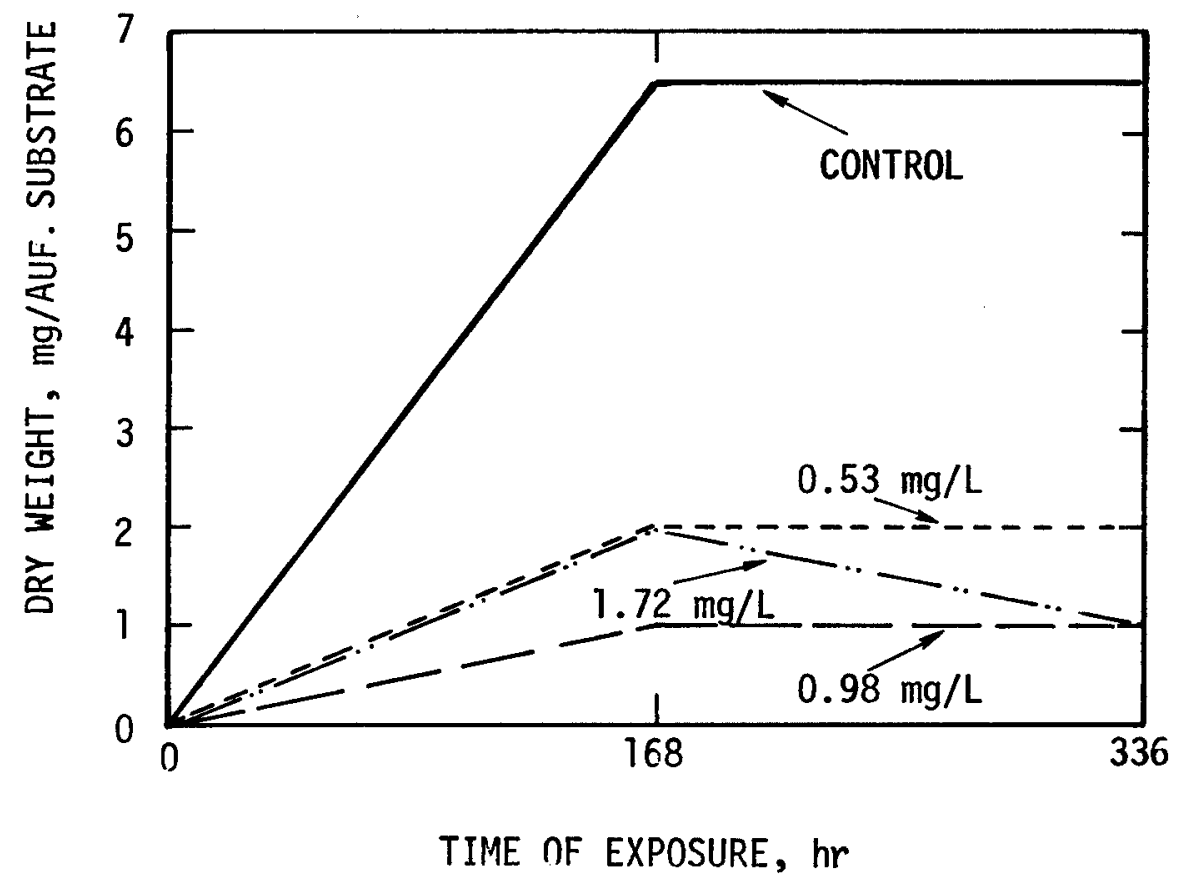

FIGURE 19. EFFECT OF INDICATED CONCENTRATION OF HYDRAZINE ON DRY WEIGHT OF GROWTH ON AUFWUCHS

(14-DAY CONTINUOUS-FLOW BIOASSAY, CENTRAL SAN FRANCISCO BAY WATER 

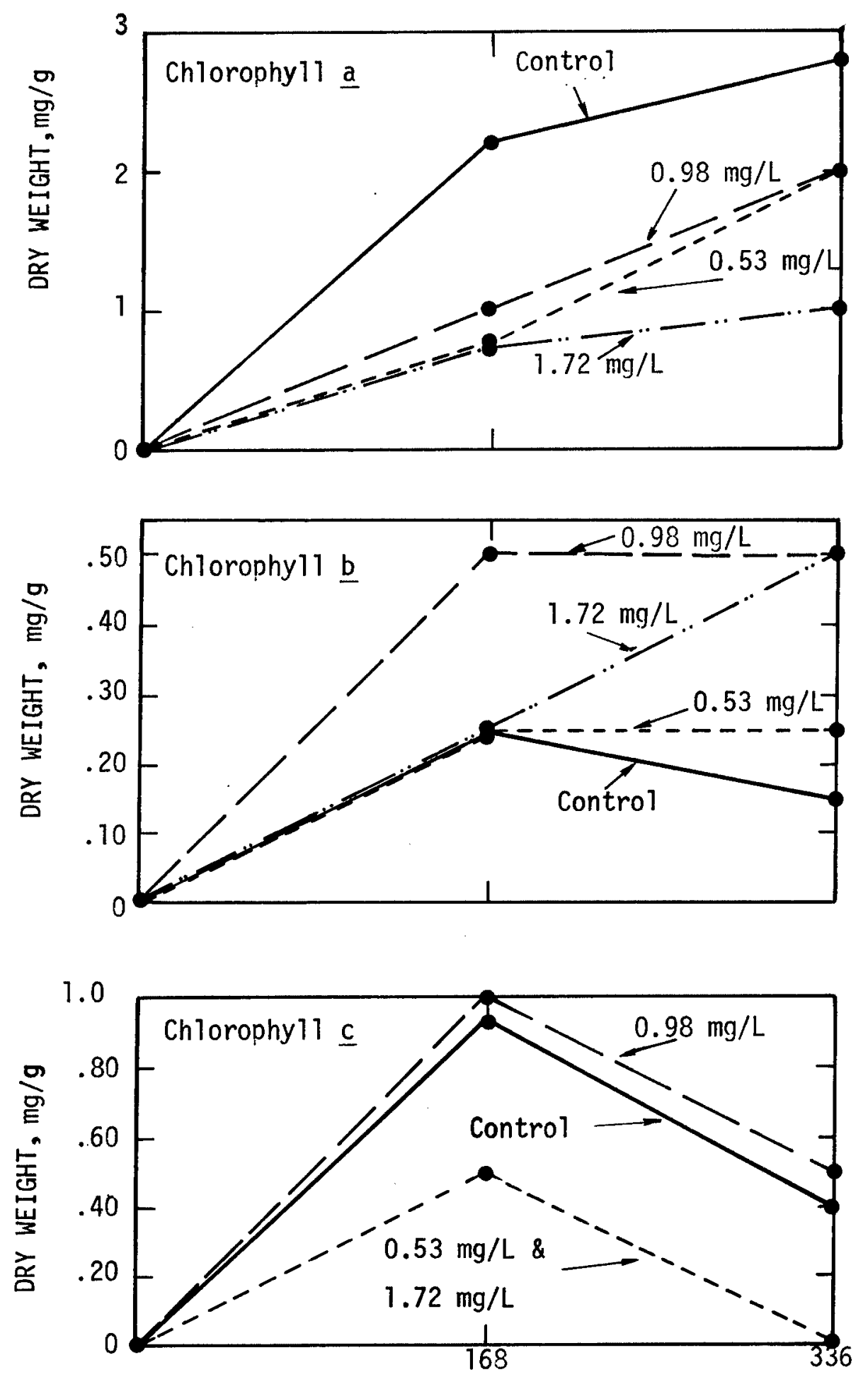

TIME OF EXPOSURE, $\mathrm{hr}$

FIGURE 20. VARIA TION OF CHLOROPHYLL CONTENT OF AUFWUCHS BIOMASS WITH HYDRAZINE CONCENTRA TIONS (14-DAY CONTINUOUSFLOW BIOASSAY, CENTRAL SAN FRANCISCO BAY WATER ) 


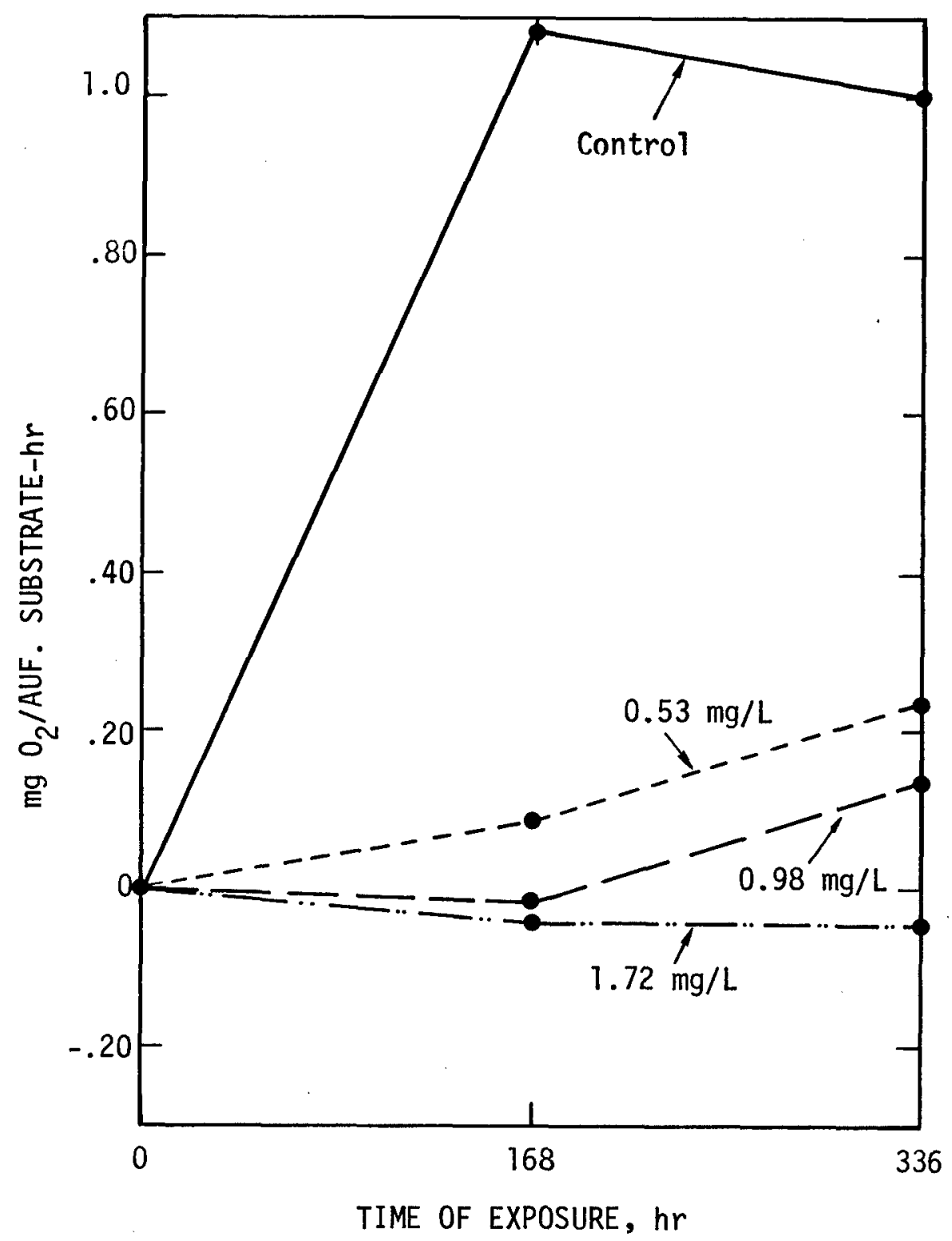

FIGURE 21. GROSS PHOTOSYNTHESIS OF AUFWUCHS EXPOSED TO FOUR CONCENTRATIONS OF HYDRAZINE (14-DAY CONTINUOUSFLOW BIOASSAY, CENTRAL SAN FRANCISCO BAY WATER), 


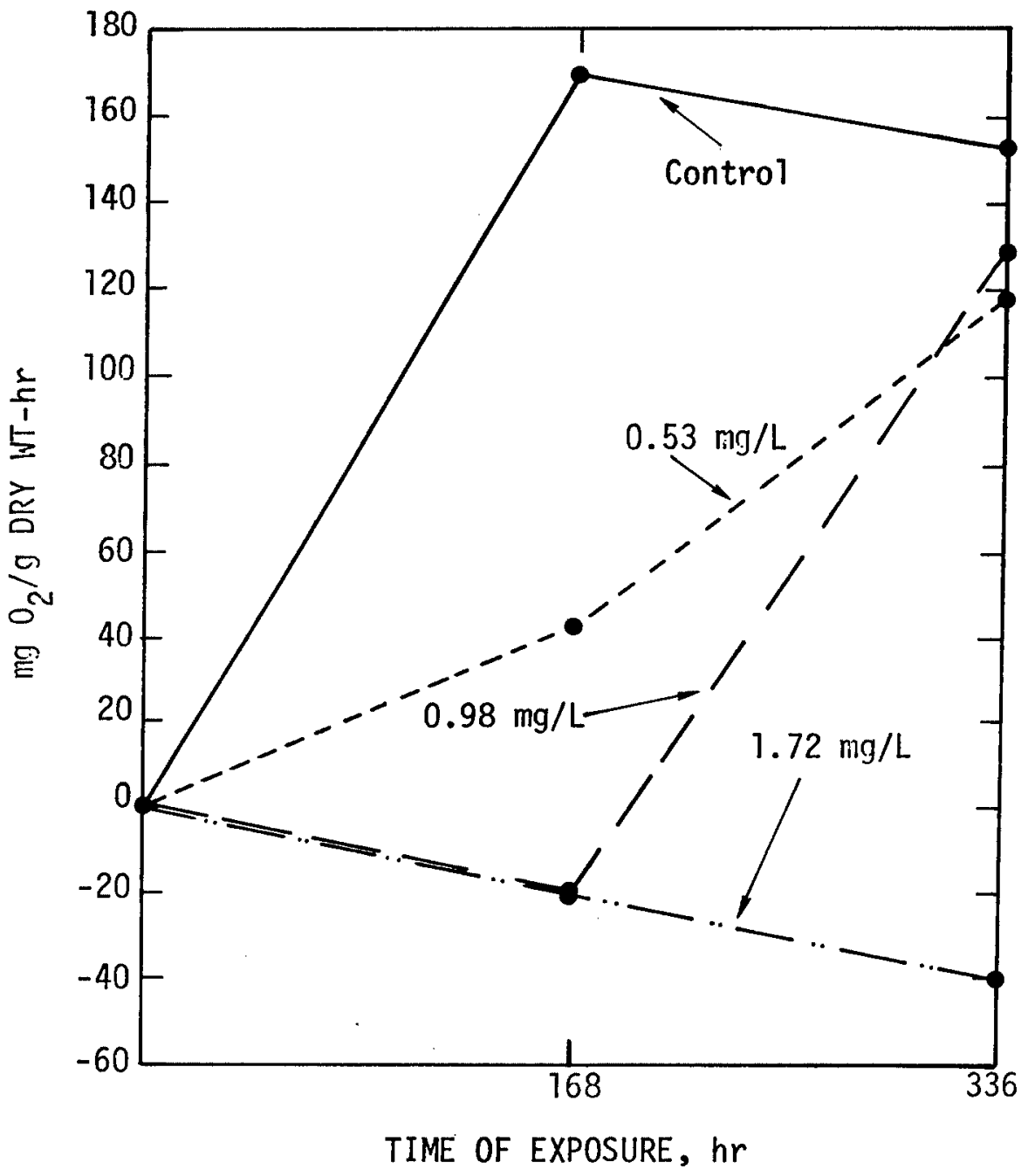

FIGURE 22. PI (wt) OF AUFWUCHS EXPOSED TO FOUR CONCENTRA TIONS OF HYDRAZINE

(14-DAY CONTINUOUS-FLOW BIOASSAY , CENTRAL SAN FRANCISCO BAY WATER) 
The photosynthetic index measurements based on chlorophyl1 a are not as consistent as those based on dry weight, possibly because of the difficulty in accurately measuring the low amounts of chlorophy11. However, these data (Figure 23) show clearly that the aufwuchs exposed to $1.72 \mathrm{mg}$ hydrazine/1 had a severely suppressed $\mathrm{PI}_{\mathrm{ch} 1}$ value.

The aufwuchs from each of the four exposure groups were collected after the 336-hr exposure period and examined microscopically to determine the species composition of the four communities. The aufwuchs were identified down to the genus level. Diatoms appeared to be the most dominant algal group in all four samples.

The control aufwuchs contained the greatest species diversity. The genera represented were Melosira (2 species), Fragilaria, Amphipleura, Frustulia, and possibly Gyrosigma and Rhizosolenia. The aufwuchs exposed to hydrazine appeared to have lower diversity than the control aufwuchs since fewer species in kind, as well as number, were observed, especially at the highest hydrazine level. The most dominant genus in the aufwuchs exposed to hydrazine was Melosira, represented by two species.

Discussion. Mortality results for the stickleback, crab, and mussel followed the pattern of sensitivity to hydrazine observed in the 96-hr continuous-flow bioassay. The crab again proved to be the most susceptible of the test organisms with a $336-\mathrm{hr}$ LC 50 of $0.56 \mathrm{mg} / 1$. This is about one-half the LC 50 for the stickleback $(1.07 \mathrm{mg} / 1)$. The paucity of data from the past studies on hydrazine toxicity to stickleback makes it difficult to compare results from this study with previous work. However, the 336-hr LC 50 of $1.07 \mathrm{mg} / \mathrm{I}$ appears to be in the same range of values that would be obtained if the previously-determined $96-\mathrm{hr}$ LC 50 of $5.4 \mathrm{mg} / 1$ were extrapolated tc a $336-\mathrm{hr}$ value.

Mussels demonstrated their tolerance to hydrazine in this study as they did in the 96-hr study. No mortality occurred even at the highest concentration of $1.72 \mathrm{mg} / 1$. The mussels may have ceased filter-feeding by shutting their shells in the presence of hydrazine. While the aufwuchs data are somewhat tenuous because of the very small amount of growth obtained, it is quite evident that hydrazine is far more toxic to aufwuchs than to stickleback. Some evidence existed to show that aufwuchs exposed to 0.53 and $0.98 \mathrm{mg}$ hydrazine/1 may become adapted to these levels after an extended period of time. No such evidence of acclimation was evident for aufwuchs exposed to $1.72 \mathrm{mg}$ hydrazine/1. To establish the no-effect level for hydrazine on aufwuchs and to determine the significance of the above observations it will be necessary to repeat these continuous-flow studies using much heavier aufwuchs growths at lower hydrazine concentration ranges and for a longer period of time than 14 days. 


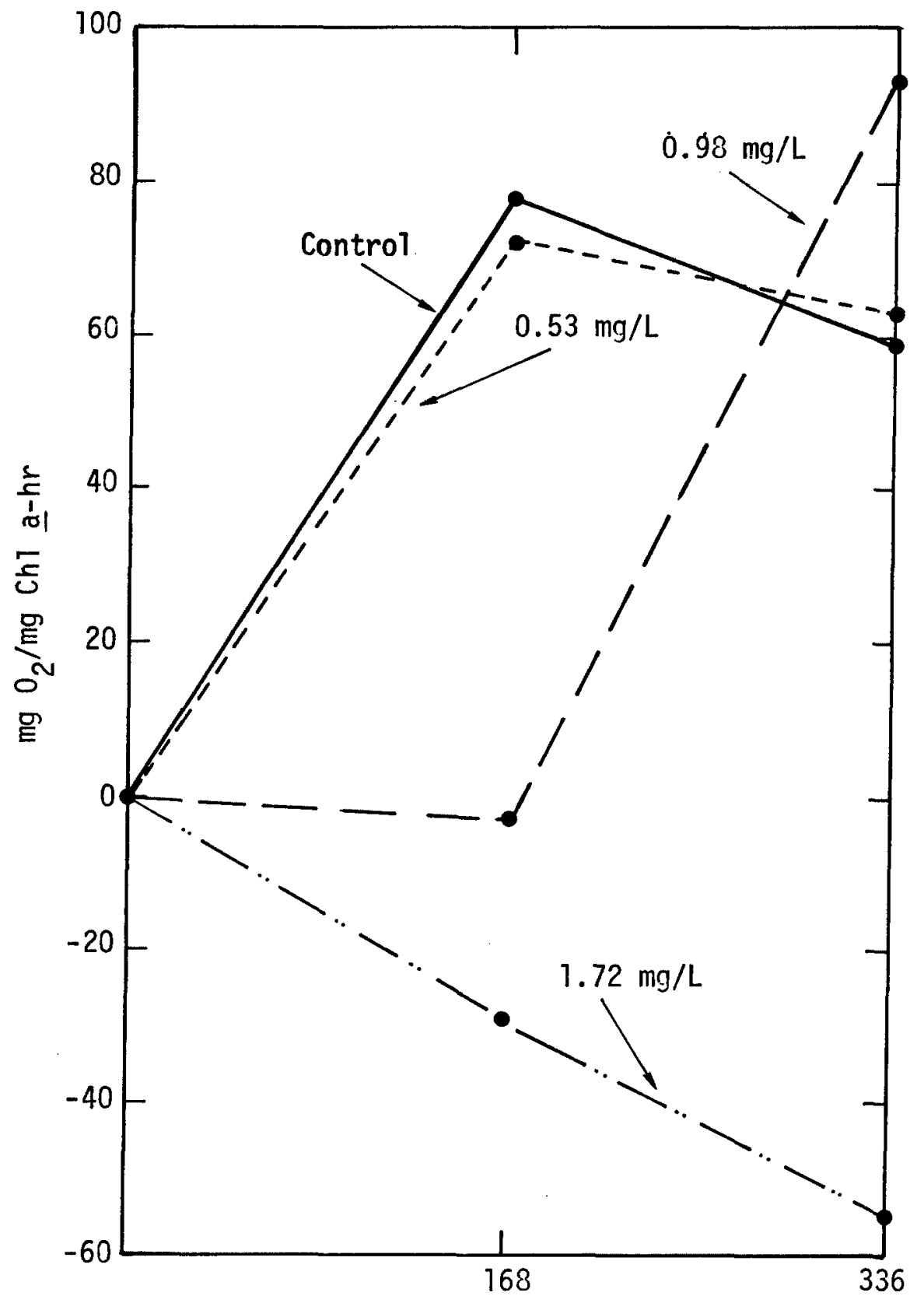

TIME OF EXPOSURE, $\mathrm{hr}$

FIGURE 23. PI(chl) OF AUFWUCHS EXPOSED TO FOUR CONCENTRA TIONS OF HYDRAZINE

(14 -DAY CONTINUOUS-FLOW BIOASSAY, CENTRAL SAN FRANCISCO BAY WATER) 


\section{APPENDIX}

Analytical Precision of Gas Chromatographic

Determinations of $\mathrm{JP}-4$

\begin{tabular}{cc} 
Day & mg/L \\
\hline 3 & $18.7,19.4$ \\
4 & $22.2,22.8$ \\
5 & $22.4,24.2$ \\
6 & $22.7,22.5$ \\
7 & $22.9,24.1$ \\
10 & $22.8,22.7$ \\
11 & $22.2,21.9$ \\
12 & $21.9,20.6$ \\
14 & $19.2,18.9$ \\
17 & $18.9,19.1$ \\
18 & $17.8,17.7$ \\
20 & $17.2,14.7$ \\
21 & $18.6,22.0$ \\
24 & $19.9,23.1$ \\
27 & $17.7,16.3$ \\
28 & $20.0,23.0$ \\
31 & $21.3,19.0$ \\
32 & $18.2,18.0$ \\
35 & $19.2,18.8$ \\
46 & $21.2,20.7$ \\
54 & $21.0,19.4$ \\
56 & $18.2,17.3$ \\
59 & $14.8,19.9$ \\
63 & $19.9,20.2$ \\
68 & $17.0,16.9$ \\
69 & $15.6,13.0$ \\
70 & $18.6,21.3$ \\
90 & $16.6,16.4$
\end{tabular}

\begin{abstract}
$\underline{\text { Mean } \pm s}$
\end{abstract}
19. $05 \pm 0.49$

22. $50 \pm 0.42$

23. $30 \pm 1.27$

22. $60 \pm 0.14$

23. $50 \pm 0.85$

22. $75 \pm 0.07$

$22.05 \pm 0.21$

$21.25 \pm 0.92$

$19.05 \pm 0.21$

19. $00 \pm 0.14$

17. $75 \pm 0.07$

15. $95 \pm 1.77$

20. $30 \pm 2.40$

21. $50 \pm 2.26$

$17.00 \pm 0.99$

21. $50 \pm 2.12$

$20.15 \pm 1.63$

18. $10 \pm 0.14$

19. $00 \pm 0.28$

$20.95 \pm 0.35$

$20.20 \pm 1.13$

$17.75 \pm 0.64$

17. $35 \pm 3.61$

20. $05 \pm 0.21$

16. $95 \pm 0.07$

14. $30 \pm 1.84$

19. $95 \pm 1.91$

16. $50 \pm 0.14$

$\begin{array}{rc}\text { Day } & \mathrm{mg} / \mathrm{L} \\ 98 & 19.4,22.7 \\ 103 & 20.9,16.9 \\ 109 & 14.9,16.9 \\ 111 & 15.1,15.9 \\ 112 & 20.0,19.3 \\ 118 & 15.8,15.7 \\ 119 & 19.8,19.4 \\ 124 & 15.7,15.2 \\ 125 & 16.3,15.3 \\ 126 & 19.9,22.7 \\ 131 & 17.3,18.2 \\ 139 & 12.7,13.4 \\ 140 & 19.5,18.2 \\ 147 & 17.5,18.9 \\ 157 & 16.3,16.2 \\ 166 & 15.5,14.1 \\ 175 & 12.9,12.5 \\ 182 & 16.1,17.1 \\ 185 & 14.9,14.8 \\ 195 & 16.7,15,2\end{array}$

Mean $\pm \mathrm{s}$

$21.05 \pm 2.33$

18. $90 \pm 2.83$

15. $90 \pm 1.41$

15. $50 \pm 0.57$

19. $65 \pm 0.49$

15. $75 \pm 0.07$

19. $60 \pm 0.28$

15. $45 \pm 0.35$

15. $80 \pm 0.71$

21. $30 \pm 1.98$

17. $75 \pm 0.64$

13. $05 \pm 0.49$

18. $85 \pm 0.96$

18. $20 \pm 0.99$

16. $25 \pm 0.07$

$14.80 \pm 0.99$

12. $70 \pm 0.28$

$16.60 \pm 0.71$

$14.85 \pm 0.07$

15. $95 \pm 1.06$

$\mathrm{n}=48$ pairs

mean of means $=18.50$

$s$ of $s=0.85$ 


\section{REFERENCES}

Bellar, T.A. 1974. The determination of volatile organic compounds at the $1 \mu \mathrm{g} / 1$ level in water by gas chromatography, EPA 670/4-74-009, U.S. Environmental Protection Agency, Cincinnati, Ohio.

Klein, S. A. and D. Jenkins. 1977. Environmental quality research, fish and aufwuchs bioassay. AMRL-TR-77-54, Aerospace Medical Research Laboratory, Wright-Patterson AFB, Ohio.

Krock, H. J. and D. T. Mason. 1971. A study of toxicity and biostimulation in San Francisco Bay-Delta waters, Vol. VI bioassays of lower trophic levels. SERL Report 71-8. Sanitary Engineering Research Laboratory, University of California, Berkeley.

Litchfield, J. T. and F. Wilcoxon. 1949. A simplified method of evaluating doseeffect experiments. J. Pharmac. Exp. Therapy. 96:99.

Pearson, E. A., P. N. Storrs, and R. E. Selleck. 1970. A comprehensive study of San Francisco Bay. Final Report, Vol. VIII summary, conclusions and recommendations. SERL Report 67-5. Sanitary Engineering Research Laboratory, University of California, Berkeley.

Pinkerton, M. K., J. M. Lauer, P. Diamond, and A. A. Thomas. 1962. A colorimetric determination for 1, 1-dimethylhydrazine in air, blood, and water. ASD Technical Report 61-708. Aerospace Medical Laboratory, Wright-Patterson AFB, Ohio.

Reynolds, B. A. and A. A. Thomas. 1964. determination of hydrazine and 1-methylhydrazine in blood serum. Report AMRL-TDR-64-24. Aerospace Medical Laboratory Wright-Patterson AFB, Ohio.

Solorzano, L. 1969. Determination of ammonia in natural waters by the pheny1hypochlorite method. Limnol. and Oceanog. 14:799-801.

Standard Methods for the Examination of Water and Wastewater, 14th ed. 1975. American Public Health Association, Washington, D.C. 